\title{
Customary law
}

\author{
Teaching Material
}

\section{Prepared by:}

\author{
Muradu Abdo , \\ Addis Ababa University, Faculty of Law \\ \& \\ Gebreyesus Abegaz, \\ Mekelle University, Faculty of Law
}

\section{Prepared under the Sponsorship of the Justice and Legal \\ System Research Institute}


Introduction.

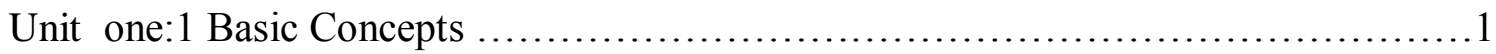

1.1 Defining Customary Law And Legal System ..........................................

1.2 Law And Custom .............................................................. 14

1.2.1 Law And Custom Compared ...........................................16

1.2.2 Custom, Habit And Convention....................................... 16

1.2.3 Custom I Primitive Society............................................. 19

1.2.4 Sanctions And Primitive Customs.......................................20

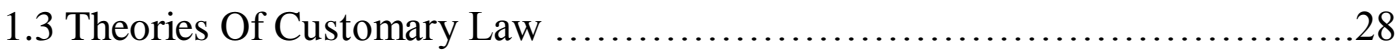

1.4 History Of Customary Law.............................................. 34

1.5 Legal Transplantation ............................................... 41

Unit Two: Customary Laws In Africa......................................61

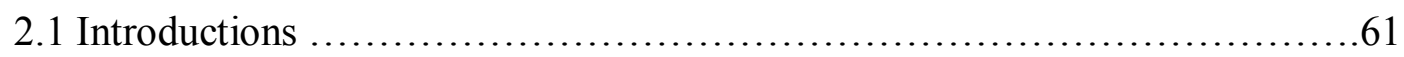

2.2 Common Features Of African Customary Laws..........................62

2.3 The Status of African Customary Laws And Legal Institutions In Colonial And Post Colonial Africa ........................................... 70

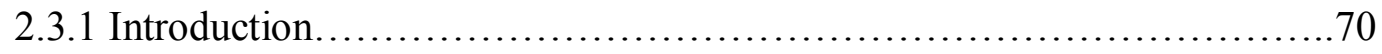

2.3.2 The Debate after Independence ........................................... 84

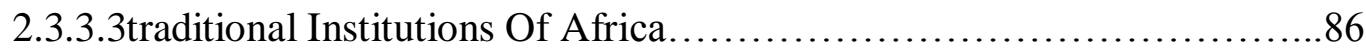

2.4 African Customary Laws And Human Rights Principles........................89

2.4.1 The Place Given To Customary Laws In International Instruments ..........89

2.4.2 The Effect Of Customary Laws In Internalizing

Human Rights Principles..........................................91

2.4.3 Cultural Transformation And Human Human Rights In Post

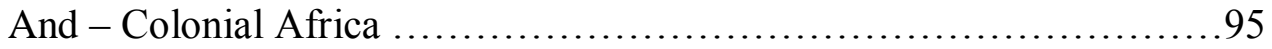

Unite Three: An Overview Of Traditional Legal Institutions In Ethiopia...............109

3.1 Customary Laws And Codes In Ethiopia....................................110

3.2 Some Selected Customary Laws Versus Human Rights In Ethiopia ............132 
3.3 More on The Customary Resolutions Mechanism In Ethiopia................. 163

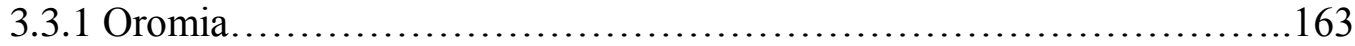

3.3.2 Southern Nations And Nationalities And People's Region ..................173

A / Gurage ................................................ 174

B/ Kambata ....................................................176

C/ Sidama...................................................... 177

D/Gedeo .................................................. 178

E/ Walayta ..................................................... 178

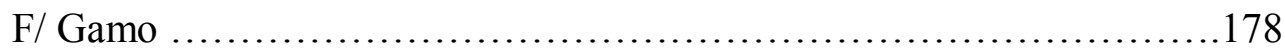

G/ South West.............................................179

Unite Four : Legal Pluralism.............................................201

4.1 Attributions Of Legal Pluralism ..................................202

4.2 Approaches To Legal Pluralism ................................218

References ...................................................233 


\section{Introduction}

The course raises two principal issues. The first issue in the course is outlining the essential features of customary law. Simply stated, this is the issue of definition. The next key point of the course is whether customary law can and should co-exist with other sources of law such as mainly state originated law. This latter issue can be put as an issue of co-existence. The co-existence issue can be broken down into three subissues. The first sub-issue is the degree of co-existence between the customary laws and state laws. The second one is the tests of the co-existence of the two system of law. The third sub-issue outlines the justifications for worrying about the coexistence of customary law and state laws in the context of developing nations such as Ethiopia.

Besides, students are to analyze provisions in the various federal and state legal instruments in Ethiopia providing a room for the operation of indigenous legal institutions. Further, you will trace the development of customary laws in other legal traditions such as western legal traditions. Thus, the scope of coverage of the course is not limited to the examination of customary laws in the Ethiopia context. Yet, the course will not discuss customary international law (which is one of the sources of international law). Hopefully, you would cover customary international law in the course on international law.

It is hoped that the course would help you appreciate that the laws made by states in developing countries such as Ethiopia are not fully applicable; a large percentage of rural population in such countries regulates itself by customary laws. So the course hopefully disillusions students from the idea that state laws in developing countries have taken roots in the fabric of societies. In addition, the course would send the message that laws come from sources other than state institutions; state institutions are just one of the valid sources of laws, not the only source of laws. Hence, the course directs the attention of students to multiple sources of laws. I also think that the course urges them to be sensitive to diverse legal traditions. 
Customary laws in Ethiopia affect the lives of millions. In some respects, customary laws are much more practical and more powerful than the state made laws. As you well know, Ethiopia has many ethnic groups. Each of these ethnic groups has its own traditional dispute settlement methods and institutions including customary laws. These groups to a large degree make use of their respective systems. For the reasons to be outlined in this course, the multiple groups in Ethiopia less frequently use the modern state generated laws. Thus, the study of traditional legal institutions in general and customary law systems in particular is very much important in the Ethiopian context.

The material is organized into four units. Unit 1 outlines foundational concepts such as the definition of customary law, legal system and legal transplantation. The next unit is concerned with customary laws in Africa emphasizing on the common features of customary laws in Africa as well the interplay between customary laws and state laws in this part of the world. Unit 3 is devoted to examining the development of the interaction between customary laws and state laws in the Ethiopian legal system. Unit 4 relates to legal pluralism, the situation where several legal systems such as customary laws, state laws and religious laws are deliberately allowed to cooperate and function together. Each unit is planned to have at least two sections. Each section includes review questions. Each unit also contains a summary of the essential issues.

In this course, you should be able to:

- Know concepts such as custom and source.

- Understand the nature of customary law.

- Appreciate the importance of customary law.

- Recognize the interplay between customary law and state made law.

- Understand the relationship between customary laws and human rights. 


\section{UNIT ONE: Basic Concepts}

\section{Introduction}

This unit is planned to define concepts, such as custom and customary law. It will see that some customs also called customary practices are customary laws while some customs are not. On the other hand, all customary laws are customs. This unit explains the historical development of customary law in the western legal system; It will appreciate that the western legal systems historically gave a secondary place to customary laws, as these legal systems regarded customary laws as undermining the efforts at national unity and legal uniformity. The unit also deals with the various aspects of legal transplantation.

At the end of this unit, you should be able to:

- define concepts such as custom and customary law.

- discuss the relevance of the course.

- explain the historical development of customary law.

- discuss the various aspects of legal transplantation. 


\subsection{Defining Customary Law and Legal System}

This section defines customary practice. It will also show the meaning of the term 'source of law.`In addition, It will define some other key concepts such as the terms 'legal system` and 'customary law.' The section will help you to distinguish customary law from state law. In the section, you will also notice the development of customary law in the various legal systems in the world.

In this section, you should be able to:

- Define customary practice.

- Analyze the theories on the definition of customary law.

- Define the term `source of law.

- Define customary law.

- Define the term `legal system.`

- Distinguish customary law from state law.

- Discuss the development of customary law in the various legal systems in the world.

Relevance: The reason for taking this course at this time in Ethiopia lies in the position adopted in the FDRE Constitution. There are three ways of understanding the historical process of bringing the various entities in the country together in the past two centuries, namely the re-union approach, the national question approach and the colonial thesis approach. You will consider the re-union approach and the national question approach. Emperor Hileselassie I and his supporters understood the process as a re-union or expansion. They argued that prior to $19^{\text {th }}$ and $20^{\text {th }}$ centuries Ethiopia lost territories as a result of wars and migrations. They argue that in $19^{\text {th }}$ and $20^{\text {th }}$ centuries, Ethiopia successfully regained her lost territories. These actors worked to bring about political centralization. They used western oriented codes. They used the methods of assimilation, integration, urbanization and industrialization to unify the country. The 1931 and 1955 constitutions were designed to implement the state policy of political centralization as well as legal unification. Their concern was to avert political disintegration in the country. Giving official and proper place to customary 
laws in Ethiopia was regarded as undermining the nation-building efforts. So, customary laws were given little official recognition. If customary laws existed under that system, thus, they existed in spite of hostile official stance.

The second group of personalities understood the historical process of the $19^{\text {th }}$ and the $20^{\text {th }}$ century in Ethiopia as a problem of class exploitation. The conquest approach has two models, namely the class exploitation and the national exploitation models. According to the first model, the issue was not ethnic exploitation. The economic elites, who were few in number, oppressed the mass. The various groups brought together under the umbrella of the central government suffered injustice in the hands of the economic and political elites. The solution sought was to end this exploitation by building a communist society in the country. Ethiopia was led for about 17 years by the promoters of this view. As the promoters of the re-union approach remade Ethiopia, the promoters of the second view, also called the conquest approach, reordered the Ethiopian polity. Ethiopia under this approach had had little faith in any thing about law whether state or customary. Law was to play a role in the transition to the communist society and then was to vanish.

The first model is the one that thinks that the main problem is class oppression whose solution is to eliminate this exploitation by constructing a classless society. The second model in the conquest approach thinks that the main problem is national exploitation. The various previously autonomous entities, once brought together under the authority of the central government were humiliated. The solution proposed was to accord true self-rule especially in the form of federal state. The second model is reflected in the FDRE Constitution, which pledges to give recognition to customary laws in some senses. This Constitution focuses on giving due place to diversity. The Constitution reflects the belief that if diversity, which is a fact of life in the country, is not respected conflict is inevitable and hence the desired national development would be impeded.

In addition to the importance of studying customary laws in the Ethiopian context, such study has general significance. In the following few paragraphs, Juma argues that customary laws in Africa are still relevant for many reasons. He states that the reasons for such importance lies in the place given to customary laws in the Banjul 
Charter, the global resurgence of politics of identity and the increasing importance attached to traditional conflict resolution mechanisms in the area of tribal conflicts, environmental laws and intellectual property law.

African traditional customs and values are not static. The erroneous assumption that African traditional customs are monolithic and unchanging finds support among some relativists. Its gradual codification, as witnessed in some countries, the inevitable mixing of populations and the movement from tribe to state has greatly disturbed its purity. However, contrary to many people's expectation, customary law has not withered away. Its resilience stems from many factors, prominently its command of majority following in Africa. Specifically, the majority of Africa population resides in the countryside or rural areas. These areas are of low economic productivity where livelihood is sustained mainly by subsistence farming. They are also areas of minimal economic growth due to neglect by the central state administration. Since independence, for instance, industrial development in Kenya has concentrated in urban areas. Improvement of infrastructure and the establishment of public facilities and services have equally taken place only in towns and cities. Meanwhile, the rural population suffers from lack of hospitals, roads and even schools. Therefore, these communities retain significance in traditional African beliefs and customs as a means of regulating societal life. Consequently, since the traditional African beliefs and customs are interwoven with political, social and economic spheres of human endeavor, it has never been possible to disassemble one area or deal with a single aspect of societal life without affecting the other.

The disparity in economic development between the rural population and the urban minority has, in itself, illuminated the differing views on the position which customary law ought to occupy in the legal system. Low levels of economic development and the near marginal conditions by which people in the rural areas live have prompted suggestions that such customary systems of rules are inimical to progress. Customary law has equally been dismissed precisely on this ground. Further, customary law has been seen to perpetuate vestiges of traditional African civilization, which, to many people, bear no relevance to modern times. One African socialist noted that the politics and ideology of the past were the concentrated expression of their economics, the economics of the past, and has no relevance to the 
economics of the present or the economics of the future. The neo-traditionalism of African legal writing, before and after independence, has kept the customary law belief alive. The claim for surviving African Customary Law was, and is still, seen as a crucial ingredient in cultural nationalism. The call to African nationalism during the independence struggles was predicated upon the plight of 'African people' as distinct persons with unique needs, aspirations, culture, and law. These struggles were legitimized by notions of rights of the African people, strengthened by the emerging principles of humanity, freedom and equality borne out of international human rights instruments and the American Constitution. It is, therefore, of no surprise that the independence constitution of most African countries contained a whole chapter on the Bill of Rights.

Most profoundly, however, is the idea of a 'peoples right,' which later provided an ideological base wherein continental unity was forged. Indeed, with the formation of the Organization of African Unity (OAU) in 1963, the independent African states affirmed their solidarity in the quest for better life of the 'African peoples. It is also within the OAU political framework that African states have adopted the African Charter on Human and Peoples Rights (also known as the Banjul Charter on Human and Peoples Rights) and the Protocol on the Establishment of an African Court on Human and Peoples Rights. In its preamble, the Banjul Charter requires the parties to take into consideration the virtues of their historical tradition and the values of African civilization which should inspire and characterize their reflection on the concept of human and Peoples rights. The implication here is that African traditional values, and by extension customary law, are key to the realization of human rights. The terminology of 'peoples rights,' recognizes the contribution that African Customary Law, appropriately developed, could render to the development of human rights in the continent. The study of African Customary Law and the institutions that it fosters is not misplaced. Currently, the world at large is witnessing a general resurgence of politics of identity. A casual look at the spate of intra-State conflicts in many parts of the world reveals that allegiance to ethnic values and glorification of customs and tradition has become part and parcel of people's agenda for political reform and development. Similarly, reference to customary rights in resource utilization regimes and environmental management has added impetus to the reification of customary values and belief systems. In Africa, the renewed recognition 
of customary rights will unravel new challenges. Remodeling agrarian policies to take cognizance of the prevailing customary practices, and adapting traditional conflict resolution strategies in resolving political disputes have all been presented as an effective way to deal with African problems. Notwithstanding, the place of African Customary Law in the legal system will have to be unambiguously defined and its antecedents cleverly reinterpreted to set the stage for a more progressive utilization of its principles.

The Concept of Source in Law: The term source has a couple of definitions. One sense of the term `source` is that all the pieces of information used in the preparation of a legal document. A legal document may be a constitution, a proclamation, a regulation, a directive, a testament and any other legal document. This sense of the term is also referred to as a material source. Secondly, the term refers to the reason why a given legal rule is valid or must be respected. When you ask the question: why should people respect law? The answer to this question gives you the second sense of the term `source.' Material source of the document may be obtained form public opinion, pertinent books, experts, past legislation, foreign sources and research, etc. In the case of customary laws, customs or customary practices are material sources.

The second sense of the term, the validity requirement, is very controversial. As you have learned from the course in legal history, in the Mesopotamian society law was perceived as god-given. The Greek society secularized law. The French legal system attributed the source of law to the legislature. The French pattern was followed in the German legal system. The Islamic legal system thought laws to come from a supernatural being called Aalh. The Confucian legal system believed that a prophet, Confucius, had to do with the creation of binding legal rules. The socialist legal system has taken the communist party as the sole source of law. The present course pertains to the analysis, among others, of the validity source of customary law; the question is What transforms customary practice into customary law? As can be see in due course, there are several conflicting answers to this question.

Importance of the Concept of Source in Law: The importance of understanding the meaning of source of law lies in two reasons. The first one is for legal research. Whenever there is a gap or an inconsistency in an area of law, you need to apply to, 
you may resort to interpretation. Interpretation may lead you to do some legal research. And legal research, in turn, may lead to consulting the historical sources of materials. The second significance is to understand the issue why a given legal rule is binding. You appreciate that different communities in human history answered the question of the validity of laws quite differently.

Definition: There is no uniformly accepted definition of customary law, and different scholars define customary law in different ways. This is so because custom varies from place to place. As custom varies from place to place, and so there is no single accepted definition of it. However, it may be defined as a rule of conduct, which is accepted and governs a group of people. In addition to its lack of uniform definition, customary law is given different names by different scholars. Some scholars have referred to customary law as folk law, people's law, unofficial law, indigenous law or primitive law often implying its inferior positions as compared with the modern western state originated laws.

Other literature, mores (plural of Latin 'mos' meaning custom) defines mores as involving several sanctions when behavior deviates from the customary rule of the group. The marriage of white woman to a black man in the Southern US or a Brahman to an untouchable in India was considered a violation of mores of these groups until recently. Custom is a norm of action, percept or rules of conduct, which is generally accepted and practiced by group of people. Custom is a rule or law set by the people themselves by which they voluntarily accept to govern their actions. A custom can be partial, specific with regard to a certain subject matter or locality or general custom applicable through out the country.

Customary law is not the mere stipulation of rights and obligation in a particular community but it is the mechanism of resolving dispute. There is a procedure to resolve disputes without the assistance of the institutionalized justice system. Customary law is unwritten law and kept in the memory of people or elders. Therefore, when a case or dispute arises, the interested party have to ask these people for a solution" Custom is to society what law is to the state. Each is the expression and realization of men's insight and ability of the principles of right and justice. Customary law involves spontaneously evolved rules emerging through dispute 
adjudication, customary law provides a rather reliable process for discovering the natural law, because spontaneously evolved and voluntarily followed custom is more likely to result in mutual advantages than a rule imposed by a powerful group.

Kinds of Custom: All customs which have the force of law are categorized into legal custom and conventional custom. "A legal custom is one whose legal authority is absolute, and one which in itself possesses the force of law. A conventional custom is one whose authority is conditional on its acceptance and incorporation in agreements between the parties to be bound by it.

Conventional Custom: The binding authority of conventional custom emanates from not because it is in advance incorporated to the law, but because the parties have accepted it as practice. In this regard, Fitzgerald argue that usage or conventional custom is, as has been indicated, on established practice which is legally binding, not because of any legal authority independently possessed by it, but because it has been expressly or impliedly incorporated in a contract between the parties concerned. Fitzgerald further argues how conventional custom may be applicable in the area of contract. He says that in the contract entered between two parties the implied terms of the contract is supplied by implication to make the contract workable and complete.

In the absence of contract with fully expressed terms, it is advisable for the courts to look for the presumed intention of the parties by accepted business practice of a particular contract. The law presumes that where persons enter into a contract in any matter in respect of which there exists some established usage, and to incorporate it as a term of contract in the absence of any expressed indication of a contrary intention. He who makes a contract in any particular trade, or in any particular market, is presumed to intend to contract in accordance with the established usages of that trade or market, and he is bound by those usages accordingly as part his contract. Terms may be implied into such contracts either by establishing a trade usage in the strict sense or even by showing that it is reasonably necessary to assume that it was entered into on the basis of some established practice of the trade.

The other point to be discussed here is the legal requirements that must be fulfilled by the conventional custom before it can thus serve as a source of a law and of legal 
rights and obligation. As opposed to the legal custom on which law imposes the requirement of immemorial antiquity whereof there is no memory, no specified duration is legally imposed on conventional custom. But what is required is that in point of duration the custom shall be so well established, and therefore so notorious, as to render reasonable the legal presumption that it is impliedly incorporated in agreements made in respect of the subject matter.

Legal Custom: As it was defined somewhere above, legal custom is one whose legal authority is absolute. It is independently sufficient to create legal rights and obligation without prior consent of the parties. Such custom is that which is effective as a source of law and legal rights directly and per se, and not merely indirectly through the medium of agreement in the manner already explained.

Legal custom is further divided into two: the one is local custom, and the other is the general custom of the realm.

Local Custom: Local custom, as the name indicates, is the custom whose applicability is limited to particular area. It prevails only in defined locality. The present day local customs consists of the most part of customary rights vested in the in habitants of a particular place to the use for diverse purposes of land held by others in private ownership.

In order that a local custom may be valid and operative as a source of law, it must conform to certain requirements laid down by law.

Paton (year)says that the custom (a) must not conflict with any fundamental principle of the common law; (b) must have existed from time immemorial; (c) has been continuously observed and peacefully enjoyed; (d) be certain; (e) must not conflict with other established customs; (f) and be reasonable. These days, advanced local customary law continues to play some supplementing part in the adjustment of local interest. Nevertheless, advanced local customary law is diminishing as the result of the establishment of a universal system of law in a given state possessing clearly defined organs of legislation. Some of the codified civil law systems of modern times 
go so far even as to reject local custom altogether as being contrary to the objective of legal unification aimed at by the code.

National Customary law: National customary law is also called general customary law. There is a legal requirement for the general custom too. As it is said for a local custom, there is time requirement for a general custom. There are also other requirements: The very same considerations of public interest which induced our early law to impose up on local custom the requirement of immemorial antiquity are applicable with equal force to the general custom of the realm. The public interest requires that modern custom shall conform to the law, and not that the law shall conform automatically to newly established customs.

Customary Practice versus Customary Law: Customary practice also called custom or convention implies a behavior that is followed by the majority member of a given community habitually and for a longer period without having an obligatory force. All customary laws are customary practices while some customary practices are customary laws and others are not.

Customary Law and Social Control: Social control consists of the whole range of instruments and institutions used to bring an individual to conformity. Every community employs social control, though the complexity and aim of such social control may differ from society to society, to create and maintain as well as instill in the members of such community values deemed essential. You can cite state law, customary law, international law, customary practice, education, family, religion, morality, etc. as parts of social control. Social control aims in general at keeping a society together. Such society may be a local community, a country, a region or a global community.

Customary Law and Traditional Laws: Traditional laws, also called cultural laws or indigenous laws, are broader in scope than customary laws. Traditional laws may be made at a certain point in time. Customary laws are just part of traditional laws. For some, traditional laws, to be made, do not have to wait for a longer period of time. Authorized elders of a given community may gather together to discuss a matter 
and to pass legislation. This latter form of traditional laws resembles modern state laws.

Customary Law V. Positive Law: Can you make a distinction between customary law and positive law? Below, you will draw similarities and distinctions between the two types of laws: positive law is also called state law and customary law. You will also learn about the distinction between customary law and customary practice.

Similarities: Both customary law and positive law have many things in common. Both are body of rules that regulate the conflicting interests of men. The other similarity between the two is the binding force each has though they differ in application. While positive law may have wide applicability, customary law may limit itself to the particular locality. Even if the extent to which they are going to bind differs, both customary law and positive law have a binding nature within a community. Both of them can adjust to the changing circumstances. Customary law is not rigid to changes, but capable of making itself flexible to accommodate the changing social, economic and political circumstances. Moreover, these rules, far from being absolutely inflexible and unchanging, are indeed in manner similar to the state legal system, subject to a process of constant adaptation to a new situation, old rules being re-interpreted and new rules being from time to time created.

Custom is to society, what law is to state. Each is the expression and realization, to the measure of men's insight and ability, of the principles oflight and justice. The laws embodied those principles as they commend themselves to incorporate community in the exercise of sovereign power. Custom embodies them as acknowledged and approved, not by the power of the state, but by the public opinion of the society at large. As modern secular laws, customary laws are in most cases secular in nature and subject to violation. Many if not all such rules are secular in character and are just as liable to be breached or disregarded, as are modern laws.

Differences: The one difference between customary law and positive law is that, while the former is not reduced into writing, the former is the codified one, customary law passes from one generation to the next through songs, chants, proverbs and etc. In a society which has no written records, or writing of any kind, the operative custom of 
the tribe must depend upon the accuracy, reliability, and indeed honesty of the memories of those, especially the chieftains and elders, in whom it is enshrined. Accordingly, the fallibility of human memory alone must account for a good deal of gradual erosion of an accretion to the body of customary law.

The fact that positive law is in black and white reduces the potential weakness attributable to customary law. The other point worth mentioning is the scope of application. While customary law is applicable only to the particular locality concerned, the positive law has binding force on all over the people living in the land. A law is general since it applies not only to one particular group of person but also to other persons with in the community. On the other hand, there are customs that only apply in a particular territory of the country and these are local customs

There is organized body to enact, interpret and enforce the law made by the state, i.e., positive law. Whereas customary law lacks institutionalized body to get assurance of being observed. This does not mean that customary law is left without any one to take care of its observance. Since it is dependent upon reciprocity, a member of the community may be denied a reciprocal right if he refuses to act in accordance with the custom. There is also other sanction against the deviant. Punishment may follow. The problem is that customary institution is not as such strongly organized and dedicated only for the enforcement of customary law. The other difference is the effect they have in the society. That is, statute law is superior in that rules are logically arranged and may easily be discovered. The predominately unwritten nature of customary law makes it difficult to ascertain the rule thereof.

\subsection{Law and Custom}

We have so far considered law mainly in the context in which it is encountered in a modern state, namely as a system of norms which derives its binding force, directly or indirectly, from some organ of the state invested with legislative authority under the constitution. Many jurists, such as Austin, have been content to confine their attention to legal systems of this character on the ground that the normative systems encountered in earlier or primitive forms of society are so different in character from 
those of developed communities that they are not deserving of being ranked as law 'properly so-called' or that they are no more than 'primeval substitutes for law'.

There is nothing to prevent jurists, any more than other systematizers, from delimiting, defining, or classifying their subject-matter in whatever way they please, and for some purposes it may be desirable or at least convenient to distinguish between normative systems occurring at different phases of human development. There may be good reasons for not wanting to bracket together the obligatory rules found in such diverse societies as those of Australian bushmen, of the Greeks of the Homeric Age, of European feudalism in the Middle Ages, and of modern England or France. To some extent the question of classification is a matter of choice as long as it is borne in mind that the choice is not entirely arbitrary seeing that it must be governed, as in any other classification system, by close attention to the features which the various types possess in common, as well as to those which are dissimilar.

In carrying out this process as scientifically as possible, there will enter inevitably some element of value value-judgment, for in the last resort we will have to decide on the relative importance of the resemblances and dissimilarities, in the same way as the biologist has to evaluate the comparative structure of different species in order to decide whether a whale is a fish or a mammal, and the physical anthropologist has to settle what characteristics justify him in treating the skeletons of early anthropoids as belonging to a human rather than an ape-like species. Nor are such classifications vitiated by the need to make value-judgments, provided they are related to a close study and analysis of the phenomena from which reasons may emerge for preferring one grouping to another. In the field of legal classification this point has already been considered in relation to international law, where it has been shown that though it by no means corresponds precisely with national law, there are nevertheless good grounds for bracketing the two together as legal phenomena. The differences between the two are not thereby in some magical way made to vanish into thin air; what is recognized is that there are persuasive reasons for treating the term 'law' as wide enough to cover various closely related though not identical types of normative systems. 


\subsubsection{Law and Custom compared}

There are many reasons why we may feel disposed to explore closely the interrelation between the legal norms operating in developed societies and the types of norms encountered in earlier or primitive societies. To begin with, the sociological jurists have taught us to see that even in developed communities law exists on more than one level and that to penetrate its mechanisms it is not sufficient to confine our attention exclusively to the sophisticated documentation of legal rules. We must also try to come to grips with the underlying social norms which determine much of its functioning; what has been graphically described by Ehrlich as the 'living law' of a society. Again, the phenomenon of a developed state, with regular organs of lawmaking, is one which has emerged relatively infrequently in the history of human culture, yet in all human societies, however distant or primitive, we seem always to find sets of norms regulating the conduct of their members inter se and regarded as binding upon them. Furthermore, even in the case of the most developed states of modern times, if we examine their legal systems from the point of view of their historical origins we will be obliged to trace these back to periods when conditions prevailed not dissimilar to those of ea rlier or more primitive cultures. If then we are to grasp the significance of law as a means of social control, it seems unwise to ignore the way normative rules operate in all different types of societies. For such an inquiry may not only enable us to decide whether there are norms in all known societies which may justifiably be classified as legal but may, by bringing into focus matters more easily visible in a simpler form of society, throw a good deal of light upon the deeply concealed roots of legal processes in more complex social orders.

\subsubsection{Custom, Habit, and Convention}

The norms operating in less developed societies are frequently referred to as customary law'. We will refrain for the moment from using this term, which rather begs at least one of the questions we are engaged in investigating, and adopt the more colourless expression, 'custom'. In the first place, this term must be distinguished from mere habit and from convention. All these phenomena exist in every society and may be illustrated from our own. A habit is a course of conduct which we regularly, though not necessarily invariably, pursue but without any sense of 
obligation or compulsion to do so. For instance, I may have the habit of wearing a hat out of doors, or of going to work by one means of transport rather than another. Such habits may become extremely rigid, for it is part of the psychological make-up of human beings that they tend to form habits, and without this tendency life would be so erratic that social order would be impossible. Some individuals are more regular in their habits than others. It was said that people in Konigsberg used to set their watches by the time at which the German philosopher Kant was wont to proceed on his afternoon walk. But the point about habits generally is that they are not regarded as socially compulsive. I may be so accustomed to take a train to work rather than a bus that I do this automatically and without reflection, yet I do not regard myself as under any social compulsion to do so, and I can change to any other available means of transport without any sense of infringing any kind of norm. It is true that some types of habit, as psycho-analysis have demonstrated, are of an obsessive-compulsive type, but this is a distinct psychological characteristic or certain kinds of neurosis and is not to be confused with the sense of obligation which arises because the individual recognizes that the doing of a certain act is imposed upon him by reason of the existence of a given legal, social, or moral norm.

It is just this socially obligatory element that is characteristic of customary observance. Again, to illustrate from our own society, it is customary for a man to dress in public in a certain way, to eat with a knife and fork, and so forth. These rules are neither absolute nor regarded as equally obligatory by all concerned. For Scotsmen may wear kilts, women may wear trousers, and 'beatniks' may adopt deliberately unconventional clothing or modes of eating, even in a society where customary observances in such matters are fairly accepted and are adhered to. The vital difference, however, between such customs and habits of the kind previously referred to is that those who accept the customs and adhere to them regard themselves as in some way bound or obliged to observe them. The ordinary citizen visiting a restaurant no more considers himself free to pick up his food in his fingers than to assault his neighbour. Although he is unlikely to analyse the reasons for this it seems clear that he regards himself as, in the one case, subject to a binding social norm or rule forbidding certain eating habits in public, as, in the other case, he feels bound by a legal norm or rule forbidding the use of physical violence. 
Lying between habit and custom, in the sense explained, are to be found in a given society certain observances which, while not regarded as fully obligatory, may nevertheless be regarded as proper modes of behaviour which people are expected to carry out, though in practice it is recognized they frequently fail to do so, and such omissions are accordingly tolerated. Such usages may be referred to as conventions, and as existing examples may be suggested the acknowledging of letters or of greetings. The weakness of such conventions may be due to the fact that they represent the attenuated survivals of customs of an earlier period, for instance, the now fast disappearing modes of etiquette towards women, such as offering them a seat in a public vehicle. The special feature, then, of conventional behaviour is that while particular individuals may feel themselves bound to observe it, it is not regarded as generally binding, and the individual may largely please himself whether he conforms or not.

It will be observed that whereas both customs and conventions are normative in the sense that they establish rules of conduct for compliance, habits do not refer to or depend on norms, but simply involve regularities of behaviour which are in fact observed. Many, if not most, habits never assume a normative character, but remain on the level of personal idiosyncrasy. An individual may lay down norms for himself, as, for instance, in the usually rather fragile 'new-year resolutions'. These, however, have little significance in the field of social regulation, for it is the outward-looking rather than the inward-looking norm that eventually becomes established in customary form. The fact is, however, that habits can and do become converted into customs, though the reasons for this transmutation may not be easy to identify and many factors may cooperate. The tendency towards imitation between human beings may well play some part here, though it has sometimes been exaggerated, especially by Trade. Much may depend upon whether a practice is established by a member or group of members who enjoy a special authority in a community and whose example is therefore likely to be followed. Again, a practice may gain currency because of its obvious or seeming advantages. Be this as it may, it seems to be a recognized form of human progression that practices which continue to be observed over a period tend, especially if they appear to possess a distinct social function or utility, to be normcreating. That is to say that the 'done thing' eventually proves to be the thing that ought to be, and perhaps ultimately, must be done. Customary observance has not 
necessarily always grown up in this kind of way. Custom may result from deliberate innovations instituted by the ruling class or the example of some authoritative or highly reverenced personage in a community. The headman or chief in a primitive society, for instance, may settle a dispute in a particular way, and although such a society may have no conception of legal precedent, either because of the authority of the chief, or because the ruling seems eminently reasonable, a custom thenceforth may be established which will be regarded as binding in like situations.

\subsubsection{Custom in Primitive Society}

Custom, operates at all levels of society, and it must not be assumed that its character or functioning is identical at widely different levels. It will be as well, however, Un begin with the more primitive types of human society, for it is to these that the main attention of modern anthropology has been directed, and widespread research in this field has yielded much information which throws light on the working of custom and its relation to law.

At one time the, view commonly held was that in early society it was impossible to differentiate between legal, moral, and religious norms since these were so closely interwoven into a single texture. Certainly the authoritative source of custom will generally, if not invariably, be attributed to some divine, semi-divine, or supernatural powers, often believed to be the ancestral founders of the tribe itself. To quote an early investigator of Australian totem-clans, when someone asks the reason for certain customs or ceremonies the answer given is 'because our ancestors arranged it thus'. And writers such as Fustel de Coulange and Durkheim have shown the importance of ancestor-worship in moulding social institutions and creating social solidarity. The fact however, that customary observances may draw upon the religious beliefs of the community and obtain from them a good deal of their binding quality, does not mean, as was supposed by earlier writers such as Sir Henry Maine, that it is not possible to distinguish between religious and secular rules in a primitive society. True it may be that such differentiation is not always practicable, but rules which constitute religious taboos of the community, violation of which will draw upon the offender direct punishment at the hands of the supernatural powers, are often distinguished from rules which regulate the social and economic organization of the community and whose 
enforcement is in the hands either of some secular authority-the tribe or clan itself, the chieftain, or group of elders-or the next-of -kin of an injured person.

Two other important misconceptions have been gradually dispelled. The first of these was that in early society custom was completely rigid and unchanging, and that primitive man was born into a helpless condition of total conformity to tribal custom. In this view the group rather than the individual was the only unit of the social order. Sir James Frazer tells us in his famous work, The Golden Bough, that 'there is more liberty under the most absolute despotism, the most grinding tyranny, than under the apparent freedom of savage life, where the individual's lot is cast from the cradle to the grave in the iron mould of hereditary custom'. Doubtless this sort of approach was a reaction to the romantic notion, disseminated by earlier writers, of the happy and peaceful savage living a life of idyllic bliss in a state of nature governed only by the beneficent control of natural law. Fanciful though this picture was, its successor in the shape of the hidebound primitive, yielding unvarying compliance to tribal custom, and overwhelmed by a sense of fear of the supernatural, was hardly less overdrawn., Some of these clouds have been dispelled by such investigators as Malinowski, who have shown how many of the rules of a primitive society derive not from dark beliefs in and fear of the supernatural, but rather, as indeed in our own society, on the need for reciprocity in social and economic relations. For just as our own society provides a legal and institutional basis for the regulated exchange of various services and commodities, so similar customary rules are to be found in primitive societies in order to provide the means of satisfying their economic and other needs. Moreover, these rules, far from being absolutely inflexible and unchanging, are indeed, bearing in mind the vast differences between the two modes of life and the technological equipment and organization supporting them, in a manner similar to our own legal system, subject to a process of constant adaptation to new situations, old rules being re-interpreted and new rules being from time to time created.

\subsubsection{Sanctions and Primitive Custom}

This brings us to the second of the major misconceptions among the earlier writers on primitive custom. This was the notion that primitive man was caught up like a fly in a 
web of inherited custom and that so great was the fear of the forces of religion and magic that violation of custom by an individual offender was virtually unthinkable. From this the conclusion was drawn that no sanctions were really necessary in such a society, for custom was self-enforcing and any occasional violation could be left to the supernatural powers, which would speedily visit death and destruction upon any person or group which disregarded the imperative norms of the tribe. Subsequent investigation of the actual conditions among primitive peoples in many parts of the world has revealed how utterly remote from reality is this model of a primitive social order. For not only is it found that primitive man is just as likely to offend against his customs and, indeed, as Seagle has put it, 'to commit adultery with civilized casualness', but all societies seem to have some form of legally controlled sanctions for punishing breaches of the rules. Malinowski himself underwent some changes of view in regard to the question of sanctions, since at one time he seemed to take a rather too idealized view of the controlling force of 'reciprocity' in the life of the Trobriand Islanders among whom his researches were largely conducted. In the end, however, he came down firmly on the side of those who hold that ultimately the working of primitive, as of developed societies, rests on coercive sanctions, though it may be the feeling or need for reciprocity that accounts for its effective functioning.

The form and indeed the effectiveness which sanctions may take will depend upon how highly the tribal institutions are developed. In a very underdeveloped state of society, as among the Urubus of Brazil, who possess hardly any formal tribal organization and no system of law enforcement, the only sanction, apart from supernatural retribution or the blood-feud, may be that of shaming a defaulter into conformity. Perhaps the simplest form of control is in relation to the blood-feud, where rules are formed, even among so primitive a society as the Eskimos, which enable force to be inflicted without revenge or the blood-feud ensuing, provided the proper procedure is followed. Among such a people as the Trobrianders, use may be made of a primitive 'stop-list'; if a man fails to comply with his economic obligations, for instance by default in making a customary payment, the economic support of the community may be withheld from the defaulter, who will thus be left helpless and alone. Moreover, in more serious cases, socially approved force may be applied, and the ultimate sanction of compulsion and even death may be inflicted when the life of the community is endangered. The main object of sanctions, nevertheless, is not so 
much to punish the individual offender as to restore the status quo ante, that is, to maintain the social order, for the breach is regarded as disturbing social solidarity, which has then to be restored.

In what respects, then, does primitive custom differ from developed law? We have seen that it constitutes a body of norms distinct from religious ritual and observance, regulating and controlling the social and economic life of the tribe in a manner closely comparable to the functioning of law in a more developed social order. Moreover, many, if not all, on such rules are secular in character and are just as liable to be breached or disregarded as are modern laws. Some kind of enforcement is, therefore unavoidable and this generally takes the form of rules which regulate the conditions in which force may be properly applied without incurring the risk of provoking a bloodfeud. Very grave violations which threaten the security of the tribe, may justify death being inflicted either directly or by cutting off the offender from all economic means of sustenance, though is some cases, if religious taboos are involved, it may be left to the supernatural powers to impose the appropriate penalty. There are, of course, many types of primitive society, some much more developed and institutionalized than others. Some of these may possess relatively developed machinery for handling legal disputes, including even a formal court procedure, as for instance among the Barotse. Broadly speaking, however, the vital contrast between primitive custom and developed law is not that the former lacks the substantive features of law, or that it is unsupported by sanctions, but simply that there is an absence of centralized government.

The Absence of Legal Machinery in Primitive Society

This absence of centralization, which expressed in modern terms, amounts to saying that there is a community but not a state, means that there are no centralized organs either for creating law or for enforcing it. This does not imply that there is therefore nothing but unchanging and eternal and self-enforcing custom. No doubt the more simple the mode of life of the particular society and the more stable it is the less need will be felt for change and the creation of new rules or the modification of old ones. Primitive law (for such, we can now see, it may justly be termed) possesses a flexibility analogous to developed law in its ability to adjust to new conditions. In the 
absence of regular machinery for formally establishing or creating law, change may still come about in a variety of ways. For instance a council of elders may give a new interpretation of an old rule or even establish an entirely new one. Or again the settlement of a dispute may result in a decision which may be treated (as occurs in modern judicial process) as a precedent for future cases. In neither instance will the new custom or interpretation derive its authority from a formal legislative and constitutional power vested in some person or body; recognition will be given to it because of the reverence felt for the chieftain or the elders, or because these have invoked the spirit of the tribal ancestors or some other supernatural force, or possible even because the decision or ruling appears to the community as being eminently just and reasonable. It must be borne in mind too, that in a society which has no written records or writing of any kind, the operative custom of the tribe must depend upon the accuracy, reliability, and indeed honesty of the memories of those, especially the chieftains and elders, in whom it is enshrined. Accordingly, the fallibility of human memory alone must account for a good deal of gradual erosion of and accretions to the body of customary law.

The lack of established judicial tribunals to settle disputes and, even in the rare cases where these exist, the absence of centralized machinery for enforcing decisions, mean that primitive law is dependent on rather indiscriminate modes of enforcement, including self-help remedies applied by the next-of-kin of the injured person. All the same in a small and closely-knit society these can prove singularly effective. In considering the views of the modern sociological jurists we have had occasion to refer to Roscoe Pound's hypothesis that every human society possesses its basic legal ideology or 'jural postulates' which form the main, though usually implicit, presuppositions of its legal system. This line of thought has been applied by Hoebel to a large variety of primitive societies in varying stages of development, and he has been able to elicit, at least tentatively, the underlying postulates of each one of these, and how they are related to and implemented by the actual rules of customary law observed by these societies.

One or two examples may be given from the many discussed in considerable detail by Hoebel. Among the Eskimos, social life is very simple and legal institutions are rudimentary, so there are very few basic premises of their culture which can be 
translated into jural postulates. Hoebel states that among those are included such postulates as that 'life is hard and the margin of safety is small, and unproductive members of society cannot be supported'; and that 'all natural resources are free or common goods, and that it is necessary to keep all instruments of production, such as hunting equipment, in effective use as much of the time as is possible'. As for the first of those postulates, it is shown to provide legal justification for such practices as infanticide, and the killing of the sick and the old, and other forms of socially approved homicide. As to the second postulate, this has a variety of important consequences, including the fact that for the 'Eskimos land is not treated as being property of any kind, so that any man may hunt wherever he pleases, for the idea of restricting the pursuit of food is repugnant to all Eskimos. Moreover, although game and most articles of personal use are objects of property notions, the Eskimos are strongly hostile to the idea of any body accumulating too much property for him self and thereby limiting the amount of property that can be effectively used in the community. In one part of Alaska, for instance, prolonged possession of more goods than a man could himself use was regarded as a capital crime, and the goods were subject to communal confiscation.

To take another example, among the Ifugao in Northern Luzon, whose social organization is a good deal more elaborate than that of the Eskimos, one fundamental postulate given is that "the bilateral kinship group is the primary social and legal unit, consisting of the dead, the living, and the yet unborn'; and that 'an individual's responsibility to his kinship group takes precedence over any self-interest'. This postulate is shown to produce important legal consequences, for instance many types of property are treated more in the nature of a trust than of absolute ownership: a holding in trust for future generations. Again, as the family consists not only of the living but also of the dead and the unborn, and concern for the well-being of the dead exceeds that of those who live now or in the future, family fields may be sold if necessary to buy sacrificial animals to accompany the spirit of a deceased ancestor; they may also be sold to bring about the recovery of a family member who is dangerously ill. It is not possible to provide more details of these and similar matters within the ambit of the present work, but it should pointed out that Hoebel indicates, with a wealth of examples, the manner in which the postulates of the particular societies with which he deals are related to the actual legal rules and institutions of 
that society, and the way in which these reflect the physical environment and the cultural circumstances of the societies in question.

Two factors, in particular, seem to emerge from Hoebel's analysis. One is the way in which each society has a pattern of legal norms directed to maintaining a stable order conforming with its basic postulates. The other is that the success of a society in maintaining such stability will depend upon the degree of integration which it has succeeded in achieving, and this in turn will be reflected in the degree to which its basic ideology commands general assent. Clearly a poorly integrated community, as Hoebel demonstrates in the case of some American-Indian tribes, is likely to have trouble when it comes to enforcing its customary law.

The concept of legal system: Can you tell the meaning of the term `legal system`? Can you tell the meaning of the term system`? A system implies that there are several elements that are put together to achieve a certain purpose. A legal system is defined as a synergy of legal rules, legal principles, legal standards, legal policies, legal structures, legal tradition, legal actors, legal extension and legal penetration operating in a given geographical area. The term `synergy` in this definition implies that legal system is not a mere summation of the elements listed. A legal system is rather qualitatively different from and bigger than, the sum totality of those elements. The complexity of a legal system varies depending on the stage of development of a country. You cannot expect the Mesopotamian legal system to show the sophistication of the current English legal system. Again you should not expect the Greek legal system to manifest the complexity of the present day French legal system in terms of the arrangement of the legal rules, the legal professionals, recording etc.

In the definition, the term `legal system` refers to a present or past legal system. The purpose of legal system may be to sustain a slave-owning system or a feudal system or a capitalist system or to achieve a communist system. A legal system may be created to assure the survival of a theocratic system. A legal system may exist at local level or national level or regional level or international level. Legal structure encompasses law schools, bar associations, the police, courts, the legislature, the executive and prison administration. Generally, legal structure means all those institutions responsible for creating, modifying, interpreting, improving and 
implementing laws. Legal actors means the persons acting in legal structures, means members of the parliament, officers of the state, law students, law teachers, legal practitioners, etc.

Legal culture: Can you define legal tradition? Do you notice that it is an element of a legal system? Do you think that it is an important element of a legal system? Can you tell the meaning of the term 'tradition'? Does the term 'tradition' imply the existence of continuity? Legal culture refers to a set of deeply rooted and historically conditioned attitude of the majority of the members of a given legal system towards the other elements of that legal system, which means the way laws are made, modified, interpreted, the way the legal actors and structures function. Legal tradition is the abstract element of a legal system. The attitude directed towards a legal system can be hostile, neutral or favorable. When the attitude of the governed is hostile, the legal system will show instability; and it will have to be changed. When the attitude of the governed is supportive of the legal system, the system will show continuity. So depending on the type of the attitude of the majority members of the legal system, the legal system may show deep and frequent changes or stability. When we say legal tradition, we are referring to the attitude of the majority members of a given community. The attitude that constitutes a legal tradition should be directed to a legal system and should be something deeply embedded in the system. The attitude should also be historically conditioned in the sense that it should be there for a relatively longer period of time and that it should have the feature of perpetuating itself.

\section{Review Questions}

\section{Part I. Answer the following questions.}

1. Explain the difference between customary practice and customary law.

2. List and discuss two types of customs.

3. Is there any difference between custom, convention and customary practice?

4. Define customary law. Is the element of intention an essential component of the definition of customary law? Why? Outline the major differences between state law (also called positive law) and customary law. Do you think the following quotation 
would help you to attempt these questions? ${ }^{1}$ Custom is a practice or away of doing things that has been handed down from one generation to the next. Customs are a part of the culture shared by members of a social group. Many customs begin because people like to know what to expect in social situation. Like all cultural traits, customs are a form of learned behavior and they differ among different peoples. For example, eating is a biological requirement for all people but table manners and customs of food preparation vary from group to group.

Customs last long partly because people often find it easier to conform than to face disapproval of their social group. Such approval may range from mild ridicule to severe punishments. Commonly, many customs produce only mild customs produced only mild reactions when broken. Blacks' Law Dictionary defined customary law in the following terms, law consisting of customs that are accepted as legal requirements or obligatory rules of conduct; practices and believes that are so vital and intrinsic part of a social and economic systems that they are treated as if they were laws.

In contrast to the statutes, customary law may be said to exemplify law. Let us therefore, describe customary law in terms that will reveal to the maximum this quality of implicitness. A custom is not declared or enacted, but grows or develops through time. The date when first came into full effect can usually be assigned only with in broad limits. Though we may be able describe in general the class of persons among whom the custom has come to prevail as standard conduct, it has no definite author, there in no person or definite human agency we can praise or blame for its being good or bad. There is no authoritative verbal declaration of the term "custom." It expresses itself not in a succession of words, but in a course of conduct. Whenever conflicts or disputes arise and a cultural mechanism for resolving them exists, or behavioral infractions occur that are punishable in some way, we are dealing with law. Therefore, we can see that customary law is broader than the western notion of law. Customary law is also associated with morality and value systems. When viewed as a series of statements of what constitutes proper behavior, the law differentiates right from wrong, good from bad. For most of the society, customary laws have been 
internalized. That is, most people do not break such laws, not because they are afraid of being punished but because if they did break such laws, they would feel guilty. In traditional societies, the enforcer of the laws is the person's conscience.

\section{Part II. Fill in the blank space with appropriate word (s).}

1. refers to any pieces of information employed in the course of making a legal document.

2. relates to the reason why a legal document is valid.

\subsection{Theories of Customary law:}

For custom to be regarded as law, more than simple usage is required, even if the usage is general and has long flourished. Consistent behavior in accordance with particular implicit rules does not indicate that people should so behave, or conversely should be subject to some sanction if they do not.

The main problem for any theory of customary law is determining the nature of the additional factor required to transform custom into law. Here you will study this issue by considering some five theories of customary law, namely the tacit consent theory, the theory of opinion necessitaties, the common spirit of the people, sovereign recognition and judicial recognition.

The tacit consent of all: Can you guess how this theory of customary law might define customary law? The Roman sources clearly indicate that some additional factor is needed to recognize custom as law, even if the nature of this factor is not apparent. For example, the Epitome Ulpiani states that custom is the tacit consent of the people, deeply rooted through long usage. Another Roman source document states that unwritten law is that which usage has approved. For long-practiced customs, endorsed by the consent of the users, take on the appearance of statute. In this instance, the additional factor is expressed by "endorsed by the consent of the users. The element that transforms custom into customary laws is deeply rooted custom is observed as a statute, not undeservedly; and this is what is called law established by usage. For since legislation binds because it has been accepted by the judgment of the people; 
then those things that the people have approved without writing will bind all. Thus, custom is law because the people accept it as law.

Can you state the problems of this theory? The theory of the tacit consent of all tells that custom would be transformed into customary law if and only if all members of a given community agree on such transformation. Thus, one problem is that it is almost impossible to get the consent of all members of a given community on each and every custom to be upgraded to customary law. Is it not impractical to obtain the assent of all? It is almost impossible to obtain the unity of minds of all to the transform of custom into customary law. The second criticisms directed against the tacit consent of all theory is that customary law binds every member of a given community; its breach would entail sanctions. But this serious matter is reduced by the tacit consent theory of customary law to a covert consent not an open and explicit consent. The point is that the idea of explicit consent makes more sense that the idea of tacit consent in such type of serious matters.

Theory of Opinion Necessitatis: For opinion necessitatis, individuals purposely follow a certain rule simply because they believe it to be a rule of law. The practice must be the expression of an intention of legal validity of the community or of a general conviction of law provided only that one is clear that this "intention of legal validity" or the "general conviction of law" is not solely a "psychological fact" but the "sense of fulfilling a norm" (of a legally commanded behavior) developing or dwelling in the individual acts of conduct according to the judgment of those sharing the same law. Under this view, custom becomes law when it is known to be law, is accepted as law, and is practiced as law by persons who share the same legal system.

Can you comment on this theory? Assume that once the custom is known to be law and is accepted as law, the practice changes. Does the old law cease to be law, and the new practice become law? If this does happen, at what moment does it happen? And, what is the machinery for change? The theory of opinion necessitatis fails to adequately answer these questions.

In the first situation, those subject to the law remember the past custom. In the second, they forget the past custom. In the first situation, a contrary practice cannot change the 
law. So long as people remember the past custom as being law, there can be no point on the custom-law continuum at which the new practice usurps what in consciousness has been the law. Accordingly, the outmoded practice must cease to be law before a different law can begin to emerge from customary usage. The theory of opinio necessitatis contains no mechanism for deleting law that no longer commands approval. Under the doctrine of opinio necessitatis, overlapping practice does not create a new legal rule because the new practice was not followed in "the general conviction of law.

the doctrine of opinio necessitatis does not allow the desuetude of a customary legal rule when that legal rule is remembered. Customary law is a "general conviction of law"; hence, it corresponds to what people generally do. People conform to customary law because it is the law. Failure to conform would be an unacceptable deviant act contrary to law. The point is not that customary behavior does not change; rather, under the doctrine of opinio necessitatis, when a rule of customary law exists and is remembered, the rule cannot become obsolete by desuetude. In other words, acts that are known to be contrary to the rule cannot affect the rule's efficacy

There is another problem in the doctrine of opinio necessitatis. A legal rule can only fall into desuetude if another legal rule replaces the existing rule regardless of whether this later rule merely states that the first rule no longer applies. But under a theory of opinio necessitatis, the new rule can only come into existence after the old known rule is recognized as extinct. Otherwise, those subject to the law would not be convinced that the new behavior corresponds to the law. Accordingly, no framework exists within which desuetude can operate in compliance with the doctrine of opinio necessitatis.

When those subject to the laws forget the past custom, the prior law effectively is not changed by a contrary practice. If the people completely forget customary law, then as a practical matter, the law does not and did not exist. People may have gradually adopted a very different lifestyle with respect to the past custom, e.g., perhaps as a result of migration. We should regard the new practice as law, not simply because new law has replaced old law, but because law has been created for circumstances where no law previously existed. When the people completely forget a rule of 
customary law, the doctrine of opinion necessitatis does not explain how a subsequent contrary practice has, as law, replaced previously existing customary law. Thus, the doctrine of opinion necessitatis excludes the possibility of changing customary law by subsequent practice, both when the customary law is remembered and when it is forgotten.

The Common Spirit of the People: This theory was developed by von F. Savigny. Under this view, law arises not from individual acts of behavior but from common consciousness. Individual acts of behavior do not create customary law but are merely appearances or indications of a preexisting common conviction about the law.

The common spirit of the people is criticized for its several failings. First, this theory presents a nation as a corporate entity; it assumes that a nation manifests unity of action when it comes to developing customary laws. Second, the theory hides several historical instances where the minority has imposed its will on the majority in the form of laws. Third, the theory dismisses the possibility of a country borrowing laws from other countries. Finally, the theory is criticized for being narrow or ethnocentric.

Sovereign Recognition: John Austin suggests that customary laws originate as rules of positive morality, which arise from the consent of the governed. However, for moral rules to be transformed into positive laws, the state must establish these customary laws. The state may establish customary laws either directly by statute, or indirectly by judicial decree. Thus, under Austin's approach, customary behavior does not make law; custom becomes law only when it is the subject of statute or judicial decision.

Austin's theory implicitly assumes that all law is legislation and that judges, insofar as they create law, are legislators. Austin's theory is consistent with his position that law is the command of the sovereign. Under this view, a statute becomes law even before it is enforced by a court decision. Scholars who do not accept Austin's theory of law will find Austin's theory of custom unacceptable. If one believes that other sources of law, such as custom, exist in theory, then law may also potentially exist without benefit of a court decision. It is precisely the binding force of custom which challenges [Austin's] initial assumption itself," and that "he failed to explain 
satisfactorily why the body of rules which he classified as positive morality' . . lacked the true character of law.

A second objection to Austin's theory concerns societal treatment of judicial decisions. Societies that do not treat judicial decisions as binding legal precedents may nevertheless treat decisions establishing a custom as binding. From this viewpoint, a legal historian might claim that custom rather than judicial precedent is law. In this system, when a court finds that a custom exists, the subsequent decision based on that custom is not binding as a decision. Accordingly, the court establishes the preexisting custom as a matter of fact, and the decision, which is not law, merely confirms the preexisting law.

Therefore, the defects of the sovereign recognition theory of customary law are that the state has no moral authority to validate or invalidate the wishes of the communities as reflected in their customary laws, that the state may distort the authenticity of customary laws in the course of validating them, that it is unsound to state that the state is the only valid source of legal rules and that customary laws are already valid by the assent of the community and thus not need to validate them any more.

Judicial Recognition: The basis of local customary law is frequently treated as custom rather than judicial precedent even though acceptance of the rule actually stems from local judgments rather than from antecedent local behavior. This treatment raises a question about the role of judgments in creating customary law. Similarly, custom is a separate source of law distinct from both legislation and judicial precedent. But like judicial precedent, custom must be accepted by the sovereign in order to constitute law. To become law, custom, like legislation and binding precedent, must be clothed with the requisite form, which marks its official acceptance by the sovereign. This requisite form requires that adjudicators incorporate custom in a judicial decision. A society may accept custom as law when incorporated in a judicial decision but deny law-making effect to precedent, thereby demonstrating that custom as a means of making law is not simply subsumed into binding precedent. So long as the courts treat the custom as law, the custom is the accepted customary 
law. Should the courts hold that the custom has changed, however, then the new ruling becomes the customary law.

In sum, a major problem for any theory of customary law is determining the nature of the additional factor required to transform custom into law. The doctrine of opinion necessitatis generally has replaced earlier consent theories, but a major flaw of the opinion necessitatis doctrine remains. The doctrine fails to adequately incorporate the creation of new customary law or the deletion of obsolete customary law. Savigny's theory of the common consciousness fails to resolve the logical failings of opinion necessitatis. Austin's work suggests that custom becomes law only by the additional factor of state confirmation. Redactions of customary law show that, although the basis of customary law is treated as custom rather than judicial precedent, acceptance of the rule often arises from official judgments rather than from antecedent local practices. Court decisions, not law themselves, function as official sovereign recognition and acceptance of rules of custom as law. Court decisions transform rules of custom into law, regardless of whether the antecedent custom was actually recognized as law. Customs do not become law until institutionalized by inclusion in an official court decision. This theory of customary law may help to explain several otherwise problematic aspects of medieval and practice.

The theory of Desuetude: Can you explain the theory of desuetude? A full appreciation of this theory warrants asking the following four questions. First what is desuetude? This term is a generic term. Desuetude means anything that is no longer in use; but originally designed to serve a given purpose. As applied to customary law, what is the meaning of this term? The doctrine of desuetude is inherent in customary law. The doctrine of desuetude states that when a practice that is recognized as law ceases to be followed or to be regarded as law, it ceases to be law. At that stage, but not before, the road becomes clear for the creation of new customary law. Adherence to the new custom before the old customary legal rule becomes obsolete is a factor in making the old legal rule obsolete. It simply means the customary law in force has lost its obligatory force. The third question is the reasons why customary law may lose its obligatory force. Customary law may lose its obligatory force owing to internal and external changes in the community that developed the customary law in the first place. The community has developed the customary law in order to solve a 
given legal problem and when the context in which the customary law changes the customary law itself must disappear or be modified. The final question in respect of theory of desuetude is whether the outdated customary law might revive. What do you think? Is there any possibility of reviving an obsolete customary law back to life?

\section{Review Questions}

Give appropriate answers to the following.

1. State the essential points of the common spirit of the people.

2. State the criticisms advanced against J. Austin's approach to customary law.

3. State the judicial recognition approach to customary law.

4. Describe why it is important to study customary laws.

5. According to Juma, why are customary laws in Africa still important?

6. For some customary laws in Africa have no longer any relevance in the modern times. What are the reasons advanced by such persons?

\section{4 History of Customary Laws:}

This sub-section describes certain information relating to the origin and development of customary laws in different legal traditions.

Origin and Development: The history of customary law is as long as the history of human kind. In those early times where there was no codified law by institutionalized organ of the state, people were governing themselves in a certain way. The evaluation of law began before history was recorded with laws built upon one by one as disputes were settled. In fact the development of rules in society predates both courts and the written law. For thousands of years, customary and private legal systems alone ordered human activities. The obligation to behave in a certain way in a particular community became a customary law in that particular community the failure to observe result in a sort of sanction from the community against the deviant. This is so because behind customary law there is moral force to behave in a certain way. They became compulsory and have acquired the force of law with respect to the place or subject matter to which it related. 
“... Rules (i.e., customary laws) can evolve and emerge spontaneously as the unintended outcomes of individuals separately seeking their own goals. Such laws are less likely to be violated than enacted authoritarian laws because they require voluntary acceptance by individuals in recognition of reciprocal benefits received, As a result, customary law is less likely to require adjudication.

Since its inception, customary law has undergone considerable change as the society is always in a constant motion. Customary rules also respond to the particular needs and interests of the social group. When these change, customary rules tend to change though the way they change is influenced by the nature of previous rules... Some customary law lost its power as there is a constant mobility and interaction of the society. As a result, there is a move from old customary law to modern law. As certain activities of human beings are beyond the reach of customary law, it is supplemented by modern law. In ancient societies a greater degree of psychological conformity was necessary. So custom is stronger in ancient than modern societies. In the present world, custom is conserved in the rural districts among less developed groups than in the cities." Circumstances were slowly changing that people themselves were unaware of the change. So law and custom change with those circumstances. The old practice were forgotten, however, people believe that they are still following the percepts of their ancestors, when the truth is that they have long since abandoned them.

Customary Laws in Some Legal Systems: Customary law is one of the elements of the civil law tradition. The modern law of merchant, whose origin is usage, has passed three successive historical stages. The first stage was the situation where by the existence of certain usage in particular business was proved by the witnesses called by the party before the court; the second stage was the time when the court took cognizance of the existence of certain custom in particular transaction. This is so by referring to earlier decisions of similar question of facts and /or laws. The second stage of development is reached when the courts take judicial notice of the custom in question, so that it no longer requires to be specially pleading or proving in the particular case. It has already been sufficiently proved in the previous cases, and has received the authority of the precedents established by those earlier cases. 
The last stage of merchant law is its incorporation into the formal national laws. This law has its first source in the conventional law, and secondary source in the precedent. The law of bill of exchange, and the law of marine insurance which were both in their origin part of the customary law merchant, have now completed its normal course of legal development.

It is said that conventional custom is the source of modern law merchant. The bulk of the law as to bills of exchange and other negotiable instruments, bills of lading and marine insurance, has originated in this manner as customary law. Law so derived from the conventional customer of merchants is known as the law merchant.

Prior to codification, Germany used customary laws. European countries regulated themselves, among other, by customary practices and customary laws in the Middle Ages.

Before the French Revolution, traditional customary laws prevailed in the north. The rules were Germanic customs while Roman law influenced the southern part of France. Roman law gradually spread northwards. The French legal system was not sharply divided because there were written rules influenced by Roman law but containing strong Germanic elements in the south. And Roman law was not entirely rejected in the North.

France received Roman law not because it had been laid down by Rome, but on the ground that it had been accepted by custom or by reason of its quality. The existence of diverse customary rules and edicts created some degree of legal uncertainty in France.

France's need for a single, unified code of laws had been keenly felt even before the collapse of the ancient regime. Whereas, southern France had inherited Roman law, northern France was ruled by a system based on customary law. The two systems were fundamentally different. The laws differed not only from province to province but also from town to town. Nor were the laws always rational. Louis XIV, the Sun 
King, had summed up his approach to lawmaking with his famous phrase "It is legal because I wish it."

Before the introduction of the Civil Code, a patchwork of customary laws based on tradition and the whim of the monarch had ruled throughout the continent. The new Code introduced the concept of a unified, logical system based on general principles of law. This facilitated the export of the ideas of the French Revolution beyond French borders.

In their move to eliminate legal uncertainty, some practitioners attempted to record customary laws of particular regions in France. It remained true, however, that the customary laws of Northern France depended principally on oral tradition. The judge who did not know the appropriate rule of the relevant area had to discover it by interviewing local inhabitants. The proliferation of custom and the difficulty of discovering their content led to great legal uncertainty. As a result, a French king in the $15^{\text {th }}$ century declared that the customs of the various territories should be written down. The king also ordered that those, which were already recorded, should be drafted anew.

The intervention of the kings in having the customs recorded met with opposition from some territories. The intervention and the effort to write down the various customs in France strengthened the power of the traditional customary laws to withstand Roman Laws. The recording of customary rules saved France from the massive reception of Roman law, which took place in Germany. The codification of customary laws created conflict of different customary rules. Recording of customary law in France had brought about legal certainty. Yet, it could not diminish the substantial differences between them. The recoding efforts of French customary laws made the difference among such rules sharp and conspicuous.

Case law grew up in England because of the accident of the early English judges being Normans. They were foreigners to England and they were bound together by an ESPRIT DE CORPS, which made them respect each other's decisions, especially when these decisions dealt with matters, which were strange and unfamiliar to them. If half a dozen of you were to be sent to the wilds of Africa as judges, naturally 
when you meet together you would discuss the strange customs of the Africans, and if in a case you feel that what you heard from another judge would help in solving the problem. You would naturally remember that example and follow the precedent. In this fashion in England the Norman judges when they used to meet at the Temple discussed their cases, and started the practice of following each other's decisions. Once the Bar discovered that the best argument in favor of a particular case was the decision of a brother judge in a similar case, they began to take notes of cases by these judges and in that manner law reporting came in to existence. Law reporting became an established practice in this manner, and now as you know the opinions of one judge are regarded as an authority binding on the other judges. The growth of case law in England was also accelerated by the reaction that set in against the reception of Roman law. On the continent, particularly in countries like Germany and France, the indigenous or local law was found to be unsatisfactory as society progressed, and whenever a complex case came up, to which the local law could supply no remedy, it was the practice of the judge to apply Roman law, with the result that at the present day, a large part of Germany and French law is nothing more than Roman law.

Also in England the local law was found to be unsatisfactory with the advance of civilization, and the same remedy of introducing Roman law was attempted. But the common lawyers in a body resisted it, and to meet the exigencies of the situation, the judges resorted to a fiction, namely, that there was no legal problem that could not be solved by the application of customary law, and that every judge carried about in his brains a complete body of such law "of amplitude sufficient to furnish principles which would apply conceivable combination of circumstances". A judgment or declaration of a judge was supposed to be in conformity with the custom of the land, and when such declarations were followed by subsequent judges for the sake of conformity, there grew up in England the practice of following precedents. It is possible as Maine points out, that the judges were influenced by Roman law principles, and that they borrowed in large quantities from the Roman law, but what is important for us to note, is that they did not rest the authority of their pronouncements on either the Roman law or on the theory of IPSE DIXIT, but on the fiction that their judgments indicated the custom of the land. It was always as indicating the custom of England, and not as an authority, that these decisions were acted upon and followed during the $13^{\text {th }}$ and the $14^{\text {th }}$ centuries. 
Customary laws that were legitimatised when found out to be in line with the teaching of the Holy Veda. There are factors that led to the differing interpretation of the teachings of the Holy Veda; one of which was customs and practices surrounding the others affected their respective version of Veda. Islamic law was also subjected to different interpretations owing to, among others, the customary laws and practices of the Muslim communities living in different geographical conditions.

\section{Review Questions}

\section{Part I. Answer the following questions.}

1. Define legal system.

2. Define legal culture. Define culture.

3. Do you think he following quotation would help you clarify the distinctions between culture and legal tradition? "Tradition, as defined by sociologists, is a set of social practice, which seeks to celebrate and inculcate certain behavioral norms and values implying continuity with a real or imagined past, and usually associated with widely practiced rituals or other forms of symbolic behavior. One writer has defined culture as "historically transmitted patterns of meanings embodied in symbols; a system of inherited conceptions expressed in symbolic forms by means of which men and women communicate, perpetuate, and develop their knowledge and attitude towards life" Glenn Fisher defined culture as a pre- tested store of knowledge and entire system of coping skills that has been crafted by preceding generations; a design that has been socially created, tested and shared and one that can be transmitted to the next generation- culture is shared and learned behavior. “2

4. European countries considered customary laws and practices found in their respective territories as inimical to political and legal unification especially in the $19^{\text {th }}$ century; thus, they as a result worked towards their replacement either by codes or by case laws. Comment!

5. Describe the manner in which customary laws helped the formation of the civil law tradition.

2 
6. Do you think that the Ethiopian legal system has lacked a favorable legal tradition since 1931? Can you indicate signs of instability in the Ethiopian legal system in this period?

7. Do you think that a legal system can be constructed?

8. Define legal structure.

9. What is synergy?

10. 9.Explain the place given to and the attitudes towards customary law in the western legal traditions. Your explanation should include two examples.

\section{Part II.}

Choose the best answer from the given alternatives.

1. Which of the following terms is found in the definition of legal system?
A. Legal rules
B. Legal structures
C. Systematic
D. All of the above

2. Which of the following is not an element of a legal system?
A. Synergy
B. Legal actors
C. Legal structure
D. Legal tradition
E. None of the above

3. A set of deeply embedded attitude of the majority members of a given legal system towards that system is called.
A. Legal tradition
B. Legal system
C. Legal history
D. Legal penetration

4. When the majority members of a given legal system have hostile attitude towards their system,
A. It is likely that a revolution is inevitable.
B. It is likely that the system will continue to survive for a longer period of time.
C. It is probable that a basic change will take place.
D. It is difficult to make a conclusion. 


\subsection{Legal Transplantation}

The main aim of this section is to examine the concept of legal transplantation. From the previous section of this unit, you have learnt the nature of customary law, legal system and legal tradition. Now, the questions are What is the origin of legal rules? Is it possible for a country to borrow legal rules form another system? What are the reasons for borrowing? Are there cases where a country may be forced to borrow? What are the implications of borrowing laws? The current section is set out to describe the answers to these questions. The study of legal transplantation is important in customary law course since legal transplantation often takes place in developing countries such as Ethiopia with diverse customary law systems. Often the transplanted laws come for a variety of reasons from advanced legal systems. Such transplanted laws officially or on paper question the validity of customary laws. In fact the customary laws continue to be little affected. The adoption of western laws presents the interaction between two sets of laws with quite distinct assumptions and methods. So the study of transplanted laws, its history, reasons and theories is significant in customary law course.

In this section, you should be able to:

- define legal transplantation.

- explain the reasons for borrowing of laws.

- discuss the history of borrowing of laws.

- examine the theories of borrowing of laws.

- discuss issues related to legal penetration.

Legal transplantation: Legal transplantation is also known by other names. These are legal borrowing, legal importation, legal reception and legal taking. Legal transplantation refers to the transfer of rules, principles and legal concepts from one or more than one legal system to another legal system. The legal system borrowing laws can be called the recipient system while the legal system lending laws can be called the donor legal system. The lending system may be an existing legal system or a past legal system. Countries, for example, borrowed from the Roman legal system that 
ceased to exist centuries ago. The recipient legal system should be an existing one or a system at its initial stage of development. Legal borrowing can involve a single legal rule; it can be a massive borrowing. For instance, Ethiopia borrowed large quantity of laws in late 1950 `s and 1960 `s. At the end of $19^{\text {th }}$ century, Japan received large quantity of laws from Germany. Small-scale borrowings takes place everyday. Appreciating legal transplantation is important to conduct legal research, as it enables you trace the right sources of the laws of a given country.

Factors for legal transplantation: Can you identify and explain the factors that may drive a country to receive laws from another system? Do you think that a country borrows laws based on its free decision alone? Do you think that there are cases where a country may be compelled to take laws from another system? A recipient country may borrow laws since they are accessible in terms of language, the laws are found out to be meritorious in terms of organizations, the laws were transplanted to other systems and found out to be fruitful and when the recipient country decided to modernize its legal system. A country may adopt foreign laws as a result of migration or commercial intercourse. A country may adopt the laws of another country because the important elites are attached to the legal system and education of the donor country. A country may be forced to accept the laws of other systems owing to war or conquest or colonization or physiological pressure. Can you give concrete examples for each of these reasons? Is it possible to say, for example, that many countries in Africa and Asia received laws form France and England as a result of colonization? Is it possible to say that the socialist laws were spread to several countries all over the world as a result of ideological threat from the ex-USSR? Can we say that Islamic law was propagated to the other parts of the world through conquest, migration and commercial interaction?

The development of legal transplantation: Legal history indicates that legal transplantation has been rampant. The Greek gave important legal theories to the Romans; the Romans borrowed from the Greek legal system some conceptions of laws. The Romans converted the idealism of the Greek into practical legal rules. The Romans gave principles of private law to European countries such as France and Germany. France added to the laws it received from the Romans some theories and techniques. France then codified its laws in early $19^{\text {th }}$ century. France propagated its 
laws first to neighboring European countries. Later, France transplanted its codes to Asia and Africa through the instrumentality of colonialism. Some countries, such as countries in Latin America, received laws from France voluntarily. England also transported its laws to all over the world via colonialism. Eastern European countries received laws from the civil law countries. After the end of Second World War, however, East European countries were forced to adopt socialist system of laws. Again after the 1980 `s, these countries went back to the civil law tradition owing to external pressures. The socialist legal system was developed as an idea in $19^{\text {th }}$ century and early $20^{\text {th }}$ century translated into practice in Russia. Russia, later USSR, became the mastermind behind the spread of socialist laws to Asia and Africa in some cases through force and sometimes through pressure.

The Islamic legal system originated as an idea in the Middle East in the $7^{\text {th }} \mathrm{c} A D$, and then taken to the coastal areas of Africa, Middle East and Asia. Now a kind of Islamic belt is created. The spread of the Islamic legal system has been attributed to a combination of the following factors: conquest, migration and commerce. Do you realize form these descriptions that legal systems develop through borrowing? Do you appreciate that legal borrowing has implied power relations in the sense that laws usually flow form powerful legal systems to less powerful ones? Do you agree with the proposition that legal transplantation can take place faster in the cases where the recipient system has gaps?

History of Legal Transplantation: Consider the origin, development, spread and decline of the Roman law in the following few paragraphs. The Corpus Juris Civilis is the name of the code developed by a roman emperor known as Justinian. The Corpus Juris Civilis of Justinian was not restricted to Raman civil law. It included much that had to do with the power of the emperor, the organization of the empire, and a variety of other matters that lawyers today would classify as public law.

The Germanic tribes, called the Barbarians, invaded and controlled the Western part of the Roman Empire. With the collapse and the invasion of the Roman Empire, the CORUPS JURIS CIVILIS became inapplicable. The invaders applied cruder, less sophisticated versions of the Roman civil law to the peoples of the Italian Peninsula. The invaders also brought with them their own Germanic legal customs, which under 
their rule that the law of a person's nationality followed him wherever he/she went, were applied to themselves but not to those they had conquered. Even so, a fusion of some Germanic tribal laws with indigenous Roman legal institutions did begin to take place in parts of Italian southern France, and the Iberian Peninsula.

As light returned to Europe, and Europeans regained control of the Mediterranean and as the Renaissance began, an intellectual and scholarly interest in law emerged. What civil lawyers commonly refer to as "the revival of Roman law" is generally conceded to have had its beginning in Bologna, Italy late in the eleventh century. It was at Bologna that the first modern European University appeared, and law was a major object of study. But the law that was studied was not the body of the rules enacted or customarily followed by local towns, merchants' guildes, or petty sovereigns. The law studied was the CORPUS JURIS CIVILIS of Justinian.

Within a short time, Bologna and the other universities of northern Italy became the legal center of the Western world. Students came from all over Europe to study the law as taught in the Italian universities. The law studied was the CORPUS JURIS CIVILLIS, and the common language of study was Latin. There was a succession of schools teaching about the proper way to study and explanting the CORUPS JURIS CIVILIS. Of special prominence, for both their views of the law and their styles of scholarship, were the groups of scholars known as the Glossators and the Commentators. They produced a great body literature, which itself became the object of study and discussion and came to carry great authority. Those who have studied in Bologna returned to their nations and established universities where they also taught and studied the law of the CORPUS JURIS CIVILIS according to the style of the Glossators and Commentators (Those persons who were experts in the Corpus Juris Civilis). In this way, the Roman civil law and the works of the Glossators and Commentators became the basis of the common law of Europe, which is actually called the jus commune by legal historians. There was a common body of law and witting about law, a common legal language and a common method of teaching and scholarship.

With the rise of the nation an state and the growth of the concept national sovereignty, particularly, form the 15 th century, the age of the jus commune of a common law of 
Europe disappeared, and the period of the national law began. In some parts of Europe (e.g. Germany), the Roman civil law and the writings of the Belgian scholars were formally "received" as binding law (civil lawyers use the term "reception" to sum up the process by which the nation - states of the civil law world came to include the jus commune in their national legal systems). In other parts of Europe, the reception was less formal; the CORPUS JURIS CIVILIS and the works of the Glossators and Commentators were received and became of value as customary law. By one means or another many countries in Europe received the Roman Civil law. These countries are now the home of the civil law tradition.

Eventually, in the nineteenth century, the principal states of Western Europe adopted civil codes (as well as other codes) of which the French Code Napoleon of 1804 is the primary one. The subject matter of the civil codes was almost identical with the subject matter of the first three books of the Corpus Juris Civilis of Justinian and the Jus Commune of medieval Europe. The principal concepts were Roman and medieval common law in nature, and the organization and conceptual structure were similar.

\section{Some Illustrations of Legal Transplantation}

French law: French law spread first to Europe, then, to Africa, Asia and Latin America. The French codes transplanted to Europe primarily through military force. In most areas where the Code was introduced, it was embraced, and survived Napoleon's personal downfall. The Battle of Waterloo did not end the application of the Code in Europe, particularly in western Germany, and Italy. In the Netherlands, the Code survived unaltered until 1838, whereas in Prussia the Code was gradually reintroduced. Even in areas where French rule had been unpopular, such as Spain, post-Napoleonic governments were held up to French standards for a codified law based on judicial equality. Following the restoration of the old order, a series of 1820 revolts in Naples, Piedmont and Spain were affected by demands for administrative reform. Within France itself, the Code survived almost unaltered for more than 150 years, and even today has not been fundamentally changed. In many ways, the Code was the most enduring legacy of the French Revolution. 
Latin America received the French codes primarily because of its technical merits and as a result of the reaction to the hated Spanish and Portuguese colonial rules. Latin American countries got independence from Spain in early $19^{\text {th }}$ century. These newly founded states needed national and unifying Civil Codes; the only available model was the French code Civil and Spanish law was out of the question since it was the law of the previous colonial power and since it was neither codified nor uniform even in Spain where local customary laws survived. The code civil was a product of the great Revolution, rooted in a world of ideas on which the Latin Americans had frequently drawn to justify their own struggles for independence. In its compactness and clarity of phrase, the Code Civil was far ahead of any other mode. And furthermore, the code was so full of traditional concepts and ideas especially from Roman law, that its reception was not a deviation from the legal institutions known to the Spanish and Portuguese settlers. Some countries in Asia and Africa received French codes due to the existence of gaps and the force of French colonialism.

The code had such a wide influence because it was the Code of the French Empire whose military powers, backed by a brilliantly integrated civilization, made such a deep impression on people not only during its brief life but many years after it was over. The reception of the French Civil Code is attributable not only to the political power of the French Empire, or to the spiritual influence of French civilization, but also in a great measure to the merits of the Code Civil itself. In the $19^{\text {th }}$ century the Code enjoyed intellectual authority and an almost supernatural appeal as the Code of the Great Revolution, which had abolished the ancient regime. The Code of Napoleon also produced for the first time legal unity and equality for the citizens of a centrally organized national state. The spread of the code civil throughout the world was greatly helped by its admirable language and the easy flexibility of its expression, in brief, by its very quality.

German law: The German codes were not transported so extensively as the French codes. They were transplanted at the end of the 19th century to Japan and thereafter to some African countries. The reasons for the little expansion of the German codes lie in: the fact that Germany did have few colonies, as she was a latecomer to the scramble for different parts of the world. There are another reasons for this little influence. The codes were a bit sophisticated and complex. The third reason is that 
when the German codes were put in place at the beginning of the 20th century in Germany, many countries had already adopted laws from France and Great Britain. So there were then little legal gaps to be filled with in countries in Africa and elsewhere.

The English Law: Originated in 11th century, the English legal tradition expanded itself predominately through colonialism. The expression "the sun never sets in the British Empire" has attained the level of a saying. In addition to some other meanings, the expression suggests the extent of the spread of the British law. The English law was transported to North America (the United States of America, to Canada), Asia and Africa. England transported legal ideas, legal methods, and legal institutions of the common law to countries in these continents. Britain also carried the substantive and procedure laws to these parts of the world. These parts of the world also reflect the English court system and the structure of the legal profession.

Theories on legal transplantation: Do you support legal borrowing? Is there any problem in borrowing laws? There are three views on whether legal transplantation is a desirable one. The first approach is referred to as the custom theory. F. von Savigny, a German thinker of $19^{\text {th }}$ century, elaborated this approach. The approach states that law and society have unique relationships. Law and society have inherent connections. There is a unique relationship between law and society means that laws are found in the common consciousness of the people. This common consciousness is manifested via the behaviors of individual members of that community. Laws are related to the identity of a society for which they are created. Further, every community is legally self-sufficient; whenever a society faces a legal problem, it creates legal rules. To this theory, if one attempts to take the laws of $\mathrm{X}$ community to Y community by way of legal borrowing, those transferred laws will inevitably fail. Legal transplantation will never solve the problems of a recipient legal system. If you know in advance that borrowed laws will fail, there is no reason to try it.

An opposing theory developed by Alan Watson holds the view that there is no unique connection between law and society. The theory also holds that no community has ever been legally self-sufficient in the history of mankind. The theory is named as legal engineering. This theory views laws as intangible instruments to achieve certain 
goals. As laws are tools, they can be taken to any society and used with success. Justifications are given for this position. The first reason is that the fact that legal transplantation has been very common in the history of legal systems shows that people have found it rational and useful. In the second place, if there are laws used by $\mathrm{X}$ Community and if Y community needs those laws, why should the latter be asked to reinvent those legal concepts and legal rules? It is rational for $\mathrm{Y}$ community to receive the laws of $X$ community, which are tested in practice.

Thirdly, the custom theory assumes implicitly, but wrongly, that countries take the laws of other nations on the basis of their own free will. However, history gives us several examples where countries have borrowed laws as a result of external pressures.

The third theory attempts to strike a middle ground. In some areas of law, for example, in the area of commercial law, public law and technology law, there are gaps or traditional laws do not exist in developing countries. In such cases, developing countries do not have a choice; they have to borrow laws. In other areas of laws such as family law, inheritance laws and land laws, developing countries have longstanding laws. In the latter cases, it is difficult to transplant laws and even if transplantation takes place, the laws so transplanted will not be welcomed. This hybrid approach is articulated by Kahn-Freund. This position is also called the degree of transferability approach. This moderate approach to legal transplantation states that the contexts of the recipient country should be studied well before the borrowing of laws is made. Which theory do you support: the custom theory (also known as the historical theory), the social engineering theory (also called the instrumentalist theory) or the hybrid theory? And why?

More on the Theories of Legal Transplantation: The debate surrounding the theory of legal transplants has an almost unique beginning. In 1974 Alan Watson and Otto Kahn-Freund presented competing theories on the viability of legal transplants. The divergence of their views can be traced to the adoption of contrary propositions about the relationship between a state's law and its society. 
Watson's theory begins with the proposition that there is no inherent relationship between law and the society in which it operates. He believes that law is largely autonomous, with a life of its own. Watson states that law develops by transplanting, not because some such rule was the inevitable consequence of the social structure and would have emerged even without a model to copy, but because the foreign rule was known to those with control over lawmaking, and they observed the apparent merits that could be derived from it.

Under Watson's theory, a legal rule is transplanted simply because it is a good idea. While Watson does not explicitly present a method to predict the viability of a proposed legal transplant, his writings provide guidance for such a method. He has further identified several factors that he believes must be considered to determine if the conditions are ripe for legal change by transplantation.

Kahn-Freund's disagreements with Watson begin with Watson's proposition that there is no inherent relationship between a state's law and its society. He claims that laws must not be separated from their purpose or from the circumstances in which they are made. Kahn-Freund argues "we cannot take for granted that rules or institutions are transplantable and believes that "there are degrees of transferability. Ewald summarizes Kahn-Freund's theory: "legal institutions may be more-or-less embedded in a nation's life, and therefore more-or-less readily transplantable from one legal system to another; but nevertheless at one end of the spectrum law is so deeply embedded that transplantation is in effect impossible.

Kahn-Freund identified a two-step process to determine the viability of a proposed transplant. The first step is to determine the relationship between the legal rule to be transplanted and the socio-political structure of the donor state. The second step involves comparing the socio-political environment of the donor and receiving state.

There is agreement, however, that the phrase "legal transplants" refers to the movement of legal norms or specific laws from one state to another during the process of law-making or legal reform. However, as a consequence of these conflicting propositions, their theories clash not only over how to evaluate the viability of a proposed legal transplant, but also over the general conclusions that can be reached 
about the usefulness of legal transplants as a tool of comparative scholars. Other scholars debate nearly every aspect of the legal transplant theory.

The study of legal transplants has been revived since the collapse of totalitarian rule. It is not. The issue of reception of foreign law has a considerable history and a remarkable topicality. As states around the globe implement dramatic political and economic changes in response to external and internal developments, their legal systems must be radically altered. In making these changes, legislators determine whether the borrowing of foreign law is feasible and if the international harmonization of a particular set of laws is viable. The argument is strong that there is no need for legislators to struggle to reinvent the wheel when others have dealt with the same issues. This argument is further supported by the fact that states are under pressure in the increasing interdependent world to create uniformity in law.

Massive successful borrowing is common in law. Borrowing is usually the major factor in legal change. Legal borrowing is of enormous importance in legal development. The borrowed rule does not operate in exactly the way it does in its country of origin. Since the time of late Roman Empire, they have been a major factor in legal change in the western world. England is no exception. Nor is the United States. Nor is Québec, even with its differences from the other provinces. The real issue is whether there should be a deliberate concerted effort, spear-headed perhaps by academics, to create a common law.

Beginning in 1991, Eastern Europe began the unprecedented effort of lawmaking on a grand scale. Almost overnight and at the request of their people and/or international organizations, former communist countries had to disassemble their political, economic, and legal institutions, which were based on centrally planned economies, to erect market-based democracies. Large sections of their old legal systems were now obsolete. The legislatures, however, were in most cases not free to form law and policy, as an "author is free to write a novel." The legal establishment of the communist era held influential posts and had contacts in the East and the West. They were ex officio called to lead reform efforts. In addition to them, foreign technical assistance arrived with ideas for "legal surgery or reception of foreign law.” A great 
number of foreign concepts (e.g., negotiable instruments of credit security devices) were introduced as if they were legal transplants to replace malfunctioning organs.

Comparative law was employed to decide either compatibility of foreign legal concepts or the merits of foreign legal systems and to provide an anthology of foreign legal ideas. Modern comparative legal methodology deals with legal transplants and reception of foreign law.

Legal penetration versus legal extension: Can you define legal penetration and legal extension? Do you think there is a gap between legal penetration and legal extension? If there is a gap between the two, in developed or undeveloped legal systems does it exist? Can you give reasons for the gap? As you may recall, legal penetration and legal extension are two of the elements of a legal system.

Legal extension: Those responsible for the importation of laws assume that the transplanted laws would affect human conducts possibly $100 \%$. The assumption is based on the belief that the actors at the time of massive importation of laws desire that communities would adjust their behaviors to the imported laws. The actors who sponsored wholesome importation of laws plan that the imported laws would be implemented in all parts of the territory of the recipient country. For example, Ethiopia borrowed large scale laws in 1950`s and 1960`s; at that time, key personalities responsible for such project, it is assumed, expected that such laws would be accepted by the people; the people would shift their allegiance towards the new western oriented laws. Was that expectation realized?

Legal penetration: Legal extension refers to the extent to which people are actually following the imported laws. If legal extension is the aspiration, legal penetration is the reality. The question is whether people have actually adjusted their behaviors to the prescriptions of the imported laws or people are settling their social and economic conflicts pursuant to customary or religious laws?

In the context of developing countries such as Ethiopia that transplanted laws from the west there is a substantial gap between legal extension and legal penetration. The gap is not. We can cite examples. In Ethiopia, the imported family law, as 
incorporated in the Ethiopian Civil Code of 1960, states that spouses are equal, at the time of the creation of marriage, in the course of marriage and upon the dissolution of marriage. The husband and the wife should conclude marriage on their free consent. The husband and the wife should share household burdens equally. The husband and wife should divide the common property equally when their marriage comes to an end via dissolution. But the customary laws do not conform to these prescriptions of imported laws. You can take the case of land. Land since 1974, in Ethiopia, has been taken as a collective property. But under customary law some tribes still believe that land belongs to them. You can go on citing examples in the area of homicide law etc. In developed countries, on the other hand, people have sufficiently adjusted their conducts to the official laws.

Additional notes on legal extension and penetration: Like other social systems, a legal system has boundaries, and its components are interrelated by an internal logic. Legal extension and legal penetration help define the boundaries of the legal system.

In every society, much is left to custom and tradition, to religion, to informal negotiation and settlement, to social convention and peer influence. But the precise location of the boundaries between such non-legal matters and those of legal concern is unlikely to be always and precisely the same. The range of variation becomes particularly significant if we identify law with the official legal system, manned and operated by the state.

The degree to which a legal system seeks to penetrate and control social life is often quite different from the extent to which it actually does so. For example, a large number of Ethiopians live much of their lives relatively free of any substantial contact with the official legal system, which actually applies with most force to an urban middle class and rapidly loses its power as one moves down the socio-economic scale and away from the major cities. In a substantial number of such nations as Ethiopia, Kenya and Indonesia, the paper legal system will look much like that of France or Spain or Italy, or England or the United States of America. But if one looks at the actual role of law in the lives of important elements of the population the resemblance is only superficial. Thus along two dimensions, the aspects of social life that proposes to affect and the extent to which it actually does so, the scale of divergence of legal 
extension and legal penetration between societies can be, and often is, substantial. Both the social reach and the social grasp of the law are important variables. Legal penetration can take to mean the degree to which a rule, code, or law takes hold in a population. Key to closing the gap and improving penetration is better communication of law to the populace.

An empirical research carried out jointly by North Western-Haile Sellassie I University on the impact of the various laws on the Ethiopian society revealed that in the area of commercial law there exist some major conflicts in the mercato between law and practice. However, according to the researchers these conflicts appear due to lack of education or knowledge on the part of the merchants with respect to accounting practice and registration requirements and reluctance on the part of authorities to strictly enforce many harsh legal provisions. Little if any, evidence of resistance to these laws on the basis that they are "foreign" to customary way of doing things was detected.

While in the area of family law, it was found that despite the fact that the new law's attempt to break the customary practice of adoption by imposing a requirement of court approval, people are still continuing to adopt according to customary procedures without seeking court approval. Although no empirical research was made and we cannot positively say that the law is not being followed, it is very doubtful whether the Civil Code's requirement that a man be eighteen and a girl be fifteen years old in order to marry is being followed. In addition, one can cite the provisions dealing with names that up to now have been more or less a dead letter.

However, even though law as an instrument of achieving the desired results may be slow or weak in matters that affect basic drives and values, the mere fact of affirmation through acts of law and government as it expresses the public worth of one set of norms, of one sub-culture vis-à-vis those of others demonstrates which cultures have legitimacy and public domination and which do not is significant in itself. Thus the law aside from its effectiveness as an instrument can still have this symbolic effect, as an act, decision or gesture important in itself. 
In developing societies such as Ethiopia, one can note a gap between a professed ideal and reality. For example, if one examines the Ethiopian Civil Code which is basically designed for the future Ethiopian society and tries to introduce new norms, one can note that some of its provisions are already out of tune with the times. One of the few mandates in the code regarding marital dispute resolution is that the parties should submit the disputes to arbitrators selected by them, Although this system of having relatives, neighbors and friends attempt to resolve a couple's dispute makes sense in the abstract, litigants with divorce petitions are coming to courts initially in increasing numbers in the cities. Under the Civil Code, family arbitration was a codified customary practice with its origins in rural Ethiopia before the rise of cities. In rural Ethiopia, family friends and community elders are quick to agree and often to volunteer to arbitrate marital disputes. But the city filled with migrants, where independence is fostered, it is relatively difficult to get acquaintances to devote the long hours, seldom compensated, that are required by family arbitrators. For this reason, then many couples approach a court to obtain an "order" that arbitrators, whom the parties select shall act in a dispute. It apparently puts the fear of authority into some otherwise reluctant candidates. The fact that the institution of family arbitration did not reduce the court congestion and the fact that divorces in present Ethiopia demand a degree of expertise not commonly possessed by most family arbitrators are some of the reasons that were given by Aklilu Wolde Amanual to justify his recommendation to abolish the institution. Constant legislative, judicial and administrative innovation are thus necessary to keep the law abreast of life and this process of innovation requires sociological investigation, for a mere guess of politicians combined with the skill of legal draftsman is not an adequate basis of law reform, nor is a more armchair analytical legal study of existing alternative rules.

Reasons for the Gap: What is the explanation for this gap? What are the possible reasons for the divergence between official legal prescriptions and the reality? We can simply speculate the answers as we do not have sufficient empirical data. The first possible reason is that the imported laws have not yet been sufficiently communicated to the people or to the governed because the laws are published in English and Amharic which millions of people in this country do not understand. Further, the laws have not been adequately communicated to the addressees since there is a huge percentage of illiterate population. The imported laws assume a literate society. 
Secondly, the state lacks the necessary resources to implement some of the provisions of the imported laws. The third reason is that the laws were defectively transplanted, which means the country's context was not properly studied and the customary and religious laws were not given the place they deserved. As a result, the imported laws lacked the necessary legitimacy from the people. A related factor is that the preexisting laws in Ethiopia are so deeply rooted in the fabric of the society that they could not easily and quickly be replaced. People are deeply attached to the customary laws. People have inherited dispute settlement mechanisms that were used by their ancestors. Simply stated the force of tradition is the reason behind the tacit resistance put up against imported laws. Finally, it is argued that the transplanted laws could not succeed since the assumption of the customary laws is different from the assumption of the western laws. The customary laws focus on the group; paramount importance is attached to the survival of the collectivity. On the other hand, it is opined that western laws are designed for and around the interests of an individual.

\section{Summary}

Customary law has several meanings. Most frequently, customary law is defined in terms of length of time, of majority members of a given community, of habit, of intention to be bound, etc. Customary law has generated several theoretical controversies; you have studied five of the theoretical debates about it definition. The orthodox view of customary law is that it is a practice habitually followed by the majority of the members of a given community for a relatively longer period of time with the intention to be bound by it. A legal system is defined as a synergy of legal rules, legal principles, legal standards, legal policies, legal structures, legal culture, legal actors, legal extension and legal penetration operating in a given geographical area. Legal culture refers to a set of deeply rooted and historically conditioned attitude of the majority of the members of a given legal system towards the other elements of that legal system, which means the way laws are made, modified, interpreted, the way the legal actors and structures function. Legal transplantation refers to the transfer of legal rules, legal principles and legal concepts from one or more than one legal system to another legal system. Legal transplantation can take place voluntarily and involuntarily. Some times a recipient country may freely choose to borrow or not to borrow laws from other systems. In many cases, however, a recipient system does not 
have a choice at all. Legal borrowing has been very common in the history of legal systems. The middle ground is stricken in relation to legal transplantation. Such middle ground holds that in some cases legal borrowing is desirable while in other situations it should be resisted. It is needless to restate the importance of examining the background to legal transplantation, legal extension and legal penetration as well the reasons for the existence of a gap between the two in multi-cultural societies such as Ethiopia.

\section{Review Questions}

\section{Part I}

Choose the best answer from the given choices.

1. In respect to reasons for legal transplantation, which one of the following is different from the others?
A) War
B) Migration
C) Commercial interaction
D) The desire of the recipient legal system to modernize itself
E) Merit of the laws

2. Which one of the following legal systems do you expect to show the widest gap between legal penetration and legal extension?
A) The Ethiopian legal system
B) The American legal system
C) The German legal system
D) The British legal system
E) None of the above

3. The aspiration of the personalities responsible for importing large-scale laws to put the same in practice to the fullest possible degree is known as:
A) Legal system
B) Legal extension
C) Legal penetration
D) Legal tradition

4. A theory of legal transplantation that states that there is an inherent connection between law and society is: 

A. The historical school
B. The social engineering school
C. The Middle approach
D. All of the above

5. A theory of legal transplantation that states that there is no inherent connection between law and society is:
A. The historical school
B. The social engineering school
C. The Middle approach
D. All of the above

6. A legal system that accepted customary rules as one of its elements in its life span is:
A. The African legal system
B. The French legal system
C. The German legal system
D. The Hindu legal system
E. The Ethiopian legal system
F. All of the above

7. The reason why some writers argue for legal transplantation is:
A. Based on the prevalence of legal borrowing in legal history.
B. Based on the idea that recorded legal history does not indicate a country that was legally self-sufficient.
C. Based on the idea that external circumstances might compel a country to transplant laws.
D. Based on the idea that there is no inherent relationship between law and society.
E. All of the above
F. $A \& B$. 
8. Identify the correct comparison between the modernization theory and the diversity theory.

A. The modernization theory plans to bring about legal uniformity in a country while the diversity theory tends to tolerate the existence of two or more authoritative sources of laws.

B. The modernization theory advocates for unofficial legal pluralism while the diversity theory advocates for legal centralization.

C. The modernization theory supports a unitary form of state while the diversity theory seeks to have a federal form of state.

D. $\mathrm{A}, \mathrm{B} \& \mathrm{C}$

E. A \& C

F. None of the above

9. One of the following shows a mismatch in connection with a test of validity of laws:
A. The Mesopotamian legal tradition-God
B. The Greek legal tradition-Natural Law
C. The Classic Roman legal tradition-Ethical Principles
D. The Greek legal tradition-Direct popular representation \& Natural Law
E. The Hindu legal tradition-the Holy Veda
F. None of the above

10. Identify the wrong statement about theories on the role of law in bringing about social and economic development in developing countries.

A. The custom theory states that developing countries should follow customary laws if they seek to achieve social and economic development.

B. The social engineering theory states that developing countries should transplant laws and eliminate customary laws if they seek to achieve social and economic development.

C. The custom theory assumes that law is linked to the culture of communities.

D. The social engineering theory assumes that law is an intangible instrument used to bring about social and economic development. 
E. The mixed theory attempts to evaluate the custom theory and the social engineering theory, and takes their positive aspects. None of the above.

\section{Part II}

Give answers to the following

i. State the possible reasons for the existence of divergence between legal penetration and legal extension in the Ethiopian legal system.

ii. State the criticisms directed against the custom theory of legal transplantation.

iii. The reception of foreign law, i.e., legal transplantation, and the question whether and under what circumstances it can succeed has generated a controversy between Khan Freund and A. Watson. Explain!

iv. 'The reception of foreign legal institutions is not a matter of nationality, but of usefulness and need. No one bothers to fetch a thing from afar when he has as good or better at home, but only a fool would refuse quinine just because it did not grow in his back garden.' Comment!

v. Explain the supposed relationship between the social engineering theory and the custom theory on the one hand and the social and economic development of developing countries.

vi. Do you think that the following factors account for legal transplantation?

The general respect in which the received law is held (e.g. Roman law);

The accessibility of the received law (means in writing and a form that makes it relatively easy to find and understand including language);

its high technical conceptual quality (e.g. Roman law); and the desire to modernize the legal system of the recipient country (e.g. Ethiopia in the 1950`s and $1960 ` s)$;

The belief that transported laws would contribute to the development of the recipient country (e.g. Ethiopia in the 1950`s and 1960`s);

The belief that modern codes would help to achieve political centralization (e.g. Ethiopia); 
Perceived colonial conquest and the need to preempt such conquest (e.g. Thailand);

Perceived deterioration of its relationship with the western powers (e.g. Japan) and

The desire to regain sovereignty.

7. Examine the analytic, the historical and the Marxist approaches to the nature and role of customary law. 


\section{UNIT TWO: Customary Laws in Africa}

\subsection{Introduction}

The previous unit has covered the basic features of customary law and the different aspects of legal transplantation. This unit will focus on the nature, purposes, functions and the development of customary laws in Africa. Discuss in all African customary laws is not the intention of this course material since doing so is neither necessary nor possible. What we have tried to do is simply to bring to the attention of students some facts and opinions therefore the students will use them as microscopes to identify the viruses and the antivirus in African customary laws. The unit is divided into three sections and several sub-sections. The first section discusses the feature of African customary laws. This section and we see the scope, nature and limitations of African customary laws. The second section relates to the study of African Customary Laws and legal institutions in Colonial and Postcolonial Period. In this section, we will discuss the place of customary laws during colonialism and the different tests and techniques the colonizers used to classify and explain African customary laws. In the third section of this unit, we will see the different opinions regarding the relation of culture and human rights. This section is mainly devoted to explain how we can transform cultures gradually to quench the need for minimum standards of human rights, which all Africans consider as their own culture. To achieve the objectives of this unit you need to relate the points discussed in this unit with cultures and customary laws you are acquainted with. In addition, to relate each and every point discussed in this unit with concepts discussed other subjects such as constitutional, jurisprudence and legal history will be an addition in achieving the objectives of this material.

In this unit, you should be able to:

- Identify the main common features of African customary laws

- Appreciate the place of customary laws and traditional legal institutions before, during and after colonialism.

- Discuss the reaction of African leaders to customary laws after independence

- Discuss the place given to women under African customary laws. 
- Explain the relation of cultural transformation and human rights

\title{
2.2 Common Features of African Customary Laws
}

Introduction

\begin{abstract}
African customary laws share many common features. The fact that many of African countries were under the influence of colonizers contributes for this phenomenon. However, some criteria are inherent to African social structure and lack of written culture. African customary laws are dominantly unrecorded. This fact challenges any scholarly effort to come with precise feature and nature of African laws. In addition, this unwritten feature of African customary laws also causes it very difficult to identify ideas introduced by European intruders. Emphasized on maintaining the harmony of the society than penalizing the offender is other important feature of African customary laws. African customary laws are known for being too normative for the modern world and less responsive for changes. The idea of this section is not to claim that there is a single body of law applicable to all Africans. The idea of this section is rather to present the main common features of the traditional legal systems in Africa. In this section, the developers tried to discuss some of the points, which many writers regard as common for many of African customary laws.
\end{abstract}

In this section, you should be able to:

- Examine the scope of the African customary law.

- Discuss the static or dynamic nature of customary law.

- Identify the lawmaker in the traditional Africa.

- Recognize the unit of analysis of African customary law.

- Discuss the goal of the African customary law.

- Examine the various tests to which customary laws in Africa are subjected. 
1 African Customary laws perceived to be primitive.

For centuries, the commonly held view has been that African customary Law represents primitive, traditional, ancient and immutable regimes non-suited for modern administration of justice. African Customary Law is the totality of norms comprised of what has variously been described as "native law," "native customary law," "primitive law," "folk law," "informal law," "non state law," "indigenous law" and even "tribal law." The nomenclature conceptualizes the perception of customary law as being inferior to other laws within a legal system. It also affirms the distinctiveness with which African Customary Law has been regarded. This form of isolation of African Customary Law has obscured its dynamism.

This historical misconception perceived traditional legal systems as 'extant and functioning in the ethnographic present. This tendency of considering African customary laws as primitive and backward ingrained in the perception of colonizers towards African customary law. The colonizers wanted to eschew its applicability because their notion of justice and fairness contradict with African notion, which give high value for communal interests. African customary law ensures that every society exists as a coherent social whole. The colonizers also want to transcended African customary laws because some of the legal principals challenge the supremacy of colonizers. .

The perception that African costmary laws are devoid of reason and logic hence they cannot solve conflicts systematically is also a common critique that almost all of African customary laws faced. African customary laws also like many chthonic laws featured by their irrational procedures and harsh punishment.

However, customary laws are sources of almost all modern legal principles. It is custom that prescribes the compensation due, for killing a man, the formalities for making a contract, the rules of inheritance, the obligations of kinship, the limitation on which one may marry and so forth. Custom (including customary law) resembles language in being a complicated, slowly changing, and decentralized system of highly exact rules.

Further, the term African Customary Law implies that the only source of African law is custom. Evidently, this is not correct. The traditional African legal systems comprised, not only of rules derived from customs, but also legislation and precedents 
of important previous cases. For example, in the Buganda Kingdom of present day Uganda, the Kabaka were known to enact law. Amongst the Meru of Kenya, a council of elders, (the Njuri Njeke) operated as a legislative body. In addition, the Maragoli and Bukusu of the Luhya sub-tribe were also known to have similar arrangements.. In fact, a wider power to enact laws seems to have been wielded by the dream prophet and by certain clan elders who gained a reputation as warriors and successful arbiters in disputes.' Amongst the Luo of western Kenya, an elders' legislative council (the Doho) was known to enact new rules for changed circumstances. One scholar, while discounting the theory that African legislative machinery never existed, remarked: In Embu, for instance, there was a very definite method of legislating though it was not readily discernible because it functioned, as a rule, only at rare intervals, viz., at the handing over from generation to generation, though it was capable of use at other times in the event of emergency or important change of Policy

2 the second common feature of African customary laws is the fact that African customary laws commonly cursed for being gender insensitive. African law sees the woman generally as inferior to man. Gordon observes that in the traditional African context, customary law accentuated male domination in patriarchal family arrangements. Thus, customary law was used to 'control and limit women's rights as persons and to limit their access to income on property. Nyamu argues that African Customary Law was predominantly shaped by the attitudes and interests of male elders and thus reflected the power relations within society. Consequently, because 'men have had the upper hand since the colonial period when the application of customary law in courts made it necessary for customary norms to be formally articulated,' the nature and content of customary norms favor their supremacy in societal affairs. Students we will discuss this issue in detail in the subsequent section of this material.

3 Other common feature of African customary laws is the fact that the customary laws commonly interconnected with religious guidelines. African law, some argued, was inchoate, just as it was difficult to understand, because it was enmeshed in customs and traditional practices. As Read observes, 'clearly, the realm of law was not articulated, defined, or formalized: It was an element of social life inextricably entwined in the religion, political, social, and moral structures of traditional societies. No effort was made to discern African legal principles from the whole morass of 
custom and traditional beliefs, because the process would have been incompatible with the colonial agenda. Instead, the colonial period merely witnessed the deliberate movement away from traditional forms and methods of judicial administration. Today, with the unification of the judicial system, the connotation has served to diminish the relevance of customary law in the face of other systems or laws.

4 The African legal system, the traditional one, is presented as being static. Nevertheless, some claim that African legal system is not static; there argument is that internally any costume is in constant change with out interruption. Culture resists only changes to be introduced by external forces.

African customary laws are also known for being too normative. The accepted principle in the scope of law is that legal regulations shall be limited only in regulating relations considered necessary for the normal functioning of the government and which are necessary to maintain social order. Purely private matters should be kept out of the scope of government regulations. The idea is that the government or any body should not be allowed to encroach in the private live of the individual. The customary laws of Africa generally criticized for stretching hands in to private matters. To some extent this may be the result of the fact that African customary laws are very closely intermingle with religious doctrines. As you may recall from the course legal history, religious laws such as Talmudic and Islamic law are known for their ambition to regulate even how a man should breath. African customary laws deal both with behavior and with the settlement of disputes. They cover everything, which must be "making no distinction between religion, morals and law.

Custom' must thus be distinguished from 'law.' The former refers to practice; what people do. The latter is the norm; what people ought to do. Custom is the 'raw material out of which customary norm is manufactured.' According to Hoebel, both custom and law have regularity. They define relationships and promote sanctions. However, the sanction of law 'may involve physical coercion' and is distinguishable from custom since 'it endows certain selected individuals with the privilege-right of applying the sanction of physical coercion, if need be.' Moreover, law has been described as the coercive instrument for regulating human behavior. Though 'value neutral' in application, it influences the character of society. In fact, it is the 
compulsion element in the legal norm that makes it a superior mechanism for achieving broad social goals. Such goals may include reordering and stabilization of society, the planning and direction of change, and the consolidation of political power. Every society enjoys a measure of social equilibrium imparted by the instrumentality of law. Law, thus, ensures that every society exists as a coherent social whole.

6 Emphasis on conciliation and mediation is also other important feature of African customary laws.

Conciliation plays a very important part in African law since community life and group isolation give rise to a need for solidarity. As a result, the Africans always seek unanimity through dialogue, since only reconciliation can put an end to disputes. Customary law is secreted by society itself. Every individual is immerged in it. Individuals in a traditional society cannot envisage living without observing it. Society as a whole accepts it and considers it a necessity. Custom is the work of Mr. 'Everyman`, both private individuals and those who govern. Custom is the natural source in the full sense of the word, composed of precedents, imitations, and hereditary behavioral patterns. It can be taken as a path, which appears on the ground when the passers by follow in the footsteps of those who have gone before. The path changes a little under the feet of each passer by; it is not in the nature of custom to be fixed.

7 the most evident feature of customary laws has been its oral nature. The teaching of the past is preserved through the informal, though sometimes highly disciplined, means of human speech and human memory. This may appear highly unreliable and vulnerable to external influence, until we remember that the tradition appears to have preserved that which it says to preserve for hundreds of thousands of years.

Most of African customary laws were not reduced in to written form. The customary laws simply transfer from generation to generation orally. Of course, this has a lot to do with the general lack of written culture in Africa. The facts that African customary laws are unwritten cause many problems in identifying and studying African customary laws. This also imposes a doubt on the original nature of African 
customary laws because if the law is unwritten it is very difficult to identify the interlopes added by latter leaders and colonizers. The unwritten law also contributed for the existing lack of consistency and uniformity among African laws.

\section{Summary}

The African systems of law are sufficiently similar in procedure, principles, institutions and techniques for it to be possible to treat them as a whole. The difficulty of subsisting and dangers from the outside world making life precarious, the inhabitants were obliged to seek refuge in communal life and solidarity, and to place themselves under the protection of supernatural forces. Such forces included God and ancestors people, laying down its laws and guarding man to survival. Thus the most important African legislative is invisible: composed of gods and ancestors. Their decrees, however, are not only legal but moral also. Their action extends to the individual conscience since they are also the counselors and judges of each individual.

The African mentality is mystic. And the fear inspired by the environment causes the African to stand still in contemplation of the past and respect for that which is. African law seeks to preserve the group and peace. Persons subject to African law are the gods, the dead and the individual. African law is designed for a structured society. African law sees the woman generally as inferior to man. Conciliation plays a very important part in African law since community life and group isolation give rise to a need for solidarity. As a result, the Africans always seek unanimity through dialogue, since only reconciliation can put an end to disputes.

Customary law is secreted by society itself. Every individual is immerged in it. Individuals in a traditional society cannot envisage living without observing it. Society as a whole accepts it and considers it a necessity. Custom is the work of Mr. 'Everyman', both private individuals and those who govern. Custom is the natural source in the full sense of the word, composed of precedents, imitations, and hereditary behavioral patterns. It can be taken as a path, which appears on the ground when the passers by follow in the footsteps of those who have gone before. The path changes a little under the feet of each passer by; it is not in the nature of custom to be fixed. 
Certain selected individuals with the privilege-right of applying the sanction of physical coercion, if need be." Moreover, law has been described as the coercive instrument for regulating human behavior. In fact, it is the compulsion element in the legal norm that makes it a superior mechanism for achieving broad social goals. Such goals may include reordering and stabilization of society, the planning and direction of change, and the consolidation of political power. Every society enjoys a measure of social equilibrium imparted by the instrumentality of law. Law, thus, ensures that every society exists as a coherent social whole, which is not a unique attribute of African traditional societies. Specifically, their legal control and response to violation of norms was backed by use or threat of force. Force varied from one group to another and was applied directly against a person, or generally against his property, to bring about the settlement of a dispute, while punishment for the guilty involved fines.

Modern African law is a collection of laws and habits of legal thought. African indigenous law is not static. African law is subject to evolution. It is generally unwritten. It has different branches including substantive and procedural laws. African law does not simply focus on reconciliation. There is a procedure to be followed and there are substantive laws to be applied. After independence, African law is restated. Restatement does not mean it is thereby made inflexible and frozen. Restatement of African law is done for the purpose of unification and convenience of administration.

One of the sources of indigenous African law is custom. Custom is the body of standardized patterns of behavior that have been established by the usages and observances of people and having the force of law. Indigenous legislation (declaration of legal rules by a competent authority) and precedents are also sources of African law. 


\section{Exercise}

1 do you think that African customary laws share some common features? Explain your answer with some historical and factual reasons.

2 why do you think African customary laws are less fair for women?

3 some argue that African customary laws are responsive for internal social changes. Do you agree with this assertion? Explain your answer by discussing any culture you are familiar with it.

3 read the following note and suggest a pattern African countries may follow to ease some problems with in the customary laws.

The era of customary laws in France: Before the French Revolution, traditional customary laws prevailed in the north. The rules were Germanic customs while Roman law influenced the southern part of France. Roman law gradually spread northwards. The French legal system was not sharply divided because there were written rules influenced by Roman law but containing strong Germanic elements in the south. And Roman law was not entirely rejected in the North.

France received Roman law not because it had been laid down by Rome, but on the ground that it had been accepted by custom or by reason of its quality. The existence of diverse customary rules and edicts created some degree of legal uncertainty in France. France's need for a single, unified code of laws had been keenly felt even before the collapse of the ancien regime. Whereas, southern France had inherited Roman law, northern France was ruled by a system based on customary law. The two systems were fundamentally different. The laws differed not only from province to province but also from town to town. Nor were the laws always rational. Louis XIV, the Sun King, had summed up his approach to lawmaking with his famous phrase "It is legal because I wish it."

Before the introduction of the Civil Code, a patchwork of customary laws based on tradition and the whim of the monarch had ruled throughout the continent. The new Code introduced the concept of a unified, logical system based on general principles 
of law. This facilitated the export of the ideas of the French Revolution beyond French borders.

In their move to eliminate legal uncertainty, some practitioners attempted to record customary laws of particular regions in France. It remained true, however, that the customary laws of Northern France depended principally on oral tradition. The judge who did not know the appropriate rule of the relevant area had to discover it by interviewing local inhabitants. The proliferation of custom and the difficulty of discovering their content led to great legal uncertainty. As a result, a French king in $15^{\text {th }}$ century declared that the customs of the various territories should be written down. The king also ordered that those, which were already recorded, should be drafted anew.

The intervention of the kings in having the customs recorded invited opposition from some territories. The intervention and the effort to write down the various customs in France strengthened the power of the traditional customary laws to withstand Roman Laws. The recording of customary rules saved France from the massive reception of Roman law, which took place in Germany. The codification of customary laws created conflict of different customary rules. Recording of customary law in France had brought about legal certainty. Yet, it could not diminish the substantial differences between them. The recoding efforts of French customary laws made the difference among such rules sharp and conspicuous.

\subsection{The Status of African Customary Laws and legal institutions in Colonial and Postcolonial Period}

Introduction

In this section of the material, we will discuss the effect of colonialism on African customary laws and institutions. As you may guess, it is a tough task to discuss the overall influence of colonialism on African customary laws and institutions. Therefore, in this section, you read only the overview of this complex topic. We will also discuss the controversial status of African customary laws after the colonizers ousted out of Africa, at least physically. 
At the end of this section, you should able :

- Explain the attitudes of the colonial powers towards traditional legal institutions in Africa.

- Explain the influence of colonizers on African customary laws

Discuss the fate of traditional legal institutions after independence in Africa.

Discuss the role of traditional legal institutions in Africa.

Migration of people and contact between different cultures did not begin with the appearance of travelers from the west but goes far back beyond recorded history. Long distance trade networks existed in many parts of the world over a long period of time. Resources not found one place were traded to areas far from their place of origin; surly, the traders did come and go back, not only with goods but also with different values and morals. However, what happened during colonization was not a natural process; it was a historical mistake that devastated the economical, moral and sociological values of Africans. The colonizers cursed any value or culture, which contradict with their values and conscience, no matter how it suits and serves the interest of indigenous peoples. One writer, learning from this historical mistake, advised the world leaders to be 'rational about being rational'. During the colonial period, administrators in colonies all over the world instituted many changes. They saw these changes as bringing 'progress ', to peoples, helping to make them modern - that is, civilized and westernized. The puzzle here is that many of these changes were not desired by the peoples them selves, but their opinions were not sought.

When colonial administration was set up in tribal areas, concerted efforts were made to abolish those practices that violated the colonizers' moral code, which was a product of their own western European cultures. Missionaries were the most zealous enforcers of these kinds of changes. Any cultural practice that emphasized the political autonomy of a tribal people was also considered threatening by the colonial power and was forbidden. Cultural practices that seemed immoral or offensive to the Europeans were also outlawed by the colonial authorities who continued those customs were fined or jailed. The Europeans develop different tests to justify their 
actions. These are the barbaric test, the repugnant test and the modern one the human right theory. In this section, we will discuss the first two theories saving the third theory for the upcoming section.

The Barbaric Test: Britain was the architect of this test. This test best reflect the perception of Occident to the rest of the world. The colonizers consider the rest of the world as thrush and with out natural ability to develop acceptable legal and moral principles. Therefore, this test proposes for the complete demise of cultures and traditions of colonized peoples. The test was taken ethno-centric; it was uncompromising as it opted for the wholesome abolition of the customary laws. The colonial powers developed the barbaric test to re-determine resources especially rights over land and assumption political power.

The position of the barbaric test is best expressed in the following quotations. One of the members of the British Parliament stated in 1908 that: "We hold our position over the colonial waters by being the dominant races and if we admit equality with the inferior races we shall lose the power which gives up predominance." Another expression of this test, which was made in 1919, is: `Some tribes are low in the scale of social organization that their usages and conceptions of rights and duties are not to be reconciled with the institution or legal idea of civilized society. "

The Repugnancy Test: The repugnancy test provides that customary laws are laws used by the people if not repugnant to justice or morality or inconsistent with legislation. During the colonial period, England introduced the concept of the repugnancy test. This test means those customary rules and practices prevalent in the colonies would be abolished if they offend natural justice, when they are found to be repugnant to fairness

This test was a progressive one as compared to the barbaric test since it allowed some customary laws to operate. This test was an excuse for the colonial powers to destroy traditional institutions they did not like. Some question if the colonial courts had the moral authority and the competence to invalidate customary laws that had been used by the local communities for generations. It is implicit and obvious that where two systems of law exist, each of them may be based on different principles or concepts of 
morality or justice. Therefore, whose value are to be used in determining the validity of the customary laws is the main source of tension however the Europeans simply decided in their favor. Even in the level ground it is very difficult to apply this test because such terms as fairness, natural justice and public morality are not open to a clear-cut definition; thus the application of these terms had given unbridled discretion to the colonial administrators and colonial courts to nullify customary laws they did not endorse. Further, the repugnancy test allowed the notion of natural justice of the colonial courts to prevail over the notion of justice of the concerned communities. The test is also criticized for tampering with the authenticity of the customary laws.

After independence several countries in Africa determined the place of their respective customary law according to the repugnant test. For example, the Ugandan Constitution prohibits "any laws, cultures, customs or traditions" which undermine the status of women. In Tanzania, equality, rights, as provided for in the constitution and included in the international instruments, have been held supreme over customary law. In both Uganda and Kenya, customary practices will have application in so far as they are not consistent with some values recognized the respective constitutions. As you will see in the last unit of this course, the FDRE Constitution adopted a similar stand

African laws have not escaped outside influence. African society has been transformed by contact with the monotheist religions such as Christianity and Islam, and under the influence of colonization, but without the successive contributions of civilization really becoming unified. The colonizing nations each organized the territories fallen to their share according to their own law. It is not without cause that African Customary Law has been underestimated. Primarily, the prevalence of customary norms and practices is questioned by the very existence of the "modern" state structure in Africa. Commentators on the subject have observed that African Customary Laws tend to be insensitive to gender equity and several other individual freedoms and rights guaranteed by modern constitutional and international human rights instruments. Despite this, legal systems of most African countries allow courts to apply African Customary Law, though with some restrictions. This process is indeed an attempt to fit the customary law principles into definitive legal criteria capable of supporting a "modern" judicial process. The adjudication of customary law 
issues is undertaken within an integrated legal system largely informed by the laws inherited from the colonizers.

During European colonization, in relation to the judicial structure as a whole the position of the local court varied from country to country. But two basic patterns can be recognized. One is an integrated system where the local courts were linked with higher judicial bodies, particularly the high or supreme courts by way of appellate jurisdiction. And the second pattern is a parallel system, which involved the separation of the local courts from the judicial system administering primary nonindigenous law. Indigenous law was invalidated where it was found out to be contrary to natural justice, equity and good conscience.

The best way forward for British administration was by way of conserving, recognizing officially and using the existing indigenous systems of rules and law of native authorities. The native courts and the native customary law were recognized as an essential part of the apparatus of indirect administration. Nevertheless, later the concept of integration was introduced. The concept of integration involved in the integration of special customary courts in the regular territorial court system without totally abolishing special courts for African customary laws. The African laws were to be steadily brought into in line with English ideas of law, justice and procedure.

The recognition of African Customary Law was paramount to the colonial enterprise. With limited resources and incongruent policy objectives, it was highly unlikely that the governance of the colony could be achieved without the help of the indigenous communities. Moreover, implementation of the principles of indirect rule necessitated the maintenance of traditional rules and regulation so as to eliminate active dissent to the British occupation. One scholar argued that African Customary Law provided a means of control because the nature of its application was imprecise, yet adaptable. No matter the motive of the colonial administrators, African Customary Law enjoyed the support of the indigenous communities. As Lord Atkin remarked, 'it is the assent of the native community that gives custom its validity, and, therefore, barbarous or mild, it must be shown to be recognized by the native community whose conduct it is supposed to regulate.' The conception of customary law, as a tool for colonial administration, engendered the modification of its principles to suit the aims of 
imperialism. The transformation in the African way of life, occasioned by the introduction of religion, changed economic relations, and the exercise of stringent powers of the state, influenced the evolution of customary law. At independence in some countries such as Kenya, the duality of courts was abolished, but the status of customary law never improved. The thirst for economic prosperity and the wholesale adoption of colonial laws diminished the relevance of African Customary Law. Instead, the latter remained applicable only within the narrow margins set by the colonial legal system. In fact, the belief amongst the ruling elitist that indigenous institutions may "help to keep the masses backward,' hampered any positive political and legislative changes in Africa have badly blemished the image of African Customary Laws.

Modibo Ocran wrote an article, which explains the colonizers approach to customary laws. The developers believe that this article will provide you better understanding of the scenario. Therefore, we reproduced this article as it is.

The historic Berlin conference on Africa in 1885 is often credited with the official beginning of colonialism in Africa However, this conference, held among the principal colonial European powers (Germany, France, Britain, Belgium, and Portugal), essentially marked the agreement among those powers to define territorial areas of influence in Africa. Long before this conference, individual European powers had reached their own accommodation with indigenous peoples of Africa in various corners of the continent.

Thus, in the southern part of Ghana, then called the Gold coast, the Bond of 1844 was signed by the British and the local chiefs in the southern part of the country under which the locals accepted British sovereignty or dominion over them in exchange for protection from their warlike neighbors further to the north. Indeed, Europeans interacted with the peoples of Africa for centuries before 1844, in the gold coast, for example, as far back as 1475, the Portuguese had set foot at a coastal place they called Elmina ( Portuguese for 'the mine'). However, the Portuguese did not have much success with colonialism in west the territory became a British colony. 
The story of the legal relationship between European and Africa legal systems that intrigues comparative lawyers starts in the $19^{\text {th }}$ century. As part of the colonial administration, the British naturally wanted to enforce law and order and to generally regulate the lives and habits of the people that they conquered. This was not always easy for the British, both as a practical matter and as a matter of legal doctrine and ideology. They encountered a legal system quite different from their own legal traditions. They had to deal with a religion-based legal system simultaneously meant for secular applications that was unlike other forms of religious law, such as canon law, which largely applied to the spiritual realm of life. They also faced hostile reaction from strong indigenous culture which were not necessarily prepared to accept the assu8mptions of the western cultural mind. Ultimately. The culture accepted the creation of legal pluralistic system in which the English dominated, but indigenous law also was maintained up to a certain point.

In other parts of Africa, it was not simply the clash between European and indigenous Africa cultural norms, but between European and Muslim or Islamic law as well. A cultural influence of a different sort had already taken root. People had converted to Islam in some parts of Africa, and indeed in sections of the same community, while others in the same society had embraced Christianity. This was the beginning of the 'tripe heritage' of the Africa legal system: traditional Judeo-Christian, and Islamic legal culture.

At the start of the legal history that we are concerned with the characteristics of Africa were either pre-industrial or traditional. Society was characterized by a subsistence level of living using the sociological classificatory scheme of societies based on their level of socio-technical complexity. African economy at that point was heavily agrarian. Societies tended to be organized in small groupings, and " $[\mathrm{t}] \mathrm{he}$ most important basis for [a] relationship was kinship." Sociologists refer to them as "kindominated" societies. However, there were other factors that bound together individuals, such as their economics, politics and religion. Thus, these societies are also referred to as "multiplex" societies. Because of these socio-economic characteristics, there inevitably was a close identification of traditional society with customary law. Individuals' roles typically were allocated "on the basis of ascriptive 
criteria" or birthright-related characteristics, which consequently depended on one's “ sex, kinship [nobility of] birth age and birth order." The people were soaked in traditionalism and custom. Their mindset was: "[p]erform the ritual customs because your ancestors did so," and "stick with something that seems to work."

The starting point of custom is of course practice or long usage. In traditional African societies, custom became the principal;, if not the only, source of law. Kings or chiefs occasionally issues edicts, but custom was decidedly the main source of law. The chief himself was bound by custom and indeed was the repository of custom. Thus, in western discussions of sources of law, the focus on this epoch in Africa would not be on legislative or judicial formulations, but rather on custom; viewed as usage of a long duration. Usage led to custom, and part of custom eventually became customary law. Customary law comes partially from the customs of the people, that is that portion of customs that the people have accepted as community-governing principles, the violation of which would result in punishment. The rest of custom, that is non-legal custom, would not normally lead to punishment when violated, but could still effectively regulate norms of conduct. Custom itself emerged not simply from what was practiced, but also from the highly influential morals and religious beliefs of the people.

Traditional or customary law at that time was wholly unwritten for the simple reason that it was not a literate culture. Even today, much of customary law is unwritten, but there has been a growing corpus of treatises and court decisions setting down customary rules of law as the authors' judge them to be therefore, it is now much easier to state the rule of customary law on a particular issue.

Indigenous or customary law in pre-colonial Africa is simply defined as rules of custom, morality, and religion that the indigenous people of a given locality view as enforceable either by the central political system or authority, in the case of very serious forms of misconduct, or by various social units such as the family. In terms of western literature on the nature of law, jurists in these African societies were much closer to philosophies articulated by the Germany Karl von Savigny, and others in the historical school of jurisprudence. The core tenets of African customary law are its 
emphasis on collective responsibility, respect for the elderly, collective rights, and respect for long-established institutions.

However, this indigenous body of law began to face an assault from external influences in the form of Christian colonial power and Islamic religion. Would the new colonial powers reject African law outright as somehow inconsistent with the primary imperative to dominate the colonized people? If customary law was not to be accepted, could European law rule both European and non-European peoples in the enlarged colonial community? In any case, what should be the actual content of customary law in the new, multi-ethnic, Africa colonial states, where there are vastly different cultures and languages within one community? This was a problem, because if custom partially defines customary law and if custom itself is something that emanates from the people, then there would be as many customary law as there were different communities. In the gold coast, for example, there were at least ten major ethnic groups. In terms of custom and customary law, whose customary law should the British apply? Further, assuming the British knew what customary law consisted of, would they automatically apply it? Now that the British were the unchallenged colonial master, intent on keeping their own proud tradition and culture, executing their so-called dual mandate in Africa, protecting the possessions of the empire, and concurrently civilizing the people of Africa in the European ways, what were the British to do with the cultural norms of the conquered indigenous population?

By way of comparison, a similar problem also arose in Latin America at the start Spanish and Portuguese rule there. Woodrow Borah, writing on the accommodation of Spanish and Indian law in colonial Mexico, noted that during the mid- $16^{\text {th }}$ century, a series of discussions among Spanish policymakers had "attempted to settle [the nature of] the relationship between the ruling Spanish group and the subjugated communities." This discussion took centre stage particularly "from 1511 onwards when some members of the Spanish bureaucracy, disturbed by the destruction of the Indian population in the Antilles and on the mainland, [sought to establish] less murderous systems of exploiting the colonies."

Borah notes that in general there were three schools of thought on this matter. One [school] held that the Indians, having developed their own [organized] society, were 
entitled to [keep] their own institutions and laws. Should they come under the rule of a foreign sovereign [such as] the Spanish king, he was bound to uphold and defend native institutions and laws since he [in effect] served as the native prince. The most that might be conceded [in the name of change was the minimum necessary for extirpating idolatry and introducing Christianity.

The second school of thought focused on the idea of one society, which signified a determined assimilation of the Indians into constitutions. This view was held by most crown jurists involved in "developing a unitary legal system which would replace feudal diversity with a uniform royal administration [based in Spain]." The third school" urged the Indians and Spanish to be organized into to separate commonwealths, each with its own laws, customs and systems of government." an extreme exposition of this view held "that the Indian commonwealth be so completely separate that it would be linked with the Spanish only by being subject to the same [metropolitan ruler]." The difference between the first and the third schools appeared to be that in the first, the Spanish and Indians would be within the same political and legal community, whereas the third school envisaged a kind of federalism or separate states both working toward the potentate in Spain.

As Borah notes, the official response was ambivalent but did suggest a rejection to a large extent of the "tow republics idea" and the approximation of the first school of thought. This response was somewhat predictable. Indeed, this appeared to be one of the imperatives inherent in the imposition of alien sovereignty and religion, as the settlement of an alien upper class. It was unthinkable that the Spanish world permit the continued practice of idolatry and human sacrifice, and the continued existence of the heathen religious hierarchies. It was equally unthinkable that the Castilian crown officials would leave intact the old native political superstructures and their administrative hierarchies.

Moreover, on the level of human relations, there eventually developed a considerable intermingling between Spanish and Indians. As "Spaniards took up residence in Indian towns to establish businesses and care for properties, large numbers of Indians were drawn into Spanish households as permanent or semi-permanent workers. "in colonial Africa, the merger of the tow cultures occurred as the British accepted 
customary law to some extent, but also riddled it with so-called repugnancy clauses, in order to avoid those aspects of African customs that European culture found most appalling ridiculous, or simply unhelpful to the inculcation of Christian ideals.

The Ashanti crime of suicide refers to successful suicide and not attempted suicide, which is viewed as a crime in many non-African legal systems as well. It was a crime to commit suicide, with only a few exceptions where suicide was excused. For example, it "was considered as honorable and praiseworthy to kill oneself in war by taking poison or sitting on a keg of gunpowder to which a light was supplied, rather than to fall into the hands of the enemy; or to return home from war to a tell of defeat." it was also excusable "to fall into take one's own life in order to accompany a considered to be a serious crime for which the society provided serious consequences" there was always a legal presumption that the motive for self destruction had been evil."

But so what? In the "right to life" discourse, the bottom line is who has the right, if it exists at all. In this traditional society, the body of individuals were supposed to belong to the community, and the central authority was the only party which had the right to take a life. Therefore the central authority viewed with disfavor any attempt to interfere with " its prerogative as the sole dispenser of capital punishment." it was also said that "the tribal authority may have placed suicide among the capital offenses out of evil inclined disembodied spirits wandering about in its midst."

The spirit of the suicide became a ghost wandering about in search of an abode; for it was debarred from entering the land of spirits until the expiration of its destined time upon earth, which it had itself wrongfully curtailed. There was yet another criminal act among the Ashantis, this time of a sexual nature that seemed ridiculous to the European mind, but vividly demonstrated the thought-process of a mind steeped in animism. In the belief system of animism, the gods are supposed to lurk in the bushes, rivers, mountains, trees, and in the elements in general. It illustrates the impact of religious beliefs on law and on people's attitudes toward punishment. Rattray described this offense as "sexual intercourse in the leaves," and in the Twi language of the Ashantis was referred to as "ababantwe" or "ahahantwe." 
A better English translation is having sexual intercourse in the bush. It was not that the Ashanti culture was unromantic, but no form of romance could come close to the defilement or desecration of the Goddess Earth, which the Ashantis called "Asaase Yaa." Thus, an act which otherwise should not be a sin was regarded as such because of the impudence displayed in the face of the great supernatural powers in some parts of Africa, there was "the absolute claim of the husband to legal paternity" despite the natural parenthood of the child. Thus, in the famous Zimbabwe case of Vela v. Mandanika and Mangutsa (1936 S.R 171) plaintiff, M's husband under customary law, successfully sued Defendant, the wife's lover who had been living with her, for the custody of M's children, fathered by Defendant. The Igberra tribe in Nigeria had the rule "that any child born within ten calendar months of a divorce could become the property of the former husband," in spite of the well-known rule that a child's best interest is of primary importance. There was a practice of domestic slavery, along with other deprivation of personal freedom that had many of the attributes of slavery.

In the face of this clash of cultures and of legal thought, what were the British to do in Africa? As with the Spanish and the Portuguese in Latin America in the $16^{\text {th }}$ Century, the matter had to be resolved one way or another. At least in some parts of Africa, the indigenous communities had very ancient and proud cultures. Their animist religious beliefs were strong and they were not about to give up their way of life and their core beliefs, despite the overwhelming military and political presence of the British. Were they to be physically exterminated? Were they to be allowed to maintain themselves as a people? If so, what should happen to their body of laws and customs? The British eventually accepted customary law but put limitations on their content and application. The British had to retain their status as an imperial power as well as their public posture of introducing the indigenous people to the civilized ways of Britain.

The legal strategy was to introduce "repugnancy clauses" into the definition of customary law. These clauses defined the portions of African customs that were to be viewed and applied as law within the colonial legal system. Not all customs would be tolerated as having the force of law under the British dispensation. Further, the content of customary law was subject to a time limitation. Customs did not have to exist from time immemorial, but such customs should at least have come into 
existence by the establishment of the colonial legislature in that particular territory (e.g. 1876 in the case of the Gold Coast). Finally, any customary rule that was inconsistent with colonial legislation would be declared invalid.

The repugnancy clauses were meant to rule out laws and customs perceived to be against Christian values and morality or cruel and unusual by the standards of the colonizers. There were various formulations of these clauses. Some stated that the rules should not be "repugnant to natural justice, equity, and good conscience." Others read: "Not contrary to [religious] justice, morality, or order." Still others read: "Not repugnant to morality, humanity, or natural justice or injurious to the welfare of the natives." The repugnancy clauses were typically contained in a statutory definition of customary or native law.

Natural justice is supposed to encompass such propositions as follows: No man should be a judge in his own cause; no man is to be condemned unheard; a man is entitled to know the particulars of the charge or claim against him; decisions should be supported by reasons; and punishments and rewards should not be excessive, but should be proportionate to the circumstances of the offense. As used in this legislation, the term "equity" did not refer to technical equity or to the body of rules formerly administered in the English Court of Chancery, but to equity in the sense of fairness. "This would permit a judge to waive technicalities of either English or African law and to disregard contemporary rules of law which would produce manifestly unfair results."

'Morality' or 'good conscience' is the least precise component of the repugnancy clauses." It refers to morality in the general sense and thus leads to the inadmissibility of slavery, many forms of marriage without both parties' consent, and many other invasions of freedom. However, it was not morality in any particularly English sense because much of what the "English might have been tempted to call immoral was not always declared repugnant by the colonial system of justice." It is also quite clear that the standards of morality in different communities are by no means the same. In fact, one British judge in a 1938 Tanzanian case stated frankly: I have no doubt whatever that the only standard of justice and morality that a British court in Africa can apply is 
its own British standard. Otherwise, we should find ourselves in certain circumstances having to condone such things, for example, as the institution of slavery.

Soon after Africa attained political independence, from the late 1950s onward, the African intellectual elite decided to modify the colonial repugnancy clauses. They felt insulted by the notion that their own African laws were somehow repugnant. "Repugnant to what or to whom?," they asked. They wished to emphasize the fact that these laws represented their own ethos. Similarly, the term "native law" fell into disfavor because of its colonial connotation as uncivilized. Thus, a new type of legislation emerged in countries like Ghana, Sierra Leone, and Botswana. Incompatibility with legislative enactments or of decisions of the highest court of the land became the main criteria for distinguishing between unacceptable and permissible customary rules within the legal system.

Yet one could deduce from the language of post-colonial statutes and constitutions that customary law is still subordinate to other sources of law in the African legal systems. A hierarchy of norms had been created, and customary law was not on top of the list. The Judiciary in Africa still has some juridical problems in applying customary law as a source of law. First, at least a portion of customary law is still the law of particular ethnic or tribal groups or communities in Africa and not necessarily the general law. Second, certain aspects of those rules are outmoded and inconsistent with modern ideas of morality, even as viewed by Africans. Third, some customary norms may be inimical to development. Thus, rather than being ultranationalist in our attitude as jurists, the task is to modify customary law in aid of modernization. The judiciary and legislature need to adapt African indigenous law to make it a tool of socio-economic development without sacrificing the core values of African society: the values of condition for the free development of all.

The modern African judge will be the first to acknowledge that, in many senses, the problems faced by the British judges in colonial Africa have not vanished. Almost one hundred percent of the African judiciary is now African. But even though there is no longer the gross disparity of national origin between a judge and his community, a judge often does not come from the particular locality whose ethnic law he is administering. A part from this ethnic question, there is an enormous educational and 
cultural gap between a senior judge with a Western education and the ordinary families he may deal with. Thus, the judicial system may have moved from a problem of race and ethnicity to one of class.

The promise of legal pluralism is still dear to us, but the fundamental difficulties in its administration are real. Jerome Frank, one of the theorists of American Legal Realist School, in his 1949 book entitled Courts on Trial, discusses what he calls "the myth about the non-human-ness of judges." In a chapter entitled "Are Judges Human," Frank notes that "legal rules express social policies and a judge's conception of such policies respond more or less to his social, economic and political outlook, which usually derives from his education, his social affiliation and his social environment." In our own time, the Critical Legal Studies scholars have restated this point of view in more radical terms, much to the annoyance of other contemporary legal theorists. But the gravament of their complaint and their determination to blow away the myth of the universally objective judge is very real. It is real even with African Judges when they are called upon to apply or reject certain norms of African customary law.

\subsubsection{The Debate after Independence:}

It is difficult to tell exactly what happened to the African customary law after independence. The reason is that different countries handled customary practices differently. In some countries, the elites who assumed power after liberation thought that customary practices were against unity. They believe that customary practices divide the nation instead of brining it together. This perception is mainly because of the fact that in every country there are different customary laws, which at the first glimpse appear to contradict with each other. It is hard to tell precisely whether customary laws hinder unity. Some may argue that recognition of customary practices imply tolerance and compromise in that community and for that reason; different communities may like to live together. However as Glenn put it the major legal traditions of the world achieved this by developing a capacity of embracing many traditions including contradictory traditions. The main idea here is that between and among different cultures and traditions, there is always a common ground. Therefore, to maintain unity what should be done is not to demise customary laws, what we have 
to do is to try to find the common ground lured deep inside the traditions and to use it to strengthen our unity.

The customary laws criticized for lack of matured principles and jurisprudence to regulate the post colonization African peoples. The African leaders find it difficult to please the western investors and partners with out scrubbing the customary laws, which according to the westerns are against development and modern human life style. The customary laws also mercilessly cursed for not bringing development and better life for Africans. They thought that customary practices were against modernization; for them modernization of the state requires the introduction of western style laws and legal institutions. Therefore, they decided not to give to customary laws any formal place on these grounds. For these and other myriad reasons, Africa leaders failed to give a place to customary laws. It is to be admitted that African customary laws do not yet developed in to refined legal principles as Germany and other European countries did. Specially, in some legal areas such as costmary la w IP African customary laws are too nascent to be taken as they are. However, this is not to mean that customary laws could not be developed in to the needed status if we enriched them with some basic principles.

Some African nations, influenced by the so-called traditionalists were under the influence of nationalism. These countries took the other extreme of 'turning back every thing in to its origin.' They propagate that ever thing, which is indigenous and is part of the culture is good and every thing not developed there is bad. The first instinct of the new African authorities was to respect completely the old ancestral customs. This attitude involves a codification of custom. Pure and simple codification will tend to establish and promote the projected development. To some extent, this altitude is the result of the misdeeds of colonizers, which boil down African leaders to this 'hatred policy'. The proponents of this idea mention the following points among others to justify as why African countries should cling to customary laws.

- To promote internal legitimacy (the new leaders would get greater acceptance by the people with African customary laws than without.) 
- To give due respect to African identity (customary laws were taken as the reflections of the identities of Africans.)

- To restore the correct versions of traditional dispute resolution methods in Africa (for colonial rule distorted the authenticity of customary laws in Africa)

- To have effective legal institutions.

- To promote the desired social, economic and political developments.

One author criticizes these extreme positions, no one wants to fetch water from far area where there is the same or better in his compound however it is only a fool who refuse to take panacea for it do not grow in its garden. At the end, for the modernists, Africa should not go back to the traditional legal institutions in general and customary law systems in particular since going back to the roots would:

- Undermine national political unity.

- Undermine the efforts of the political elites to bring about legal uniformity.

- Be inimical to modernization.

- Promote the divide between the urban (to be governed by the western transplanted laws) and rural (to be regulated by the customary laws) population.

- De-link Africa from the rest of the world especially from the western world.

- Ignore the shortcomings of customary laws (i.e., the gaps in them and the difficulty of ascertaining them).

\subsubsection{Traditional institutions of Africa}

After independence, many African countries retained and maintained with the institution of traditional leadership. The only exception in this respect is Tanzania, which abolished the institution of traditional leadership altogether. Many modern states in post-independent Africa did not really know what to do with the institution of traditional leadership. Some aspects of traditional rule are not only incompatible with democratic rule but are violative of some of the basic rights and freedoms, which form the basis of modern society. Specific examples of these range from the constitutional principles of succession to the throne (where according to customary 
law only males are generally favored) to the difficult question of the role of these leaders in public administration at local and national governmental levels. In addition, the institution is often seen to be male and age biased and therefore in disregard of the equality principle.

Some Examples of the African Experience: The following is a brief summary of some select African states on an African perspective on the institution of traditional leadership after independence.

The Constitution of Ghana recognizes the institution of traditional leadership. It provides for the national and regional houses of traditional leadership. Traditional leaders have a role to play in issues of development although they are forbidden from active participation in party politics.

In Namibia, the Namibian Constitution provides that traditional leaders must pay allegiance to and accept the authority of the modern state. It also provides for Council of Traditional Leaders whose responsibility it is, to advise the president on the control and utilization of communal land and on all other such matters as may be referred to it by the president for advice.

The Constitution also provides that traditional institutions should give support to the policies of the (central) government, regional and local authority councils in the performance of their duties and functions. Where their powers conflict with the powers of either central government regional or local authority councils then the powers of the central government should prevail.

In Zimbabwe, soon after independence the government tried to dismantle the inherited legal dualism to create what was described as a single, politically united non-"tribal" nation. Traditional leaders were stripped of their judicial functions and made to remain explicitly as symbolic cultural figureheads. This was revered in 1993 and today the constitution provides for National and Provincial Houses of Chiefs. The National Council of Chiefs is also entitled to have 10 of its members form part of the 150 member National Assembly. Traditional leaders are also represented in Rural 
District Councils. Traditional leaders also qualify to stand elections on party political tickets.

In Botswana, the constitution provides for a House of Chiefs, which is an advisory body to the National Assembly and the Executive. The House does not have legislative powers but must be consulted on certain specific Bills.

In Uganda, the Constitution in 1966 abolished the kings and the kingdoms. Upon coming to power in 1986, Yoweri Museveni restored title to traditional leaders but denied them political power or role. Article 246 of the Constitution of Uganda states that:

The institution of traditional leaders or cultural leader may exist in any area of Uganda in accordance with culture, customs and traditions or wishes and aspirations of the people to whom it applies" "the allegiance and privileges according to a traditional leader or cultural leader by virtue of that office shall not be regarded as a discriminatory practice prohibited under Article 21 of this Constitution, but any custom, practice, usage or tradition relating to a traditional leader or cultural leader which detracts from the rights of any person as guaranteed by this Constitution, shall be taken to be prohibited under that article.

\section{Review Questions}

Answer the following questions

1. Discuss the common characteristics of customary laws in Africa.

2. Examine the position of traditionalists and modernists on the role to be given to customary laws after independence in Africa.

3. Discuss as to how customary law may be ascertained.

4. Explain whether customary law may be brought from other communities.

5. Did the colonial powers give some role to customary laws? Why?

6. List and explain the methods the colonial powers used to ascertain customary laws. 
7. Did the colonial powers treat African customary laws as inferior to their laws? What were it manifestations?

\subsection{African customary laws and human rights principles}

\section{Introduction}

In section one of this chapter, we have seen that most of African customary laws are gender insensitive. In addition to this, there is also a doubt about African customary laws effectiveness in protecting and enhancing human rights principles and doctrines. On the other hand, almost all international instruments and many of African constitutions recognize the right to develop and practice once own cultural heritage. In this section, we will try to analyze the existing relation between the universality of human right principles and the place the customary laws in international instruments.

In this section, you should be able to

- Explain the position of international human rights instruments towards traditional legal institutions

- Discuss the recognition given to customary laws in international human rights instruments.

- Explain cultural transformation in light of its effect on human rights.

\subsubsection{The Place Given To Customary Laws in International Instruments}

In recent years, governments around the world have shown much interest in customary or indigenous laws. This interest affects the development of both national and international policies. In addition to domestic organizations, a number of private and public international organizations are also examining issues involving the use of customary laws. In the international sphere, the status of local customary laws is a matter of international human rights law that guarantees indigenous peoples the right to enjoy their own cultures. One aspect of this right is the right to use their laws.

To begin with, the Universal Declaration of Human Rights of 10 December 1948 binds all members of the United Nations to respect cultural heritage of their citizens. 
Article 27 of this Declaration gives everyone the right to participate freely in the cultural life of the community. The International Covenant on Economic, Social and Cultural Rights enunciated in article 15that states should recognize the rights of everyone to take part in cultural life. The African Charter of Human and Peoples Rights of 21 October 1986 Article 17 of the charter provides that every individual may freely take part in the cultural life of his community and that the pro motion and protection of morals and traditional values recognized by the community shall be the duty of the state. The Charter also obliges individual to preserve and strengthen positive African cultural values in his relations with other members of the society. This is to be done in the spirit of tolerance, dialogue and consultation, and, in general, to contribute to the production of the moral well being of society. It obliges him to contribute to the best of his abilities, at all times and at all levels to the promotion and achievement of African unity. Articles 22 of the Charter also provides that all peoples shall have the right to their cultural development with due regard to their freedom and identity and in the equal enjoyment of the common heritage of humanity.

The UN Charter, the Universal Declaration, the International Covenant on Civil and Political Rights of 1966, directly or indirectly, have shown that customary law is a part of a people's culture. The emergence of a right to culture since the 1950s provides additional support for the argument that states are bound to foster customary laws. Many conferences held under the auspices of the United Nations Economic, Scientific, and Cultural Organization ("UNESCO") have emphasized the central role of governments in promoting cultural development. Participants at a 1965 UNESCO seminar on multinational society urged the "recognition of the importance of maintaining permissible legal traditions" in many fields of law. The seminar's participants unanimously agreed that states should not impose limitations on the customs of traditional groups. The 1970 Intergovernmental Conference on Institutional, Administrative and Financial Aspects of Cultural Policies stressed that all governments are responsible for the adequate financing and appropriate planning of cultural institutions and programs. In 1972, the Intergovernmental Conference on Cultural Policies in Europe suggested that governments have a duty to promote the right to culture. Two years later, the UNESCO Seminar on the Promotion and Protection of Human Rights of National, Ethnic and Other Minorities encouraged public financing to support local customs. These pronouncements suggest that 
international law guarantees a right to culture and thus binds states. Therefore, governments are expected to maintain customary legal system truly representative of and responsive to the people's needs. Merely to accept the body of law that anthropologists designate as customary will do nothing to advance groups' cultures.

\subsubsection{The Effect of Culture in Internalizing Human Rights in Africa.}

The centerpiece in the process of universalizing human rights is to find out the role of custom and culture in this process. There are different opinions as to the effect of culture in enhancing and strengthening human rights and democracy in Africa. The first argument, mainly advocated by western powers, is based on the idea that cultures shall be refined and squeezed to make them in line with internationally accepted principles of human rights and democracy. Here above we have discussed two of the testes usually used by the colonizers know we will see the third test developed after colonization. That is the human rights. This test has got currency since 1980`s. The test states that any customary law or practice that offends human rights as stated in a constitution of a nation or human right instruments that country has ratified shall have not legal effect. Thus, a distinction is made between customary laws that contravene human rights values and those customary laws that are consistent with those human rights values. The criterion of such distinction is human right values.

This test has several merits. The test stands for human dignity, as it states that those customary laws and practices that offend human dignity shall lose ground. The test is for the general welfare; it tries to free several people from the tyrannical aspects of customary laws. The test has the capacity not to eliminate but refine customary laws. The test is easier to ascertain as compared to the repugnancy test. Even if the test is European in origin, it can serve in other parts of the world; the proper consideration should be is it useful everywhere, irrespective of where it originated. This test is not however immune from criticisms. The test is criticized for advocating for the existence of universal values. Some would like to regard some aspects of human rights as particular. The argument comes from those who argue for cultural relativism, that culture is peculiar to place, time and people. The other criticism directed against this test is that it tends to integrate the world of values in the European perspective. 
The proponents of this argument insist that culture contrasts with progressive or independent thinking thereby hindering human rights from becoming internationally acceptable guidelines in the life of human beings. They believe that there should be the same version of human rights all over the world notwithstanding the cultural differences. When the culture of the community contravene with the established human right principles there should be immediate action to ban that culture. This argument is not devoid of some acceptable arguments, among others the idea that all human beings endowed with human rights is the main one. Human rights are inherent with humanity therefore any culture or thinking which tend to limit their application or challenge their validity is the result of some kind of corruption committed on that that culture by certain groups to protect their interest and privilege. Some advocators of radical change go out of human touch by criticizing culture and tradition as source of inequality in many societies. The idea is that culture especially the non-western cultures are obstacles in creating a world free from any human right violations. Nevertheless, this thinking is fallacious as giving primacy to human reason in the world is the tradition ceded at least in the early stages of Greek philosophy. Secondly tradition is a common feature of society and of laws and working with tradition allow us to work with a common factor thus tradition is the sign of quality and endurance. We have seen the function of culture in chapter one therefore we believe that you can challenge this arguments based on that. There is also strong opposition to the conception that African cultures have hindered the establishment of modern and prosperous African society. In explaining his doubt, one writer writes:

One might wonder also just how much the current state of lack of rights in Africa has anything to do with African cultures at all. The major abuses of political rights at the state level are the products of the political institutions bequeathed by the colonial powers. The failures of the multi -ethnic states created by colonialism power and their powerlessness in relation to the goals of the development because of the structure and workings of the world economy, arise from premises given to Africa, not originating in it.

The second argument is that human right principles as they are advocated today are the result of western philosophy and history. The human rights as they are uttered know are born out of conflict and war occurred in the west. The activists of human rights also put first the interest of the individual over the interest of the community as a whole. The African communalism was attacked as primitive and inferior, which 
contravene human conscience and dignity. Then they tend to conclude that human right principles as they are articulated in the international instruments are against the cultures and choices of Africans therefore Africans should not be obliged to embrace the alien principles by scarifying their own. They urge for the development of human rights based on African values and principles. That is Africa shall develop its own version of human rights based on its own culture and choice of preference, which will contribute for social and economic development of the peoples of Africa. Here again the criticizers of such kind of categorization rejected such a difference between the West and African notion of human rights. Chanock writes,

The long tradition of liberal philosophy of rights as well as western inspired rights declarations are very clearly about groups. They are about the nature of groups' life, and how it should ideally work. They endeavour to prescribe the rules for associating in groups. The differences, therefore, are about the ground rules for associating in groups, not about individuals as opposed to groups, nor even about which priority has. Classical liberalism, from which rights, doctrines follow, does not subordinate group to individual, but is concerned with the kind the of group to which individuals belong. Further more the attempt to depict Western societies as individuals misses the point that these very societies, with their powerful cohesive ideologies of nationalism, patriotism, collective action and welfarism, have been and are far more 'successful' groups on a large periods of time, with better working consensual traditions of government than the often fragmented, authoritarian, familistic, localisitically based societies which invoke their cultural attachment to groupness.

The third argument tries to accommodate the two opinions. The proponents of this opinion argue that cultural differences are no simply given. The experience of difference depends on the power to create culture on the labour of elites in essentializing, displaying and institutionalizing elements of the myriad of practices in any community. Our focus should therefore be on the current process of cultural creation instead of treating culture as historically given which weigh upon present and futures. Therefore, the core idea of this argument is that cultures are not some thing biologically attached to a certain community. We can transform and create culture. One writer writes:

First Culture profoundly affects the articulation and implementation of human rights in all societies because of its formative and constant influence on human motivation 
and behavior. While this does not mean that culture is the sole determinant of all human activities, the ability of members of a cultural tradition to take alternative courses of action is conditioned by the broad parameters of their culture. Third, every culture is constantly changing through the interactions of a wide variety of actors and factors at different levels of society. This internal discourse within each culture includes the activities of non-elite actors who contribute to cultural change through different patterns of behavior and other forms of non-verbal communication, as well as the more visible and articulate forms of interaction by elite and openly active social actors. In other words, people are generally predisposed to act in culturerally sanctioned ways, but they are to varying degrees agents of change in the transformation of their own culture. Forth, the speed and sustainability of change in particular ways tends to vary with such factors as the level of entrenchment of the values and institutions in question, degree of stability in the circumstances of conditions of the society, and ability and willingness of social actors to engage in deliberate strategies of cultural transformation.

By the term cultural transformation, we are referring to the dynamics of change as internal processes of societal adaptation by a variety of actors in response to a wide range of stimuli at different levels, rather than simply the product of internal hegemony or external imposition. With due regard to the impact of differentials in power relations within each society, and in relation to external actors and forces, the notion of cultural transformation incorporates the whole process as an indigenous expression f a people's right to self-determination. Moreover, we use the term transformation in order to de-emphasize the internal/external dichotomy in crosscultural dialogue because externally initiated change is unsustainable except to the extent that it is internalized by the people concerned. Such an understanding of cultural change, we believe, is crucial for the theoretical validity and practical application of human rights norms in all societies throughout the world.

To pour oil on the troubled water, the proponents of this opinion hold that to quell the tension between universality of human rights and the tendency of maintaining the culture a given society we have to accept that tradition first and then to work to gather to refine that culture slowly not radically. The same writer writes 
Since this cannot and should not be done through external imposition, the very nature of the human rights paradigm requires its proponents to generate sufficient domestic constitutional protection of human rights. This can be done, we suggest, through a deliberate effort at building an overlapping consensus around the normative content and implementation mechanisms of human rights. The project of the universality of human rights is to be realized through a confluence of internal societal responses to injustice and oppression, instead of attempting to transplant a fully developed and conclusive concept and its implementation mechanisms from one society to another. The way to get a universal idea accepted locally is to present it in local terms, which can best be done by local people. Conversely, local acceptance enriches the universal idea (Daniel I975: 2II) by giving it meaning and relevance to people's lives.

Part of the process of influencing the course of cultural transformation in favor of the stronger protection of human rights as a matter of the free expression by the people of their right to self-determination is to insist that a genuine commitment to the protection of human rights is inherent to the raison d'etre of any state. For African states, this was not only the premise of their struggle for self-determination from colonial rule, but has also been repeatedly proclaimed in national constitutions and policy statement after independence.

\subsubsection{Cultural Transformation and Human Rights in Post-colonial Africa}

There is very little understanding of the actual process of cultural change or transformation. 'We do not know why something that has often been said before will suddenly catch on, or why both events and opinions seem to remain static for a long time, and suddenly begin to move, and keep on moving. Most mysterious of all is how a consensus of opinion forms, and why it takes the shape it does' (Daniel I975: 88). In our view, however, better understanding of the inner working of the formation and transformation of cultural norms or practices can be achieved by examining the synergy of context and process. For our purposes here, the focus should be on how the context, and the terms of the interaction of actors and factors, influence transformation, whether in favor of, or opposition to, the domestic protection of human rights. 
With regard to context, we are concerned with the role of the post-colonial state in Africa in its broader regional and global setting. While each state should be understood in its own specific pre-colonial history, type of colonial experience, and political and economic conditions at independence, it would be useful to consider such factors in the light of the broader processes of interaction between the local and the global. As briefly explained below, there are political, social and cultural, as well as economic, dimensions to what is commonly referred to as 'globalization'. For our purposes here, we focus on the dynamic of the pull of self-determination and domestic jurisdiction, on the one hand, and the push of diminishing sovereignty under conditions of multifaceted globalization, on the other. By 'process' we are referring to the relationship between what we call internal discourse within each culture, and cross-cultural dialogue between cultures (An-Na'im [ed.] I992: 4-5).

In our view, understanding the operation of process in context is important for mediating the dichotomy between the so-called internal and external actors and factors who participate in cultural transformation, and the likely outcome of their interaction. However, this duality of context and process is used here merely for the purposes of analysis, without suggesting a dichotomy between the two. In fact, many of the factors indicated below under the rubric of context can also be seen as part of process, and vice versa. The impact of such factors on each aspect is also contingent and ambivalent. Globalization, for example, is a vehicle of economic liberalization and consequent political penetration through such processes as the decentralization of production, mobility of capital and labor and international trade regimes. At the same time, and by its very nature, globalization can also facilitate mobilization and collaboration between global social movements and non-governmental organizations working on the local protection of human rights, or of the environment.

Moreover, African cultures and their transformations should be understood in historical perspective. This will be difficult and problematic not only because of the lack or inadequacy of written documentation for the pre-colonial period, but also because all phases of the history of any society are often contested for the purposes of the present. But that is hardly a good reason for rejecting the historical component in culture. So, such factors as the nature and dynamics of political organization, social institutions and economic relations during the pre-colonial and colonial state and its 
role in cultural transformation today. In probing the past so as to understand the present, however, one should note that such historical reconstructions can only be statements of probability rather than established historical fact (Bascom and Herskovits [eds] I959: 8).

the state, with its juridical sovereignty, extensive powers and relatively much larger resources, is a key element in the context of cultural transformation everywhere, both as an object of contestation among the competing perspectives, as well as a proponent of the policy priorities of those who control it. At the local level, many actors seek directly or indirectly to capture the state in order to implement, or at least influence its behavior in favor of their own concerns. Moreover, its presumed monopoly over the legitimate use of force induces all other actors to look to it as the arbiter of disputes. It is therefore clear that the nature and functioning of the state are particularly important for the prospects and orientation o cultural transformation. The exclusive or hegemonic control of the state by one religious or ethnic faction of the population is bound to provoke severe strife and probably civil war, as can be seen in the tragic conflicts in Liberia, Rwanda, Somalia and Sudan and many other countries. In these cases, cultural transformations likely to be manipulated to support the militant or confrontational objectives of each side to the conflict, rather than enhance peaceful coexistence and cooperation.

The post-colonial state in Africa has been cogently characterized by Patrick Chabal as 'with few exceptions, both overdeveloped and soft. It was over-developed because it was erected, artificially, on the foundations of the colonial state. It did not grow organically from within civil society. It was soft because, although in theory allpowerful, it scarcely had the administrative and political means of its dominance. Neither did it have an economic basis on which to rest political power' (Chabal [ed.] I986: I3). Another study of the colonial /post-colonial state finds it hardly surprising that the post-colonial state followed so closely its parent, the colonial state. The legitimacy of the state is derived from international agreements, earlier among European colonial states, and through the UN Charter and the Organization of African Unity (OAU) since I963, rather than the consent of their African populations. The colonial system of government organized according to European colonial theory and practice (tempered by expediency) was simply continued after independence, but only 
as a poor copy. Colonial economic relations, legal systems and administrative policies were largely continued by the post-colonial state. Even the lack of constitutional standing for the majority of African populations under colonial rule was continued after independence through the effective exclusion of major segments of citizens from the political process, despite the explicit terms of the constitutions of the newly independent African states (Jackson and Rosberg I986: 5-6).

To almost all African societies, independence usually signified the transfer of control over authoritarian power structures and processes of government from colonial masters to local elites (Ayoade I988: I04). Lacking an effective presence in most of the state's territory, ruling elites tend to focus on controlling the government apparatus and patronage system. Instead of seeking popular legitimacy and accountability to the people at large, ruling elites strive to retain the support of key traditional leaders (Atiade I988: I07-15). State security became the security of the regime in power, with no possibility of transparency in the functioning of security forces, or of their political and legal accountability for their actions. Constitutional instruments, where they were allowed to exist, have repeatedly failed to hold governments legally or politically accountable to their own citizens (Okoth-Ogendo I99I). Moreover, the majority of constitutions were either suspended or radically altered by military usurpers or single-party states within a few years of independence. It is not surprising, therefore, that African societies tend to regard the post-colonial state with profound mistrust, instead of with a sense of ownership, expectation of protection and service, and a general belief in their ability to influence its functioning. They tolerate its existence as an unavoidable evil, but prefer to has the least interaction with its institutions and processes (Young I994: 5). ${ }^{5}$

Of particular importance for our purposes here is the continuation of colonial attitudes to rights. Organized differently in rural areas from urban ones, the colonial state contained a duality of two forms of power under a single hegemonic authority. 'Urban power spoke the language of civil society and civil rights, rural power of community and culture. Civil power claimed to protect rights, customary power pledged to enforce tradition. The former was organized on the principle of differentiation to check the concentration of power, the latter around the principle of 
fusion to ensure a unitary authority' (Mamdani I996: I6). Once more, these attitudes continue for decades under both civilian or military governments.

To emphasize such strong continuities from the colonial to the post-colonial state does not mean that there is no tension between the two worlds. In fact, suspicion of the motives and intentions of the former colonial powers and their allies remains a strong factor in all cultural interchange between African and Western societies today. There is genuine sense of moral indignation felt by millions of people all over the world about colonial rule and post-colonial Western exploitation and African dependencies. To many opposition groups and community leaders, the knowledge that such exploitation continues is grounds for suspecting ulterior motives beneath whatever Western powers tend to support in international relations, especially their advocacy of human rights (Daniel I975: 22,23).

Another key element of the context of cultural transformation is civil society, which is supposed to be partner/ protagonist of the state, whereby their relationship is often described from one of two perspectives. For the state-centrists, the question would be whether the state has failed to penetrate society sufficiently and is therefore hostage to it. For the society-centrists, it is whether society has failed to hold the state accountable and is therefore prey to it (Mamdani I996: II). For example, Ali Mazrui cautions 'that whoever captures the state is in mortal danger of being captured by it ... The survival of the state becomes the paramount aim, even if this means repressing fellow workers or fellow nationals' (Mazrui I990: 55). Upon capturing the sate, leaders of liberation and grassroots movements become converted to the state system itself.

As a historical construct, civil society is said to be the result of an all-embracing process of differentiation: of power in the state and division of labor in the economy, giving rise to an autonomous legal sphere to govern civil life (Mamdani I996: I4). The realm of civil society is not the market but public opinion and culture. Its agents are intellectuals, and its hallmarks are voluntary association and free publicity, the basis of an autonomous organizational and expressive life. Although autonomous of the state, this life cannot be independent of it, for the guarantor of the autonomy of civil society can be none other than the state, presumably in interaction with civil society 
itself. A specific constellation of social forces organized in and through civil society may be the guarantor of the autonomy of civil society, but they can do so only by ensuring a form of the state and a corresponding legal regime to under gird the autonomy of civil society (Mamdani I996: 15).

Whatever role civil society may have is also conditioned by the nature of the state in its global context. In addition to the global system of sovereign states, social movements are also constrained by the global capitalist system and its implications. 'The underprivileged races, classes and groups like women or ethnic/ religious minorities, have not as yet made a difference to the fate of the global system' (Mazrui I990: 58). Generally speaking, men dominate both the state system and the capitalist global economy. In west Africa, for example, women have been conspicuous in trade and marketing, but this is only in relation to small-scale economic activities. The ratio of men to women changes dramatically upon considering the growing internationalization of local economies, with 'more men taking decisions on boards of directors or assuming control in factories, overshadowing the "market ladies" of yesteryear ... Similarly, greater mechanization of African economies has resulted in diminishing feminine share in them' (Mazrui I996: 60).

Another integral component of the context of cultural transformation is the nature of interaction between different levels of so-called internal and external actors or factors. With regard to this aspect of the context, it can be argued that human rights can be an instrument of mutual cooperation between European powers and African nationalist leaders in a new form of 're-colonialization' of Africa that allows colonial power relations to continue without direct colonialism (Hargreaves I996; Bach I993). Instead of the dependency of former African colonies on their colonial powers diminishing, there are now multiple and complex dependencies, ranging from daily reliance on colonial ties in economic activities, political processes and security arrangements, to technological, legal, administrative and educational matters (Mamdani: I45, I46). Even the internal security of the ruling elites against political challenge is sometimes 'delegated' to former colonial powers, as shown by the continued French military presence in several west and central African countries to 'keep the peace' (Gambari 1995). These complex dependencies continue to intensify under the growing globalization of the post-colonial world. 
Globalization is normally taken to mean such phenomena as the transformation of relations between states, institutions, groups and individuals; the universalization of certain practices, identities and structures; and the expression of the global restructuring that has occurred in recent decades within the framework of modern capitalist relations. But what many popular definitions fail to appreciate is 'the importance of notions such as coercion, conflict, polarization, domination, inequality, exploitation and injustice ... there is little or nothing about monopolies, disruptions and dislocations of the labor and other markets, the emergence of a global regulatory chaos and possible anomie and how these are being exploited for gains' (Aina I997: II). To the extent that globalization is the expression of existing power relations, it will become the means by which developed countries sustain their economic and political hegemony over developing countries. Should those power relations be transformed to reflect partnership in development and more equitable distribution of wealth and power around the world, globalization will become the instrument of justice and liberation for all human societies.

As suggested earlier, the process of cultural transformation can be seen in terms of internal discourse and cross-cultural dialogue, but this distinction is only for the purposes of analysis, as the two processes constantly overlap and interact. There are many aspects to cross-cultural dialogue, including interstate economic, political and other relations. Regarding human rights in particular, the governments of some developed countries, mainly in Europe and North America, claim to seek to influence the governments of developing countries through what is known as political conditionality, whereby the provision of foreign aid and assistance is linked to the 'human rights record' of African or Asian governments. But the nature, size and scope and other features of such aid are determined by considerations of the domestic politics of Western countries, rather than the needs and conditions of developing countries. Moreover, there is also the strong role of the principle of exchange in the capitalist ethos. 'Much of the transfer of capital to developing countries ends up by profiting the giver more than the receiver. Conditions are imposed on the receiver, designed to "maximize return" for the donor countries' (Mazrui I990: 202). 
Cross-cultural dialogue is also exceedingly difficult because of universally deeply engrained ethnocentrism. 'It is common to all cultures to dislike what is not common to them ... xenophobia is a basic condition of humanity. Unfamiliarly creates misunderstanding, and misunderstanding, suspicion, and hatred and suspicion grow rapidly from small beginnings' (Daniel I975: 7-10). As Mineke Schipper has explained:

People tend to reject differentness, and the definition of what is human often extends no further than the borders of one's own group, country, race, or sex, to the borders of one's own language, continent and culture. The 'barbarians' are always the others ... During the twentieth century, a Western multinational 'Otherness' industry has developed, allowing a relatively small but powerful group to decide the fate, content, form presence, and absence of its Others - to decide whether, where, and how these Others are supposed to exist, to be seen, or to be ignored ... The Other has been studied and classified in terms of appearance, gender, language, behavior and customs. When the results of these investigations are presented, one is told that this is what 'they' look like, that this is their reality, or that this is how our ancestors or learned predecessors characterized 'them' ... the assumption that only the representatives of a single group are qualified to interpret the world ... prevents dialogue and perpetuates a stereotype that is exploited to label Others and to justify their exclusion from a mutually beneficial partnership. (Schipper I993: 39-40)

Mike Featherstone has suggested that by trying to employ a broader definition of culture and to think more in terms of processes, it might be possible to talk of the globalization of culture. Processes of cultural integration and cultural disintegration are taking place not only on an inter-state level, but also at a trans-national level. 'It therefore may be possible to point to trans-societal cultural processes which take a variety of forms, some of which have preceded the inter-state relation' (Featherstone I990: I). instead of the binary logic of seeing culture in mutually exclusive terms of homogeneity /hetero-geneity, integration /disintegration, or unity/ diversity, there should be an inquiry into the grounds and generative processes of the formation of cultural images, as well as the inter-group struggles and interdependencies (Featherstone I990: 2). Increasing cultural interrelatedness is generating a series as processes which produce both cultural homogeneity and cultural disorder, in linking together 
previously isolated pockets of relatively homogenous culture which in turn produces more complex images of the other as well as generating identity-reinforcing reactions. This global interrelatedness is also producing trans-national cultures, as genuine 'third cultures' oriented beyond national boundaries (Featherstone 1990: 6). This is not to suggest that there is or will be a unified global culture, but rather to indicate the growing possibility of global cultures in the plural. 'The world is a singular place which entails the proliferation of new cultural forms for encounters' (Featherstone I990: II).

\section{Summary}

African customary law is basically unwritten. It is characterized by diversity. The African law focuses on compromise and settlement. It tends to be static, not subject to frequent change. Because of this stability, African law, like religious laws, tends to be conservative.

In the light of the problems of creating cohesion and national identity in a society in which the colonial powers elevated the strategy of "divide and rule" to a high art, many may not view the continued existence of customary law as a good thing. Over the years, some scholars and politicians have advocated legal unification rather than dualism. Throughout the developing world, governments often point to the requirements of modernization and the necessity of fostering national unity as reasons for abandoning customary law and replacing it with unitary, national systems. In many African states, governments have viewed customary law with hostility. As colonizers applied customary law on a racial basis, many Africans considered its use to be tainted by discrimination and antithetical to the goals of African nationalism. Many nationalists have seen it as representative of the old, unprogressive order, and have considered Western law, be it capitalist or socialist in orientation, as representative of the forces of modernity, especially in the civil and economic arenas. Consequently, various African countries dispensed with customary law when the regimes considered such law to be a colonial relic.

New governments often addressed questions of customary law through codification. African codification commissions typically adopted one of two methods of treating 
customary law in their search for its appropriate role in a new legal order. First, as in Ethiopia, they have endeavored to change legal systems dramatically abolishing customary laws. The second approach to codification has involved the creation of codes that recognize the continuing vitality of customary law. This sympathetic approach, which, curiously, often enjoys more support from Western scholars than from African politicians, derives from a belief that customary law best mirrors social reality and comforts with people's value systems. The 1959 Madagascar Code was representative of this view. The framers of that code intended to furnish the country with a unified law, but the code did not fully retain customary law. Rather, it too, albeit in a less pernicious way than in Ethiopia, modified existing customary law. Madagascar harmonized conflicting rules, removed rules that the central government deemed unacceptable, and, in certain instances, consolidated customary and civil law. In Madagascar, therefore, the change was evolutionary, while in Ethiopia it was revolutionary. Nevertheless, attempts to codify or abolish customary law have generally been doomed to failure.

Some scholars of customary law in Africa liken these attempts to the 1926 introduction of the Swiss Civil Code in Turkey. While the imported Swiss code was adequate for urban elites and members of the legal profession, the vast majority of the people neither understood nor used it. It is unrealistic to believe that people will automatically abandon local customs because an edict comes from their central government. The attempts of central governments to remove customary law and thereby undermine the power of "traditional" authorities who uphold it may have unintended results, causing great resentment with in societies whose traditional law is challenged and, rather than foster national unity, invigorate separatist movements. Codification attempts often fail because many African countries have high degrees of illiteracy, and written codes thus have no attraction for the people.

Some countries, on the other hand, have attempted to unify only customary laws. The argument advanced in such cases is that differences in customary law divide the country. Thus, in the 1960s the Tanzanian government, with the express objective of fostering national unity, began a unification program that produced only superficial uniformity. Yet, it would seem that conflicts among types of customary law, as when persons in different groups marry, are insignificant in comparison to the more 
substantial problem of the conflict between customary law and national law. Such conflicts will continue to occur even if customary law is made uniform or codified.

Traditional leadership is an institution that has developed over many hundreds of years in Africa. It has served the people of Africa through wars, periods of slavery, famine, freedom struggles, economic and political restructuring, and during colonial and apartheid periods.

Prior to the introduction of colonialism, social organization in some African countries such as South Africa was characterized by a number of tribal regimes based on patriarchy norms. Each tribe, as is still the case today, had a traditional leader who was the central figure. He was the highest authority in the territory. He had various functions, which he did not exercise as an autonomous individual but in collaboration with a tribal council that represented the people. His people saw him not only as a link between them and their ancestors but also as a spiritual, cultural and judicial leader, and the custodian of the values of his community. He was the coordinator of the various aspects of everyday life, the realization of community dreams and aspirations, and the creator of harmony between people and their natural, spiritual, social, physical, and economic environment. He ruled the tribe and the tribe considered him as both father and son. His leadership role was a bonding factor as he was responsible for the common good.

With the advent of colonialism, the African traditional government was systematically weakened, and the bond between traditional leaders and their subjects was gradually eroded. Colonialism deprived people not only of their land and property but also of their dignity and culture. The ancient African societal system, which was the basis of its humanity and mutual co-operation and protection, was destroyed.

Human rights are meant for protecting and enhancing human dignity and respect. The logic behind the need to have universally accepted minimum standard is to protect a possible violation of these rights by governments or local leaders. However, this tendency of universalizing human rights commonly faces opposition from scholars and leader who are suspicious of the idea as a mechanism designed to impose western philosophy on the other peoples. To solve this problem distinguished 
scholars of human rights are now proposing for achieving the objective through cultural transformation.

\section{Review Questions}

Answer the following questions.

1. Africa is a diversified continent; do you think it is acceptable to think of common features of African customary laws.

2 do you think that there is a universal value which the world community should protect.

3 do you think customary laws impede the democratization process of a country?

4. Do you think that states in Africa have an obligation to maintain customary laws found in their respective territories?

5.. Customary laws in Africa are most commonly unwritten. Can you tell the reasons for this state of customary law? What are the implications of the unwritten form of customary laws?

6.. Enumerate the possible factors for the hurdles to the inheritance rights of women in Africa? Indicate the possible solutions too.

7. List some customary practices that, in your opinion, offend human right values.

8. In Botswana, in Bimbo v. State, the accused was convicted of adultery by a customary court and fined 500pula (about \$250). The magistrate's court in Gaborone, exercising its appellate jurisdiction, confirmed the conviction. At the next appeal, however, the High Court quashed the conviction on the ground that adultery is not an offense created by the Penal Code or other written law and that the accused could not be charged with a non-statutory criminal offense. Comment. 
9. In South Africa, in 1996, Mthembu v. Letsela was brought before the Transvaal Provincial Division. The applicant alleged that she had been married under customary law to Tebalo Watson Letsela, deceased. In accordance with customary law, the estate of the decedent, who had no male children, reverted back to his father. The applicant brought a constitutional suit on behalf of her minor daughter, Mthembu, on the grounds that customary rules of succession excluding women from intestate succession should be declared invalid. Judge Le Roux postponed the application, referring the matter for a hearing on whether the applicant had in fact been married to the deceased in a valid customary union. Judge Mynhardt, the second judge to hear the case, found that no customary union existed and dismissed the application with costs. The applicant appealed the ruling, and Mthembu came before the Supreme Court of Appeal in May, 2000. In a third decision authored by Judge Mpati of the Supreme Court of Appeal, the applicant's case was dismissed on the grounds that (a) Mthembu is illegitimate as no customary union in fact existed and (c) the development of customary law is best left to the legislature. Give comments on the basis of Ethiopian laws.

10. In Zimbabwe, in Magaya v. Magaya, Shonhiwa, Lennon Magaya, a Zimbabwean of African descent and practitioner of traditional Shona custom died. He left behind two polygamous wives and four children, a house in Harare and some cattle at a communal home outside the city. He did not, however, leave a will. Venia Magaya, the eldest child and Mr. Magaya's only daughter, was born in 1941 of his first, or senior wife; his three sons, Frank, Nakayi and Amidio, were all the children of his second wife, born in 1942, 1946 and 1950, respectively. Shortly following the decedent's passing, Ms. Magaya sought heirship of the estate in the local community court. The eldest brother, Frank, declined to seek the inheritance, claiming he would not be able to look after the family as is required under traditional law. Ms. Magaya had been living in the house with her parents until her father's death. With the support of her mother and three other relatives, she received the appointment and title to the house and cattle.

Soon thereafter the second son, Nakayi Magaya, applied to cancel this designation. Nakayi filed a case, claiming that the failure to involve him and "other persons interested in the deceased's estate" contradicted $\S 68(2)$ of the Administration of Estates Act. Ms. Magaya's appointment was cancelled forthwith and all interested 
parties then attended a new hearing on October 14, 1992. Nakayi Magaya was proclaimed the rightful heir under customary law. He proceeded to evict his sister from the Harare property. In justifying its decision, the Court relied on the Administration of Estates Act, which at that time stated: If any African who has contracted a marriage according to African law or custom or who, being unmarried, is the offspring of parents married according to African law or custom, dies intestate his estate shall be administered and distributed according to the customs and usages of the tribe or people to which he belonged. The African custom defined by the community court is not articulated within the decision, yet its intent is clear: "Venia is a lady (and) therefore cannot be appointed to (her) father's estate when there is a man."

Ms. Magaya appealed to the Supreme Court. Writing for the Court, Justice Muchechetere affirmed the Community Court's decision primarily on the basis of a personal interpretation of customary law and the 1983 Zimbabwean Constitution. After a perfunctory review of the facts and lower court's decision, he sought to define applicable customary law. He determined that "what is common and clear from the texts is that under the customary law of succession of the above tribes males are preferred to females as heirs." Citing a number of cases in support of this interpretation, he then proceeded to address the legal merits of the case. Given that customary law appeared to indicate that males generally are the rightful heirs under customary law and that such bias was constitutional, the holding appears inevitable. The Court dismissed Venia Magaya's argument that an inheritance preference for male offspring "constitutes a prima facie discrimination against females and could therefore be a prima facie breach of the Constitution of Zimbabwe. Give comments on the basis of Ethiopian laws. 


\title{
Unit three: An Overview of Traditional Legal Institutions in Ethiopia
}

\author{
Introduction
}

In the 1960 s the central government had already expanded its tentacle and incorporated the outlying areas. In 1960`s, the Ethiopian central government came up with legal centralism. Legal centralism relates to the idea that there should be one code for a given country. Legal centralism does not recognize multiple laws. This legal centralism raised a theoretical debate. This theoretical debate was not actively raised in Ethiopia because of lack of adequate number of Ethiopian legal professionals at the time. This theoretical debate was raised elsewhere. The debate was custom theory versus instrumentalist theory. It appears that the Ethiopian codification process adopted a predominately instrumentalist approach. Customary laws were used, to some extent, as a material source of the Ethiopian codes.

This unit consists of four sections. The first section explores issues linked to legal codes and customary laws in Ethiopia. This section serves as a background to the next three sections of the unit. The second section deals with the impacts of customary practices on the realization of the rights of women in Ethiopia and the different approaches to tackle such discriminatory practices. The same section traces the various methods Ethiopia used in the past to address this issue. The third section of the unit is about customary laws and human rights in Ethiopia. This section examines the nature of the commitment of the present Ethiopian legal system to the recognition of customary practices and human rights as well as the problems associated with such commitment. The final section has reproduced materials that survey customary dispute resolution methods in Ethiopia. The excerpts in this last section also assess the advantages and disadvantages of traditional dispute settlement mechanisms in Ethiopia.

In this unit, you should be able to:

- Analyze the relationship between customary laws and codes especially the Ethiopian Civil Code. 
- Examine the adverse impacts of some customary practices of the rights on women in Ethiopia.

- Analyze the different approaches to eliminate gender insensitive customary practices in Ethiopia.

- Determine the relationship between customary laws and human rights in Ethiopia.

- Evaluate the merits and demerits of customary dispute resolution mechanisms in Ethiopia.

- Identify common features among the various customary dispute settlement mechanism

\section{1: Customary Laws and Codes in Ethiopia}

The present section discusses the features of the Ethiopian legal system prior to the codification of 1950`s and 1960`s. It explains the different positions held in relation to the place given to customary laws under the various regimes in Ethiopia. Besides, it discusses the tests adopted in recognizing customary laws in the Ethiopian Civil Code. It also discusses some of the common features of customary laws in Ethiopia as well as describes the role of assessors in the administration of justice in the past in this country.

In this section, you should be able to:

- Discuss the features of the Ethiopian legal system prior to the codification of $1950 ` s$ and 1960`s.

- Explain the different positions held in relation to the place given to customary laws in the Ethiopian Civil Code.

- Discuss the tests adopted in recognizing customary laws in the Ethiopian Civil Code.

- Discuss some of the common features of customary laws in Ethiopia.

- Describe the role of assessors. 
State and Customary Law in Ethiopia: The relationship between State and Customary law can be divided into three phases: (1) The imperial imported sacred tradition in the pre-modern era, (2) the modern secular imported nation-building period under Emperor Haile Sellassie and the Derg, and (3) the post-modern ethnic federalist period under the EPRDF.

The first phase during the imperial period from the $15^{\text {th }}$ century till the early $20^{\text {th }}$ century can be characterized within the realm of the Empire by the imperial reliance on reference to indigenized translated texts based on 'imported' biblical and RomanByzantine traditions with a strongly sacred flavor. There was only nominal and limited reference to the importance or precedence of local customary law in imperial edicts and much of the country remained beyond the confines of the monarchies, administered in practice in legal terms through customary law.

The second phase began with Emperor Haile Sellassie's modernising drive from the early 1930s, pursued more vigorously after the Italian occupation especially in the mid 1950s and 1960s with the development of legal codes. Here again much of the legislative drive and influence, signalled most clearly in the assigning of the drafting work to foreign experts, was external to the Ethiopian context. Customary law was repealed by the Civil Code which included only token references to limited areas where customary rules could be applied. The second modernist nation-building phase ended with a socialist twist under the Derg, which continued the centralist project with very minor concessions to religious and ethnic interests as expressed in the 1987 Constitution.

The third post-modern ethnic federalist phase began with the defeat of the Derg in 1991 and is most clearly expressed in the 1995 Constitution which represented a radical break from the centralist unitary past and was exceptional in the extent to which ethnicity was proposed as the organising principle. Logically this premise implied a greater recognition of customary values. In fact customary and religious laws and courts were provided at least some constitutional space in family and personal law. However, the translation of constitutional provisions into practice to date has not provided clear legal recognition of customary institutions and the lack of constitutional mention of their potential role in criminal and other legal areas restricts 
their mandate de facto despite their clear and vigorous involvement in all legal domains, and the strong informal reliance of the formal judicial system on them.

We conclude by arguing that the role of customary dispute resolution needs revisiting and suggest that the recognition of the mandate of credible customary institutions and their relationships and interactions with the formal judicial structure should be reconsidered to enhance local level justice delivery, while ensuring the protection of human rights, notably those of women, children and minorities.

1) The imperial sacred tradition in the pre-modern era

Ethiopia is believed to have existed as a polity, shrinking and/or expanding in shape and power, for more than two thousand years. Its long history of existence was for the most part dominated by a history of traditional mode of administration and social relationships. Modern bureaucracy started to emerge in Ethiopia during the early $20^{\text {th }}$ century under Emperor Menelik II (r. 1889-1913). This coincides with the time in which the present Ethiopia was also consolidated under the same ruler through expansion and conquest (Bahru 1991).

Ethiopia had its first written Constitution in 1931 under Emperor Haile Sellassie I (r. 1930-1974). Before this Constitution, customary law and some legal instruments governed the socio-political life of the people. The first attempts at using written codified law date back to the $14^{\text {th }}$ and $15^{\text {th }}$ centuries. Ser'ate Mengist, the 'Law of the Monarchy' was a short collection containing altogether twenty-one articles of law, which appears to record a continuous legislative activity which started in the $14^{\text {th }}$ century, with King Amde Tsion (r. 1314-1344) and culminated in the $17^{\text {th }}$ with King Fasiledes (r.1632-1667). This Law mostly deals with religious affairs, but also contains texts on civil and penal matters, scattered among attacks against heresies of the time (Vanderlinden, 1966). The first codified law of Ethiopia was Fewuse Menfessawi ('the Spiritual Remedy'), according to Aberra (1988). Emperor Za'ra Ya'eqob (r.1434-1468) caused the compilation of this law, which had 24 articles through the Ethiopian church scholars from the principles of the Old Testament of the Bible. 
Later during the same Emperor's rule, a more elaborate law that had both secular and religious rules was 'imported' from abroad and made to replace Fewuse Menfessawi. This law was the Fitha Negest ('Justice of the Kings'). The Fitha Negest was introduced into Ethiopia from the Coptic Church of Alexandria and was translated from Arabic into Ge'ez. It comprised two parts, the first based on biblical texts, and the second mainly on Roman-Byzantine laws (Paulos 2005:534). The Fitha Negest was used as a law in both criminal and civil matters from the $16^{\text {th }}$ century under the kings and was mentioned in chronicles of at least eight emperors from Sersa Dingil who reigned in the late $16^{\text {th }}$ century until Haile Sellassie (Girma 2005:274-9). The first Penal Code of 1930 stated that it was a 'revision' of the Fitha Negest updated to meet the needs of present times and the revision in 1957 and the Civil Code of 1960 also refer to it creating an impression of continued legitimacy (Paulos 2005:535).

The Fitha Negest and other written legal instruments were used in areas under the monarchical administration and therefore covered limited areas of the country among Christians, and people living in other areas had their cases adjudicated and disputes settled through customary institutions (Krzeczunowicz, 1965). This tendency as shall be argued below, has continued to the present time, particularly in the borderlands.

Much of the pre-modern legal tradition used by the monarchs was thus foreign in inspiration. However, Aberra noted (2003:839) that the emperors on assuming power, 'stated in the preamble of their first decree that the custom of each and every locality should be respected and that cases were to be adjudicated according to the customary law of the locality'. He also suggests that at times customary laws, if found useful, could receive the status of law and be accepted as atse sir'at, 'the law of the emperors', which he translates as 'presidential jurisprudence' used as precedent for future cases.

2) Modern secular nation-building laws under Emperor Haile Sellassie and the Derg

Ethiopia embarked on a politically motivated modernization of its laws with the coming to power of Emperor Haile Selassie I, and the drafting of the first Constitution of 1931 and more emphatically as of 1955 when the Constitution was revised. The 1931 Constitution was drafted by Bejirond Tekle Hawaryat Tekle Mariam, and was 
influenced by the Japanese Meiji Constitution of 1889, (which in turn was influenced by German Constitutions) and the drafter was said to have been provided by the Emperor 'English', German, Italian and Japanese constitutions (Bahru 2002:62). The 1955 'revised' Constitution was influenced by Anglo-American constitutional traditions, the Westminster Model and the 1948 United Nations Declaration of Human rights, but also further consolidated imperial powers including as head of the chilot, the imperial court (Scholler 2003:788).

From 1957-1965, Ethiopia gave itself six modern legal codes in a massive codification project that aimed at 'modernizing' the legal system. These laws have a predominantly western flavour, and seem to bear little relation to the traditional patterns of life which prevailing in the country (Fisher 1971). The chief drafter of the Civil Code of 1960, René David borrowed from continental civil codes notably the French, Swiss, Italian and Greek, though he also consulted Egyptian, Lebanese, and German codes, and for some provisions Portuguese, Turkish, Iranian and Soviet codes. Though some attempt was made to incorporate certain principles of customary law into the enacted modern codes, they aimed at being comprehensive and governing all the legal relations in the country without leaving any space for the widelypracticed customary mode of dispute settlement. This state policy was clear notably in the Civil Code, which in its repeals provision, states in article 3347:

Unless otherwise expressly provided, all rules whether written or customary previously in force concerning matters provided for in this code shall be replaced by this code and are hereby repealed. (Emphasis added).

It is striking that the repeal by the Civil Code did not aim only at those customary rules that were inconsistent with the provisions of the Code, but rather at all customary rules concerning matters provided for in the Code, whether they are consistent with the Civil Code or not. Nor did the Code allow some grace period until the Code could be disseminated - both physically and in content - but rather its immediate enforcement was sanctioned, superseding the customary laws extant in the various groups of the Ethiopian society. 
The drafters of the Code in fact made an attempt to include some elements of the customary rules into the Civil Code. Some have claimed that the "general" custom of the land (its "common law") in areas of civil matters has been more or less included in the Ethiopian Civil Code (Krzeczunowicz 1963). There are in fact certain examples of inclusion of the pre-existing customs of the Ethiopian peoples in, for example, family matters (concerning betrothal, moral prejudice, kinds of marriage, and intestate inheritance), contracts, property law (about the principle of usucaption, right of way, and rural servitude), and torts (in fixing the amount of fair compensation) (Aberra 2003:840, Scholler 2003:750).

However, these cannot be taken as a fair and realistic treatment of the customary law in the country. In the first place, the examples of incorporation cited above could not possibly represent the customary laws of all the ethno-national groups of the country. Secondly, the so called incorporation of the general custom was made in rather limited areas and do not match the body of customary laws with a veritable mass of rules in all areas of the civil and criminal law. Thirdly, the modern legal system of Ethiopia did not give any place for the customary institutions that exist in various sections of the society. All courts of judicature, therefore, were restricted to be the ones that would be established by the State to apply the State formulated and codified laws.

The political motives and justifications for this usurping of customary law was primarily the belief that providing a uniform and modern legal regime would be necessary for the socio-economic development of the country, and a precondition for effective nation-building. However, half a century after the enactment of the modern codes and the establishment of a modern judicial system, neither was the much sought legal uniformity achieved nor were the modern codes able to successfully supplant customary laws and institutions of dispute settlement. Fifty years after the enactment of the Penal Code and the Civil Code which aimed at providing a comprehensive body of law in the criminal and civil matters, respectively, customary laws and institutions are still active and vibrant. This may indicate that the approaches taken by the modernizers of the Ethiopian law might have been wrong, or at least require rethinking and revision. 
The Derg period introduced a socialist orientation reflected in the 1987 Constitution of the People's Democratic Republic of Ethiopia (PDRE), drafted by the Institute for the Study of Ethiopian Nationalities in 1986. It was modeled along the lines of MarxistLeninist constitutions, notably those of the Soviet Union, Romania, and Albania (Scholler 2003:789). Although there was recognition that the Ethiopian state has, 'from the beginning been a multi-national state', the constitution is centralist and the PDRE is viewed as a unitary state, which 'shall ensure the equality of nationalities, combat chauvinism and narrow nationalism and advance the unity of the Working People of all nationalities' (Article 2), with only token concessions to the idea of autonomy (Clapham 1988:92-5). Despite the Derg's attempt to instill secular values, the only significant change from the draft to the final text which was debated prior to approval by referendum was a minor concession to religious interests in the removal of the monogamy clause (Clapham 1988: 95, Pankhurst 1994).

3) The post-modern ethnic federalist period under the EPRDF

After the defeat of the Derg by the EPRDF in 1991 the new approach based on ethnic federalism was both radical and pioneering (Turton 2006:1). The principle of selfdetermination for federated regional units was a departure from the formerly highly centralised and unitary state which went further than any African state and took ethnicity as its fundamental organising principle to a greater extent than 'almost any state worldwide' (Clapham 2002:27).

The 1995 Constitution of the Federal Democratic Republic of Ethiopia approved through a referendum reflects these changes in direction which have a direct bearing on customary dispute resolution and its relation to the formal justice system. The Constitution, itself a product of the shift in paradigms of approaches to the complex nature of the Ethiopian society and its problems, has allowed a greater space for customary and religious laws and courts extant in the country. The 1995 Constitution embodied a clear recognition of the jurisdiction of customary and religious laws and courts in family and personal matters among the disputants that consent to such a jurisdiction: 
Article 34(5):

This Constitution shall not preclude the adjudication of disputes relating to the personal and family laws in accordance with religious or customary laws, with the consent of the parties to the dispute. Particulars shall be determined by law.

Art. 78(5):

Pursuant to Sub-Article 5 of Article 34the House of Peoples' Representatives and State Councils can establish or give official recognition to religious and customary courts. Religious and customary courts that had state recognition and functioned prior to the adoption of the Constitution shall be organized on the basis of recognition accorded to them by this Constitution.

These articles therefore imply that at least in those areas mentioned, the CDR systems can exist separately from, and parallel with the state-sponsored legal-judicial system. In effect family law and the law of succession are therefore now potentially within the competence of the members states (Article 55) (Scholler 2003:751).

However, there is the danger that customary institutions that reflect societal structures and represent dominant interests may pass judgements that are against the interests of women, children and minorities. Although the Constitution's article 34(4) specifies that disputes relating to personal and family can be adjudicated according religious or customary laws 'with the consent of the parties to the dispute' , as Meaza points out (2007:108): 'there are various social and economic factors that push women litigants to submit to customary and religious courts. In the rare event that women assert their right to submit their case to secular courts may find religious courts not allowing them to exercise these rights'.

There are also serious risks for individual human rights, notably of women, children and minorities that need to be taken into consideration and protected through federal as well as state legislation and legal provisions. The advocacy work and campaign of the Ethiopian Women's Lawyers Association achieved tremendous progress in this respect in obtaining the proclamation of the Revised Family Code in 2000 (FDRE 
2000) and the Penal Code which was renamed the Criminal Code in 2004. This removed the discrimination between men and women evident in the 1960 Civil Code which had differential marriage ages for men and women, designated the husband as the household head with the right to chose common residence and manage common property, disallowed divorce until fault was proved, and did not recognize common law marriages. Likewise the Penal Code of 1957 criminalised abortion, did not recognise or criminalise domestic violence, or female genital mutilation, and provided an inadequate penalty for rape. However, four Regions, notably Afar and Somali, have still to adopt their family laws (Meaza 2007:100-2).

Regarding other civil matters than family and personal, the Constitution does not specifically prohibit the operation of CDR systems. Although this could potentially provide the space for the involvement of CDR systems in other legal domains, the fact that CDR is mentioned in the contexts of family and personal law without reference to other legal areas creates a pervasive impression that CDR jurisdiction is or should be restricted to family and personal law. Under the system of division of the legislative competence among federal and state governments in Ethiopia, civil matters (other than those specifically mentioned as federal under Art. 55 of the Constitution) fall under state jurisdiction. One could therefore imagine the possibility of States recognizing certain jurisdiction for the CDR systems when they enact laws on those civil matters.

With regard to criminal matters, however, the old, de jure state of affairs still continues under the new constitutional regime: the uniformity of criminal law and jurisdiction. CDR systems are not allowed any formal space of operation in the criminal law areas in spite of the fact that they are heavily involved in criminal matters. De facto CDR institutions are involved in criminal cases in many of the States, particularly, though not exclusively, in the border regions. Moreover, the formal justice system often relies on CDR institutions to solve less serious cases, to bring criminals to courts, to ensure that verdicts are upheld and to achieve reconciliation after cases are concluded. Therefore, for the customary institutions and legal processes would need to gain legal recognition of their role in the criminal area to collaborate effectively with the state judicial system. 
In general the whole question of the mandate of customary dispute resolution institutions and their relations and interactions with the formal justice system deserves careful reconsideration to allow for greater recognition while ensuring that human rights abuses are avoided and the rights of women, children and minorities are respected. We are not as such proposing that all customary dispute resolution institutions are worthy of legal recognition, nor are we arguing that customary institutions do not have weaknesses. However, we believe there is a strong case for acknowledging the value of certain customary institutions, the rights of people to make use of them in legally recognised ways. CDR systems can contribute through partnership and collaboration with the formal system to providing culturally acceptable and meaningful justice.

In short, we believe that the Constitutional space for CDR is still limited and even the space that has been accorded has not been followed through with practical provisions and the creation of an enabling environment for a fruitful cooperation, alliance and partnership in the legal sphere between state and civil institutions.

\section{Review Questions}

Answer the following questions

1. How do you assess the position given to customary laws in Ethiopia under the FDRE Constitution? What about under the PDRE Constitution?

2. is appropriate to describe the Revised Constitution and the many codes adopted under it inimical to customary legal institutions?

3.Comment on the following. " The areas of law likely to be most resistant to change in developing countries in general are family relations, successive and landholding. Conversely, new commercial laws would most easily be absorbed because of the lack of customary law in that field. The commercial, educational, social elites in the nation would be the first to absorb and utilize new laws and legal institutions to a modern society. However, the ultimate testing ground for the reception of large bodies of new law and new legal institutions is to be among the Ethiopian sub-elites, who constitute the overwhelming majority of the urban population. " ...It is argued by some that "customary laws can easily and substantially be disregarded in contract law, administrative law, penal law and labor law because either there are no customary rules in these areas, or even if there are, some customary rules are so crude and not 
highly entrenched. The argument is that personal laws such as family matters and succession are highly embedded in the fabric of traditional societies such as Ethiopia that it would be very difficult to modernize this area of law. On the other hand, in the areas of public law and commercial law, the promise of successful importation of laws would be upheld."

Lack of Uniformity: Customary law is diverse. Different communities answer a question differently. For example, there is no consensus on whether marriage requires the consent of the prospective partners. There is no agreement on whether a dowry should be paid, if yes, by whom, how much and the type of the dowry. There is also variation on the grounds for divorce. There is variation on the extent of issue of the blood relationship between the spouses. In addition, who succeeds and how much, how should common property be divided upon divorce and what are the rights of a child adopted are not treated in a similar fashion. You can say that there is diversity in the area of land law, family law, succession, and homicide law and dispute resolution in Ethiopian customary laws.

Unifying Factors: Some argue that a long period of and continuous economics, trade relations, similar economic stage, social (e.g., inter-ethnic marriage) and political [expansion] led to cultural assimilation /intermingling among the several ethnic groups in Ethiopia. Christianity and Islam also helped forge unity among the diverse groups

Policy instructions: Following the decision to modernize her laws and after adopting the policy position of designing her laws after the civil law model, the next step was to form a body responsible for accomplishing the actual task of codification and giving policy directions to the same. Emperor Haileselassi I, offered policy guidelines to the members of the Codification Commission and to key foreign draftspersons. You find these guidelines in the prefaces of the Ethiopian Commercial Code, the Civil Code and the Penal Code. The key part of the direction reads: " the genius of Ethiopian legal traditions and institutions as revealed by the ancient and venerable Fetha Nagast, natural justice and the needs and customs of the people must be incorporated; that law must be clear and intelligible to each and every citizen of our 
empire; the laws must form a consistent and unfired whole; must be that which keep pace with the changing circumstances of this world of today."

In a nutshell, the Emperor directed these persons first to take rules mainly from the continental legal system. But he gave them discretion to take rules from any sources so far as they were convinced that these legal rules and institutions would promote the best interest of the country. In confirming compliance with this first instruction of the Emperor, the drafter of the Commercial Code stated that: '...without taking into account the so-called preference to be given to this or that model in the continental or Anglo-American legal system, I have always had in mind the interest of Ethiopia and I have selected the solutions which I believe to be the best no matter where they come from, on condition that they may be applied to Ethiopian conditions, if not immediately, at least within a reasonable time." Second, the Emperor advised them to endeavor to adapt these legal rules and institutions to Ethiopia's situation. In third place, he instructed them to incorporate customary laws and traditional legal institutions of the country.

The policy guidelines the Emperor gave to the Codification Commission and the foreign drafters contain some indications of the manner in which his instructions could be reflected in the codes. One clue is that the persons in charge of drafting should take customary rules into account. The other indication is that the best foreign laws should be included in the codes. Obviously, the insights of the drafter should be taken into consideration. The findings of comparative law should also benefit the preparation of the codes for Ethiopia. Most importantly, the Emperor asked the Codification Commission and the drafters to combine customary rules and in such way that they would fit in to the existing and the future needs of the country.

On the position given to customary rules: On the issue of whether or not tradition has been disregarded, there are different views. Emperor Haileselassie I thought that the codes, especially the Civil Code gave adequate place to customary laws. He expressed this idea in the preface of the Civil Code and in his address to the Codification Commission. Upon the completion of the codification project, the Emperor confirmed that his instructions had been properly observed. 
Professor Rene David also joined hand in supporting the Emperor. This draftsperson argued that the central essence of the Civil Code lies in the sufficient incorporation of traditional legal institutions of the country. He summarized his view in this regard in the following most often quoted statements: "the Ethiopian feeling for justice is the basis of the Code. No rule in the Code violates this feeling. The dispositions of the preliminary draft prepared by foreign jurists were rejected or modified whenever they seemed contrary to it even when the foreign advisors considered them useful and advantageous for Ethiopia. The most important accomplishment of the Civil Code in the area of persons, family law, property and delictual liability was clarity, rather than to change the customary rules, to clarify these rules, to distil their essence and to unify them on the basis of those which appeared most reasonable. Our goal was to end an intolerable confusion and uncertainty by choosing the rule most in conformity with the Ethiopian sense of justice and Ethiopia's interests, economic and otherwise."

Rene David thinks that the areas of family law, tort law and property law of the Civil Code are significantly influenced by the customary rules then prevalent in the country. To the draftsperson, the only cases where he did reject customary rules were those that, in his opinion, would conflict with the demands of modern life in the country and those that impede the social and economic progress of the country. Rene David was of the opinion that the active participation of influential and knowledgeable person at the various stages of the codification, e.g., in the Codification Commission, in the Council of Ministers and in the two chambers, assured the sufficient indigenization of the Civil Code.

There are, however, those who think that customary laws were not given the place they should deserve. They raise the following points. If customary laws then prevalent were given proper place, why has the Civil Code not got the acceptance of the addressees some 48 years after its coming into force? They think that defective transplantation should explain the apparent absence of legitimacy on the part of the provisions of the Ethiopian Civil Code. The other justification provided is customary laws in Ethiopia were not sufficiently recorded prior to and in the course of the codification process. Therefore, there was no sufficient information about the nature and types of customary laws prevalent in the country. The other factor mentioned in support of the position that there are reasons not to believe that the Civil Code 
adequately included the traditional legal rules and institutions is that the code provisions themselves; there are few provisions in the Civil Code that assign some roles to customary laws. Finally, the main justification for the limited role assigned to customary laws is the general policy stand of the then government. The basic policy was to bring about legal unification via a general codification of laws in line with the civil law tradition. Legal unification through western style codes was aimed at facilitating the intended political unification, assimilation and integration of the various groups in Ethiopia.

Rene David's Methods: Professor Rene David, the drafter of the Ethiopian Civil Code, argued that he included a number of customary rules. He stated that he used several methods to do so. One method is incorporation. The term "incorporation" refers to the direct writing of a given customary rule into a code. He stated that he incorporated customary rules if those rules met the following criteria. Incorporation of custom took place when the custom was sufficiently general as to be practiced by at least a majority of the highland population, when the custom was not repugnant to the natural justice which permeated that ultimate old authority, the Fetha Negast, when custom was not contrary to imperatives of social and economic progress and when the custom was sufficiently clear and articulate as to be capable of definition in Civil law term.

The second means the Professor used to give room for custom is explicit reference to custom. Professor Rene David also stated that several provisions in the Ethiopian Civil Code made an explicit reference to custom.

The third strategy the drafter of the Civil Code used was to give a gap-filling role to custom. The idea was to state that whenever the code is silent about a given issue, custom might step in. Article 3347 is designed to play this role. Article 3347 (1) provides that:

Unless otherwise expressly provided, all rules whether written or customary previously in force concerning matters provided for in this Code shall be replaced by this Code and are hereby repealed. 
The key function of the provision is to repeal all customary laws that existed before the coming into force of the Ethiopian Civil Code (prior to May 1960) provided those customary rules are in conflict with the provisions of the Code. From this, you should notice the following points. First, this article abolishes all pre-existing customary practices if in clash with the code provisions. Second, this provision impliedly says that those customary practices that were in force before the enactment of the Code would continue to work provided they are not in conflict with the provisions of the Code. Third, this sub-article tells you that there are certain customary practices that existed prior to the Code are written into (incorporated in) the Code. Finally, the provision in question does not say anything about those customary practices that would come into operation after the coming into force of the Civil Code. These last types of customary practices can fill in the gaps left by the Civil Code. So, Article 3347 (1) has two critical roles: repeal role and gap filling role.

There are other provisions of the Civil Code dealing with customary practices. These provisions give a role to customary practices in the area of family law (Articles 507, 573, 577, 580, 606, 624, and 807-8), property law (Articles 1131, 1168, 1371, 1489, 1490, 1496-97 and 1363-67) and contracts law (1713 [2983(2), 2990(1-2), 2997(2), 3006(2), 3013(3) and 2116).

Fourthly, judges are permitted to attach customary meaning to disputable code terms. You may, for example, look at Article 1168 of the Civil Code. What is the meaning of the term "family" in this Article?

Rene David states that these four methods were included to give space to customary laws in the Ethiopian territory as they are found to be consistent with the following tests. As stated above, those customary rules that would not impede the economic and social progress of the country, those customary rules that would not be repugnant to natural justice or equity and those customary rules that would be sufficiently expressed in civil law terms were given recognition. So, you can say that the generality test, the social and economic progress test, the repugnancy test and the clarity test were employed. 
Assessors: An amicus curiae, literally means a friend of the court, expresses the desire to involve the grass root in the administration of justice. You can say that an amicus is curiae similar to assessors. An amicus curiae a concept that states that interested individuals should be given a chance to participate in the administration of justice. The term "interested individuals" is very broad. For sure the term "interested individuals" includes the parties directly affected by the outcome of a given litigation. The term also includes those individuals who may not have a direct interest in the final result of the litigation but are seeking to give information or any other sort of assistant to the court or the tribunal examining a given case. You can say the concept of amicus curiea advocates for the participation of individuals in the administration of justice. You can say that the role of individuals who try to influence in the outcome of a given case play a role similar to the jury in the common law.( We hope that you know the role of the jury in the common law, especially in the United States of America. Just for your information, In the United States of America, in criminal litigation, some group of individuals participate in criminal litigation and they give a guilty or not guilty verdict after assessing the facts of the case. Getachew`s article)

In Ethiopia, amicus curiea was recognized. You can take the following examples of the recognition of the institutions of the amicus curiea. In the Zufan Chilot dignitaries expressed their views before the Emperor had a lasting word on the case. Article 19 of the Administration of Justice Proclamation issued in 1942 gave some roles to assessors in the administration justice. Another example is the traditional roadside courts. The roadside courts as the name suggests heard cases by the roadside. Where a dispute arose between two or more individuals, they could approach an elderly person, even a passerby, and ask him to settle the case. Normally, it was customary for the elderly person to rest by the roadside in order to settle the matter. The institution of the roadside courts was the practice in the highland parts of Ethiopia. You can say that the roadside courts in Ethiopia were signs of the desirability of the participation of ordinary individuals in the administration of justice in the country. Another example of the recognition of the concept of amicus curiea is the current Ethiopian Criminal Procedure Code. It is desirable to reproduce Article 223 of the Ethiopian Criminal Procedure Code. The Article states: 
- The atbia dagnia shall whenever possible settle by compromise all cases arising out of the commission, within the local limits of his jurisdiction, of minor offenses of insult, assault, petty damage to property or petty theft where the value of the property stolen does not exceed five Ethiopian Birr.

- Where the atbia dagnia is unable to effect a compromise he may sitting with two assessors adjudicate on such offenses and on conviction impose a fine not exceeding 15 Ethiopian Birr.

- The atbia dagnia shall cause a record to be kept which, among others, shall show the opinion of the assessors.

The participants traditionally in Ethiopia were private citizens who themselves did not seek justice relief Amicus curiae. Before 1942, assessors had had a big place in the administration of justice in Ethiopia. Assessors are supposed to have no interest in the outcome of a case in which they are involved with. Assessors give important input to the decision of a court. However, the opinions assessors give do not bind the court; the court may disregard such opinions. The involvement of assessors in the administration of justice is believed to increase the acceptability of a judgment.

\section{Review Questions}

Part I. Choose the best answer from the given choices.

1. The test not used in assigning a space to customary laws in Ethiopia in the codification process especially of the Civil Code was:
A) Clarity test
B) The social and economic progress test
C) The repugnancy test
D) None of the above

2. The test (s) Professor Rene David, the principal drafter of the Ethiopian Civil Code, used in including certain customary laws in and excluding some other customary laws from the Code was: 

A) The social and economic progress test
B) The clarity test
C) The repugnancy test
D) The sufficient generality test
E) All of the above
F) He did not use any test.

3. One of the following does not belong to the methods Professor Rene David, the key drafter of the Ethiopian Civil Code, used to give a space for customary laws.
A) Incorporation
B) Express reference to customary laws
C) Gap-filling
D) Tools of interpretation
E) A, C \& D
F) None of the above

Part II. Answer the following questions.

1. Comment on the following quotation.

"...In Ethiopia, during the codification process, codification was seen as a process intended to use the law as a tool for social engineering in order to improve the development prospects of the country. In so doing, it was intended that the best out of the external systems of law and practices that happened appeared to have worked in those societies would be adapted to the new socio-political milieu in Ethiopia. Although the point of adaptation was stressed and the importance of infusing Ethiopian traditions and culture into the law was an objective, it was clear that those who were responsible for the new codes were guided by the keen desire of modernization rather than by attempts to infuse traditional practices and values. Indeed, "after a general meeting of the Codification Commission established to oversee the codification, the expert then retired to the privacy of his workman, located in Paris, to do the actual drafting... 
2. Comment on the following text, which is the preamble of the Ethiopian Civil Code of 1960. Your comments should focus on the objectives of the code, the aspirations of the Emperor and the sources of the rules.

" The Civil Code has been promulgated by Us at a time when the progress achieved by Ethiopia requires the modernization of the legal framework of Our Empire's social structure so as to keep pace with the changing circumstances of this world of today. In order to consolidate the progress already achieved and to facilitate yet further growth and development, precise and detailed rules must be laid down regarding those problems which do not only face the individual citizen but the nation as a whole. The rules contained in this Code are in harmony with the well-established legal traditions of Our Empire and the principles enshrined in the Revised Constitution granted by Us on the occasion of the Silver Jubilee of Our Coronation, and have called, as well, upon the best systems of law in the world.

No law which is designed to define the rights and duties of the people and to set out the principles governing their mutual relations can ever be effective if it fails to reach the heart of those to whom it is intended to apply and does not respond to their needs and customs and to natural justice. In preparing the Civil Code, the Codification Commission convened by Us and whose work We have directed has constantly borne in mind the special requirements of Our Empire and of Our beloved subjects and has been inspired in its labors by the genius of Ethiopian legal traditions and institutions as revealed by the ancient and venerable Fetha Neguest.

It is essential that the law is clear and intelligible to each and every citizen of Our Empire, so that he may without difficulty ascertain what are his rights and duties in the ordinary course of life, and this has been accomplished in the Civil Code. It is equally important that a law, which embraces a varied and diverse subject matter, as is the case with the Civil Code, form a consistent and unified whole, and this requirement, too, is fully satisfied by the law, which We promulgate today.

The careful preparation of this Code by the Codification Commission and the painstaking review which it has received in Our Parliament assure that this law will achieve the purpose for which it is intended. 
3. Comment on the following text, which is the preamble of the 1957 Ethiopian Penal Code. Your comment should focus on the policy objectives of the Code.

The codification of the principal branches of law of any country is always a difficult task, since it must be profoundly grounded in the life and traditions of the nation, and it must, at the same time, be in keeping with and responsive to the influences, not only juridical, but also social, economic and scientific which are in the process of transforming the nation and our lives and which will inevitably shape the lives of those who come after us.

These considerations apply with particular validity to penal legislation at a time when, throughout the world, the expanding frontiers of society brought about through the contributions of science, the complexities of modern life and consequent increase in the volume of laws require that effective, yet highly humane and liberal procedures be adopted to ensure that legislative prescriptions may have the efficacy intended for them as regulators of conduct. New concepts, not only juridical, but also those contributed by the sciences of sociology, psychology and, indeed penology, have been developed and must be taken into consideration in the elaboration of any criminal code which would be inspired by the principles of justice and liberty and by concern for the prevention and suppression of crime, for the welfare and, indeed, the rehabilitation of the individual accused of crime. Punishment cannot be avoided since it acts as a deterrent to crimes; as, indeed, it has been said, "one who witnesses the punishment of a wrong-doer will become prudent." It will serve as a lesson to prospective wrongdoers.

We have, therefore, taken upon Ourselves the responsibility of ensuring to Our beloved subjects, both of the present and of the future, that the codification which We are today promulgating is, in all respects, consonant with these high principles and preoccupations.

To this end, We have personally directed the labors and recommendations of the Commission of Codification convened by Us three years ago, after the completion of many years of preparatory work, and which throughout the ensuing period carried on 
its work at Our Imperial Palace. We have ensured that their concepts adopted as point of departure the venerable and well-established legal traditions of Our Empire as revealed in the Fetha Negast and in subsequent legislation and practice, including those customs and usages, which are common to all citizens. To this end also, We have utilized these services not only of our most qualified publicists and jurists, but also those of the most distinguished jurists of the Continent and the contributions of the most significant systems of jurisprudence in the world today. All of these contributions have been carefully assessed and have been adopted to the extent that they respond to the particular needs of Our Empire and can be incorporated into legislation so as to provide a fresh impulsion to the forces of progress, justice and humanity. As We stated three years ago on the occasion of the formal convening of the Codification Commission: "Although Ethiopia claims what is, perhaps, the longest-standing system of law in the world today, We have never hesitated to adopt the best that other systems of law can offer, to the extent that they respond and can be adapted to the genius of our particular institutions . . . However, ..... the point of departure must remain the genius of Ethiopian legal traditions and institutions which have origins of unparalleled antiquity and continuity."

It is in this sense also, that the work of the Codification commission has progressed in the allied fields of criminal and civil procedure and civil, commercial and maritime law. The penal code forms, therefore, but a part, although a highly significant part of one integrated whole, itself conceived within the yet larger framework of the Revised Constitution as granted by Us on the occasion of the Jubilee of Our Coronation, and designed to serve and supplement in practice the high principles of the instrument. It has been Our constant aim that the primary result of this vast undertaking should be to give reality and depth to the principles of human rights contained in that historic document.

4. On the issue of whether the codes adequately considered customary rules and Ethiopian traditional legal institutions, Professor Rene David, the drafter of the Civil Code made the following statements on different occasions. Do you think that these statements are consistent? As stated earlier he said that the code incorporated those customary rules and local traditions. The Professor stated that: 
"the Ethiopian feeling for justice is the basis of the Code. No rule in the Code violates this feeling. The dispositions of the preliminary draft prepared by foreign jurists were rejected or modified whenever they seemed contrary to it even when the foreign advisors considered them useful and advantageous for Ethiopia. The most important accomplishment of the Civil Code in the area of persons, family law, property and delictual liability was clarity, rather than to change the customary rules, to clarify these rules, to distil their essence and to unify them on the basis of those which appeared most reasonable. Our goal was to end an intolerable confusion and uncertainty by choosing the rule most in conformity with the Ethiopian sense of justice and Ethiopians interests, economic and otherwise."

On another occasion, Professor Rene David wrote: "Like the Soviet Union and cocommunist countries, although with another ideal, Ethiopia and a number of African countries are presently in a revolutionary period. While safeguarding certain values to which she remains profoundly attached, Ethiopia wishes to modify her structure completely, even to the way of life of its people. Consequently, Ethiopians do not expect the new code to be work of consolidation, the methodical and clear statement of actual customary rules. They wish it to be a program envisaging a total transformation of society and they demand that for the most part, it set out new rules appropriate for the society they wish to create."

In his view, customary law was not stable, was not really jurisprudential, and differed greatly from place to place. He argued that it was responsible for Ethiopian underdevelopment. Thus, "Ethiopia cannot wait 300 or 500 years to construct in an empirical fashion a system of law which is unique to itself, as was done... by the Romans and the English. The development and modernization of Ethiopia necessitate the adoption of a "ready-made" system; development and modernization force the reception of a foreign system of law in such a manner as to assure as quickly as possible a minimal security in legal relations.

5. Do you think that dualism (existence of modern criminal laws and traditional criminal laws) features the Ethiopian criminal law system? Do you think that traditional criminal laws should be accommodated? To what extent? 
6. State some factors which necessitated the revision of the 1957 Revised Penal Code.

7. Is it sound to conclude that the state criminal law in Ethiopia sought to replace the multiple traditional criminal justice systems, protect feudal and capitalistic relations between 1931 and 974, to primarily safeguard socialist interests between 1975 and 1991, and then back to the protection of individual or capitalist relations after 1991 ? Is it also sound to conclude that the attempt of the state criminal justice system to replace the traditional criminal justice systems has not yet met with success?

8. Do you agree with this: Another point that should not be overlooked is the Penal Code's failure to acknowledge the grave injuries and sufferings caused to women and children by reason of harmful traditional practices. Surely, the Constitution guarantees respect for the cultures of peoples, but it does not buttress up those practices scientifically proven to be harmful. It is also futile to issue a law that does not have the trust and support of the people for it usually remains impracticable. But it is well recognized in the philosophy of criminal legislation that the legislature should by adopting progressive laws at times, educate and guide the public to dissociate itself from harmful traditional practices. ${ }^{3}$

\section{S.2: Customary Laws Versus the Rights of Women in Ethiopia}

In the previous section of this unit, you studied the relationship between customary laws and code in Ethiopia. For several decades, Ethiopia has implemented western styled laws through centralized legal institutions that have aggravated the exclusion of women. The result is that most women continue to be governed by customary or religious laws and practices, which are stagnant, outdated, and constraining. The present section argues that the approach underlying legal reform needs to shift, if law is to be used as an instrument for facilitating sustainable and equitable change for women. Legal reform, in the area of personal relationships, must move away from an approach that involves the top-down imposition of norms considered beneficial for progress (a norms-based approach), and shift toward a more participatory approach that will support a process whereby men and women can have a say in the choice of applicable norms (a process-based approach).

\footnotetext{
${ }^{3}$ Taken from the preamble of the Criminal Code of Ethiopia (Proc. No. 414/2004.
} 
In this section, you should be able to:

- Discuss process-based approach to tackling discriminatory customary practices.

- Discuss norm-based approach to tackling discriminatory customary practices.

- Evaluate the norm-base and process-based approaches to tackling discriminatory customary practices.

Background: In 1960, Emperor Haileselassie introduced a new civil code that radically challenged gender relations under customary laws and ushered in a new legal regime governing personal relationships. Underlying this legal reform was a modernist approach that sought to revise customary laws and impose norms considered universally beneficial and conducive to economic and social development. The new formal legal system attempted to sweep away, with the stroke of an emperor's pen, the complex system of customary laws that had governed the personal lives and relationships of Ethiopians for many centuries. In the other eastern African countries, the colonial powers had hesitated to impose such broad-ranging revisions to customary laws. Nevertheless, they irrevocably and significantly affected gender relationships and customary institutions by regulating access to the most important household resource-land. The role of land was inextricably embedded in the social and economic lives of most communities in these countries, and was radically different from the role it played in the west. Even Emperor Haileselassie's direct challenge to customary institutions through the Civil Code was unable to truly influence customary laws in the way that intervention in land-administration matters did in some other countries. Far-reaching changes in personal laws derived from the introduction of new centralized systems, which replaced the authority of lineages and other similar communal enclaves with the authority of a state-controlled agency. With the advent of colonialism, legal constitutions gradually introduced new norms, centralized legislatures promulgated laws, external authorities such as the police enforced the law, and impersonal agencies such as judges and magistrates interpreted and applied the law. 
The use of law as a tool for social development is nowhere as clear as in the attempts of Emperor Haileselassie. Driven by an urge to modernize his people, he promulgated the Civil Code of Ethiopia in 1960, which attempted to harmonize laws and provide a uniform system of administration. His foreword to the Civil Code explains: "The progress achieved by Ethiopia requires the modernization of the legal framework of Ethiopia's social structure so as to keep pace with the changing circumstances. To consolidate the progress already achieved and to facilitate yet further growth and development, precise detailed rules must be laid down..." The intention was laudable. Before the 1960 Civil Code, each of the diverse ethnic groups within Ethiopia applied its own laws to its own people. Muslims administered the provisions of the Sharia; Christians applied the traditional legal code, or the Feteha Negaast. In Gambella, Beninshanghul, and the southern regions, large numbers of groups practiced customs and traditions different from those of Muslims or Christians. The Civil Code adopted a rigid view of customary laws with the intent of harmonizing the diverse and mostly unwritten customary rules into a set of predictable and written legal provisions. It invalidated customary and religious laws as far as they related to personal matters governed by the Civil Code, and introduced far-reaching changes by imposing norms that were hitherto alien to large sections of the population. Ethiopia's reform went further than in other countries. It adopted a uniform code of personal laws for all Ethiopians, ignoring differences in religious practices. This type of legal reform has eluded many governments, including those in Kenya, Tanzania, or India. In matters related to gender, the Civil Code maintained an interesting dichotomy. On one hand, it gave women economic rights that were far greater than those enjoyed by women in industrialized countries in the 1960s. On the other hand, it preserved the social status of Ethiopian wives as subordinate to their husbands. The Civil Code tried to ensure greater equity in the allocation of economic resources within the typical household. For example, both sons and daughters inherited the property of their parents equally when there was no valid testament. Married women also obtained significant rights to and control over household property. The concept of "common property" was introduced, covering all property that was obtained by either spouse during the marriage.

All property was presumed to be common unless one of the spouses proved that he or she was the sole owner. Salaries of either spouse were also declared to be part of 
common property, and the wage-earning spouse was obliged to account for its use to the other, providing considerable advantage to women in a context in which men were the primary wage earners. The Code gave spouses equal rights to common property both during and at the termination of a valid marriage.

Despite these progressive provisions, the Civil Code explicitly conferred the status of head of the household on the husband. The husband was presumed to be the primary manager or administrator of common household assets and resources. The Civil Code also formally reiterated the culturally ascribed, gender-based division of household labor, requiring women to perform all household duties when the husband could not afford servants. Some of the above-mentioned norms were not necessarily inconsistent with codified laws of the time in other countries. Although the 1960 Civil Code changed a number of discriminatory provisions in Ethiopia's customary laws, dispute-resolution processes were surprisingly kept decentralized and traditional as far as they applied to personal matters. Disputes continued to be settled through the traditional form of arbitration arranged at the request of the disputants, and the Civil Code maintained this mechanism. Each party to the dispute could select his or her arbitrator (shimagele), and the decision was provided jointly by the arbitrators along with a third neutral arbitrator. In the case of marriage-related disputes, the witnesses to the marriage were expected to act as arbitrators. Appeals against the arbitrators' decision were possible in limited cases.

This preservation of the traditional process of dispute resolution ensured that men and women continued to have access to a wide range of methods for resolving their disputes. Maintenance of the traditional dispute-resolution system made implementation of the Civil Code more difficult, however. Although well intentioned, arbitrators in the traditional system were not trained in law and often had little or no knowledge of Civil Code provisions. They continued to apply customary rules to settle disputes, although these were invalid after 1960. In addition, these arbitrators traditionally were respected men who tended to perpetuate customary practices and customs because they were ignorant of or did not appreciate the new norms. The lack of legal literacy among women also meant that women were unable to enforce or enjoy their newly conferred rights. In fact, even at the formal level, there seems to have been an informal understanding of the applicable law. If a case was brought to 
the Sharia courts first (which had authority to settle disputes among members of the Islamic community), the dispute was settled according to the Sharia. If the case was brought before the Civil Courts, Civil Code provisions were applied. The Revised Family Code, which came into force in 2000, has removed provisions in the Civil Code, which discriminated women. (The Revised Family Code applies in Addis Ababa City Administration and Dire Dawa Adminsitrative Council. The following regions have since 2000 have passed their respective family laws, which are compatible with the FDRE Constitution. These regions are: Tigray, Ahamara, Harari, Oromia, and Southern Nations, Nationalities and Peoples` Region,)

The FDRE Constitution and Personal Laws: The Ethiopian experience questions the effectiveness of a centralized legal system to provoke change in personal relationships in contexts where social relationships are not under the control of external authorities. It raises serious doubts about the suitability of imposing norms that are based on a vision of society not shared by those affected by the law, unless preceded by a participatory consensus-building process or accompanied by committed and, perhaps, high-handed methods of implementation. It also demonstrates what has been the experience of many other countries-that addressing selected aspects of substantive discrimination in the law without addressing issues related to the structural aspects of law enforcement and dispute resolution is an ineffective means to legal reform.

In Ethiopia, the law seems to have stepped away from a centralized legal framework in personal matters, an approach that was evident in the 1960 Ethiopian Civil Code and one that characterized the colonial and post-colonial era in other eastern African countries. The new approach complements the ambitious decentralization of administrative, legislative, and executive powers being implemented in these countries, and is in line with traditional legal institutions and processes. A second characteristic is a movement away from the imposition of norms in personal matters and a greater recognition of the validity of differing norms in personal laws. Within this framework exists a clear shift toward greater emphasis and deliberation on the processes rather than on the norms. The focus seems to be on providing transparent and participatory processes through which both men and women can be involved in determining the applicable norms, rather than the prescription of norms by some 
external authority. Ethiopia's Federal Constitution (1995) takes a step away from the 1960 Civil Code that invalidated the application of customary laws to personal matters. Given the difficult and emotionally charged debates on the issue of customary and religious law, the government chose to adopt a process-based approach. It articulated a broad paradigm for gender justice in conventional terms of gender equality. In recognition of religious and cultural diversity, however, the Constitution also adopted a process-based approach to dealing with personal laws. This approach permits parties to settle a dispute related to personal matters by applying customary or personal laws, provided all parties agree. For example, a wife could agree to settle a dispute under customary laws, or she could seek to settle the dispute under the principles of the Civil Code if those customary laws appear unfavorable. This process thus provides a range of options for consideration according to the situation and context within which the disputants reside. It permits women to choose the least-costly option in terms of personal status and standing within the community, and also caters to both the educated elite and to poor rural women.

Merits of the Process-based Approach of the FDRE Constitution: This process-based approach permits a range of norms to be applied to the dispute, and is focused on ensuring that both parties participate in the selection of these norms. It permits women to participate meaningfully in the resolution of their own disputes, and allows them to choose the option that is least costly or damaging in terms of personal status and standing within the community. Through this procedure, the Ethiopian legal system is responding to different women's interests. Most eastern African women live in rural areas and are not necessarily ready to or capable of asserting equality with their male counterparts in any meaningful way; for them, the social costs may simply be too high. Economically independent women, however, may be ready to assert their equality in matters related to the home.

Risks of a Process-based Approach: A purely process-oriented approach would ideally have little influence over the final norms that are selected. The selected norms may therefore not be consistent with the popularly accepted principles of gender justice. Second, a process-based approach, as in Ethiopia, can be gender-sensitive only if women's voices can be heard in the process. Social, historical, and other extraneous factors often discourage the participation of women in these processes-particularly 
rural women. In addition, communities or countries are no longer homogenous groups of tribes or clans that have shared centuries of history and culture. The fear is that the dominant voices will be those of men and that a process-based approach may be used to legitimize a failure to protect women's interests. These risks arise from the fact that women's interests are often not identified or considered in preparing laws. In addition, few groups can represent women, in particular, poor women, effectively.

In the third place, access to information and knowledge is a critical aspect of the process-based approach; all participants must make informed choices based on an understanding of the relevant information. When women in Ethiopia agree to be subject to the application of more discriminatory customary laws and provisions, for example, they should do so with full knowledge of their options. If the process-based approach to customary laws is to succeed effectively and equitably, both men and women need to be fully informed of their choices under Ethiopian law in determining which norms should apply to them. Men alone should not make such critical decisions. In Ethiopia, a process-based approach may entail the risk of not providing women with proper access to relevant information, thereby constraining their search for equity.

\section{Review Questions}

Answer the following questions.

1. Explain a norm-based approach developed to eliminate discriminatory customary practices.

2. Explain the processed-based approach developed to eliminate discriminatory customary practices.

3. Do you think that under a process-based approach discriminatory personal laws might be applied? Why? What about under a norm-based approach?

4. List the demerits of a process-based approach.

5 . What are the merits of a process-based approach?

6. What is the position of the FDRE Constitution in relation to gender insensitive customary laws and practices? Cite provisions.

7. Identify the position of the Ethiopian Civil Code in relation to gender insensitive customary practices. Cite provisions. 
This section, except with a little adjustment, is based on an article entitled "Homicide in Ethiopia..." published by Professor Dolores A. Donovan and Ato Getachew Assefa. We have reproduced this article since it is an instructive one; it vividly describes the relationship between customary laws, state and human rights in Ethiopia. Besides, the article describes four customary practices especially in the area of administration criminal justice.

In this section, you should be able to:

- Describe some customary practices in relation to criminal justice.

- Examine the commitment of the Ethiopian government to customary laws and human rights.

- Evaluate some selected customary practices in the light of modern laws.

- Discuss the point of views of communities in maintaining certain customary practices.

Introduction: Ethiopia enjoys a rich heritage of customary law systems. There are more than sixty such legal systems in Ethiopia, some of them operating quite independently of the formal state legal system. There are two reasons for the relative autonomy of Ethiopia's customary law systems. First is that the state's resources are insufficient to extend the state legal system to every corner of its empire. Second is that the Ethiopian government has a real commitment to the preservation of the customary law systems within its boundaries. The Ethiopian government also has a commitment to establishment of the rule of law in Ethiopia, in the conventional nineteenth-century European meaning of the term. A central attribute of that nineteenth-century European rule-of-law model is the notion of a unitary legal system generating uniform legal rules from a central state authority. Another attribute of that sort of rule of law is the guarantee of protection for individual rights, today better known as human rights.

Tension exists between the Ethiopian government's commitment to the concept of uniform legal rules throughout its territory, including rules protecting human rights, 
and its commitment to preservation of the Ethiopian customary law systems. The Ethiopian Federal Constitution of 1994 guarantees protection for a broad range of human rights, incorporating by reference the major international human rights covenants signed and ratified by the Ethiopian government and repeating, verbatim, the language of the most important rights. The state constitutions tend, on the whole, to mimic the federal constitution in this regard. The customary law systems, however, deviate in at least some ways from the norms set up by the federal and state constitutions. The tension between the customary law systems and the statutory and constitutional norms of the Ethiopian government is most clearly seen in the rules and practices relating to the crime of homicide.

The Federal Penal Code, written in 1957, (now replaced by a new criminal code in 2004), established rules uniformly applicable throughout the geographic confines of the Ethiopian state. Cases of homicide are dealt with by the sixty Ethiopian customary law systems. In such a situation, the classical European goal of total certainty in the law, especially the criminal law, must necessarily be reconsidered. The nineteenthcentury model of uniform legal rules, expressed by code and uniformly applied throughout the country, is not viable in large multicultural nations such as Ethiopia. Ethiopia is a vast and multi-ethnic nation. The modern European-style legal apparatus of the state, established in the mid-20th century, has only recently been extended to the more distant regions of the country. In those regions, the norms of behavior that govern the taking of human life, and the procedures that surround its sanctioning, are not those established by the (1957) Ethiopian Penal Code and the Ethiopian Criminal Procedure Code, but rather the norms and procedures of the ancient customary law systems of the Ethiopian peoples. Even in regions that for more than two thousand years have formed the nucleus of the Ethiopian state, loyalty to customary law norms and procedures continues to frustrate enforcement of the modern criminal law and to fuel dissatisfaction with the government's system of criminal justice.

Some Attributes of Customary Laws: A few generalizations about the customary law of homicide in Ethiopia are in order. First, the typical outcome of customary law homicide procedure is that the slayer is freed by the payment of compensation to the families of the victim. In other words, the slayer does not encounter any loss of liberty as a penalty. Once the amount of compensation is paid out in full, the offender can 
engage himself in day-to-day activity as though nothing has happened. He is not to be put behind the bars as is the case where the written national laws apply.

Second, there are variations as to the amount and mode of payment from one group (culture) to another. The slayer may be required to pay in compensation as many as a couple of hundreds heads of animal beginning with camels down the line to cattle, sheep and goats.

Third, since the amount of compensation to be paid is extremely high, the slayer cannot pay it all by himself. It, therefore, is one of the principles of the law of homicide that the offender will be assisted by his clan, the members of which will contribute as much as they can to the full amount of the compensation fixed as payable. Responsibility for homicide is thus familial rather than individual. Fourth, the amount of compensation to be paid sometimes differs in the event of the homicide of a woman and that of a man. Among peoples adhering to this principle, the life of a woman is compensable with approximately fifty per cent fewer heads of animals than the life of a man.

Homicide in Ethiopia: This topic presents the customary law systems of the Amharas, the Gumuz and the Somalis as they relate to homicide; the behavioral norms of the Amhara people resulting in revenge killings, those of the Gumuz resulting in sorcery and status killings, and those of the Somalis resulting in the forced marriage of female children and the systematic devaluation of the lives of women are examined, as are the responses of the respective customary law systems to these practices.

Revenge Killings Among the Showa Amhara: Many ethnic groups in Ethiopia follow the practice of revenge killing. Traditionally, a homicide by one Amhara against another was to be revenged by the victim's family, not by local authorities and certainly not by the distant royal government. The revenge killing by a male relative of the victim (the blood avenger, or dem-mellash) was, more often than not, directed not against the perpetrator, who had fled to the woods or mountains, but against a member of the perpetrator's family who had nothing to do with the original killing. A male relative of the new victim would then be expected to avenge that victim's death, and a blood feud lasting many years would follow. The man who avenged his family, 
a blood avenger, was seen as fulfilling a moral and social obligation and was honored by his family and by the society in which he lived. These norms of conduct are still adhered to by Amharas in rural settings. The only exits from this vicious cycle were, and at times still are, the conciliation procedures known as erq and shemgelena. Erq, meaning conciliation, and shemgelena, meaning either conciliation or mediation, are terms often used interchangeably to denote settlement of a dispute between families.

The goal of these processes is an end to bloodletting and restoration of peace to the community. Technically speaking, the term erq should be used only when a settlement process is commenced under the authority of the Ethiopian Orthodox Church. Erq commences when an offender who has been in hiding in the forest or in a far-away village decides, for whatever reason, to return to his community to engage in mediation with the family of his victim. Such a return may occur shortly after the initial homicide, or only after many lives have been taken in a blood feud involving all adult male members of the extended families of the victim and the offender. In erq the offender seeks sanctuary in a church and rings the church bell to announce his presence. Clergy and senior members of the church community respond to the sound of the bell by going to the church. The offender then asks their intervention and seeks their services as conciliators.

The next step is the commencement of the erq or shemgelena conciliation process. It should be noted that it is the offender, his family, or the family of the victim that must initiate the process. Unlike modern State criminal justice systems, customary law systems are generally not self-initiating. They must be triggered by the individuals or the families involved. Shemgelena and erq merge with the selection of three to five well-respected members of the community to act as conciliators. These persons, known as shemagles, convene a hearing in a public place, take testimony and hand down a judgment. If a case is brought to shemgelena immediately after the initial wrongful killing occurs, the multiple homicides of family feuds can be averted. Even after family warfare gets underway, it can be brought to a halt by shemgelena. The shemagles are usually elderly men, though younger men and even occasionally a woman have been known to fill this position. A shemgelena proceeding terminates in an order for compensation (guma) to be paid by the offender's family to the family of the victim. The purpose of shemgelena is to restore peace and order to the community, 
not necessarily to punish the individual who perpetrated the crime. The applicable Amharic saying is "Blood dries up through reconciliation." In pre-modern times, the shemagles could authorize the family of the original victim to kill the perpetrator themselves if the perpetrator could not pay the blood money ordered by the shemagles.

Nowadays the only remedy which the shemagles are authorized to impose is the blood money. Examining the shemgelena proceeding from the perspective of modern criminal justice norms, it appears at first glance that the customary law processes are defective. Achievement of the purposes of the criminal sanction, as they are understood in modern western legal systems, is almost wholly absent. A human being has been killed and yet the only response of the customary law is to order the offender's family to pay financial compensation to the victim's family. The family of the killer pays blood money to the victim's family, and the killer walks free. A life has been arbitrarily taken, in violation of the applicable universal human rights norm, and yet the killer is not punished, at least not insofar as the term "punishment" is understood among jurists trained in the civil law and common law traditions.

Where the killing has been a revenge killing, not only does the slayer go free, but he is honored by his family and community for the killing he has committed. Arguably, a criminal sanction in the form of a fine has been imposed, but it has been imposed on the family of the offender(s), not on the individual offender. The deterrent effect of the fine on the specific offender and on the members of the general community is minimal to non-existent. The same minimal to non-existent impact holds true for two other purposes of the criminal sanction: incapacitation and rehabilitation. The precise dispute that was before the shemagles may have been settled, but the killer(s) will kill again, the next time that their Amhara sense of family honor dictates that blood revenge is required. The same is true of other members of the general community whose sense of honor may in the future militate in favor of homicide.

The only function of the criminal sanction that has arguably been served by the customary law settlement proceedings is that of retribution, assuming that the victim's family feels avenged by the receipt of compensation. From the perspective of modern Western criminal law, the Amhara customary law system does not carry its burden of 
preventing its people from arbitrarily taking each other's lives. The result of this customary law proceeding did not and does not satisfy the applicable human rights norms. From the perspective of modern international human rights law, the Ethiopian state that tolerates this system is not carrying its burden of protecting the internationally recognized right to life of its people.

At the end of the first quarter of the 20th century, the modern Ethiopian state began to prosecute homicide in state courts. First in the Ethiopian capital city of Addis Ababa, then in a few regional capitals, criminal prosecutions were brought against the dem-melash, the blood avengers. Blood avengers were convicted and sentenced to imprisonment under the 1957 Ethiopian Penal Code. At first, this state intervention proved ineffective in bringing blood feuds to a halt. The relatives of victims on both sides of the fence did not feel that imprisonment of the killer relieved them from their traditional duty to seek vengeance through homicide. Only the payment of compensation by the killer's family could relieve them of their duty to exact revenge. Thus, for many years the state's imposition of the criminal sanction lacked deterrent effect.

In recent times, however, progress has been made in many Amhara regions: consistent prosecution and punishment of killers on both sides of blood feuds have increasingly proved to be capable of deterring follow-up revenge killings. However, in outlying rural areas, the ethos of private revenge still holds sway. At times the state is still unable to prosecute. At other times, it prosecutes and convicts, but imposition of the criminal sanction proves ineffective to halt the deadly cycle of revenge. Because the relatives of the victim are neither compensated nor reconciled, through shemgelena and erq, with the killer's family, the male relatives of the victim are not freed from their moral and social duty of exacting revenge. Thus, the offender, who in modern terms has paid his debt to society by serving time in jail, is still, on his release, a target for homicidal vengeance at the hands of the relatives of his victim. The blood feud continues.

The Ethiopian state should be applauded for its efforts to bring its people into compliance with modern norms relating to respect for the right to life, but faulted for an overly simplistic approach to the problem. Individual prosecutions and punishment 
are indeed necessary to achieve the specific and general deterrence of homicide required by international human rights norms and the provisions of the Ethiopian Constitution of 1994. On the other hand, the zeal to modernize has resulted in the destruction of traditional practices that were highly effective in their own way. The traditional Amhara erq and shemgelena proceedings were, and probably still are, far more successful than State proceedings in restoring peace to the community as a whole. A culturally sensitive approach to the undesirable Amhara custom of revenge killings, one that preserved the traditional customary law processes, might have saved many lives. It still could.

Sorcery Killings and Adventure Killings Among the Gumuz: Although the Gumuz lands are said to have been part of Ethiopia since recorded human memory, the administrative apparatus of the state was extended to the Gumuz only in the late 19th century, in the time of Menelik II. The Ethiopian state administration was strengthened under Haile Selassie for purposes of collecting tribute and revenue, but not for purposes of settling disputes among the people. Use of the state courts by some of the Gumuz first began in the mid-1970's under the Derg (the military government that deposed Haile Selassie). In 1991, use of the state courts by the Gumuz increased dramatically, for members of the Gumuz ethnic group were hired to act as administrators and interpreters and thus, for the first time, the Gumuz could use their own language.

Still, however, the state courts are used only as a last resort, when settlement under the customary law has failed. Both the Gumuz people and the state administrators prefer that a case should be settled at customary law if possible, for settlements at customary law bring peace, whereas judgments in the state court do not. Further, the Gumuz people present special problems of legal integration because their behavioral norms regarding homicide diverge radically from those of the rest of Ethiopian society. Perhaps it is also for this reason, as well as out of a preference for amicable settlement, that the representatives of the Ethiopian state have tended to cede jurisdiction over these cases to the Gumuz customary law system.

The information about Gumuz behavioral norms relating to homicide and the correlative customary law processes of the Gumuz people is conflicting and unclear. 
Central issues as to which there is a lack of clarity are Gumuz behavioral norms relating to sorcery killings, the procedures employed by Gumuz elders to deal with homicide, and the distinction drawn under Gumuz customary law between killing non-Gumuz people (traditionally permissible) and killing Gumuz people (in general impermissible). Extensive fieldwork by legal anthropologists is required before any informed attempt to incorporate the little-known Gumuz customary law system into Ethiopia's formal legal system can be begun. With these caveats, the information in our possession concerning Gumuz behavioral norms relating to homicide is set forth immediately below. There are three major types of homicide in Gumuz society: 1) the standard killings which are found in every society; 2) status or "adventure" killings; and 3) sorcery killings. Status or adventure killings are directed by the Gumuz against non-Gumuz strangers to their community. These killings seem to be a cross between revenge killings pursuant to a very ancient blood feud and killings for purposes of improving social status. Adventure killings of non-Gumuz men are not penalized nor dealt with in any way by the Gumuz customary law system. In fact, such killings are tacitly encouraged as proof of manhood and status as a warrior. Sorcery killings occur when a group's Gafia, who is a sort of priest, healer and witch doctor combined, identifies a person as a witch who has caused the death of one of his patients. The male members of the deceased's family are then expected to kill the witch. All homicides except sorcery killings can trigger revenge killings and a subsequent blood feud between the families or clans involved. Sorcery killings do not trigger revenge killings because they are accepted as justified even by the family of the murdered "witch."

Settlement of intra-Gumuz family feuds generated by homicide is done by elected or appointed "go-betweens" or conciliators who arrange a settlement and then pronounce it before the assembled male members of the families or clans involved. The settlement procedure is commenced at the request of one of the families involved. As in the case of the Amhara, the elders of the community do not themselves initiate proceedings. They wait for a request for intervention from a member of the families involved. The procedure for settlement varies according to the social or relational distance between the killer and his victim. If the killer and his victim are members of the same family, the matter will generally be dropped. No request will be made to the elders for initiation of settlement proceedings. Statements from Gumuz informants are 
in conflict as to procedures where the killer and his victim are from different families. One version, probably the most reliable, has it that compensation must be arranged. Non-Gumuz sources of information have stated that if the killer and his victim are from different families, the conciliators will arrange a payment of compensation in the form of cattle and the banishment of the killer for five years. If a cycle of revenge killing has commenced and the number of deaths is unequal, the go-betweens will usually arrange for the side with the fewer deaths to give a young girl and three cattle to the other family. It is not clear whether the girl is intended for marriage, thereby serving to conciliate the warring families, whether she is viewed merely as an item of valuable property, or both.

The weight of authority among our sources indicates that the Gumuz customary law mechanisms for dealing with intentional homicide are similar to those of the Showa Amhara. As in the Amhara system, compensation is paid by the family or clan of the offender to the family or clan of the victim. Thus, criminal responsibility is seen as collective rather than individual. The offender, as in the Amhara system, goes free.

If the Gumuz procedure is indeed similar to the Amhara procedure in these respects, the Ethiopian representatives of the modern state would do well to learn from the Amhara experience. Substitution of a state legal process designed to impose criminal punishment on the individual offender will not necessarily end the cycle of revenge killings.

\section{Review Questions}

Answer the following questions.

1. Can you draw the distinctions between criminal justice system under customary law systems and under the modern system?

2. Can you tell the perspectives behind the customary practices of revenge killing, status killing, and witch killing and devaluation of women's lives discussed in the first part of this section?

3. Has the Ethiopian government taken concrete steps with the view to eliminating the customary practices discussed in the section?

4. Discuss the common attributes of the customary practices discussed above. 
5. State five justifications why the Ethiopian government is currently constitutionally committed to the recognition of certain customary law systems in its territory.

6. At present, there are sufficient reasons why the Ethiopian government cannot recognize every customary law systems that exist in its territory. Argue for or against the idea of this statement.

7. State the reasons why the Ethiopian government has opted for the co-existence of human rights and customary law systems.

8. Article 9 (1) of the FDRE Constitution states in part that 'Any law or customary practice...that contravenes with this Constitution shall have no effect. 'Article 91 (1) of the same provides that 'Government shall have the duty to support, on the basis of equality, the growth and the enrichment of cultures and traditions that are compatible with fundamental rights, human dignity, democratic norms and ideals, and the provisions of the Constitution. 'Give a comprehensive comment on these provisions.

9 Ato Abebe Hailu is a teacher in an elementary School in Debre Markos town. He has been living happily with his wife Taitu Yilma and their 3 years old daughter in a house he built a few months ago. One Monday evening (Jan. 13, 2002), he came home with candies and chewing gums eager to see his daughter's face filled with smile and joy when she finds out what her dad has brought her. He arrived home and started calling his daughter's name. But there was no sign of Bethelehem anywhere. When he entered his bedroom he found his daughter lying on the bed and part of her dress stained with blood. He could not believe his eyes and started shouting. His wife came in and asked him what the problem was. Then she told him that Bethelehem was circumcised at 2:00 p.m. that afternoon according to the custom of the area. She further said that W/o Kebebush Tesema, the woman who performed the circumcision has also said that the ritual will make Bethelehem a disciplined and respected girl. Some neighbors of his also told him that they have witnessed the circumcision not only of his daughter but also of their own daughters and further said they were proud of that. They also admitted that they have helped W/o Kebebush by holding the child's legs and hands.

However, Abebe, so upset with what happened to his daughter, went to the police station of the town and accused his wife, W/o Kebebush and the three neighbors. The chief 
police officer finalized the investigation and sent the file to the public prosecutor of the Zone. Comment. ${ }^{4}$

Sentencing Practices Among the Somali: Although the homicide settlement proceedings of the Somalis are highly developed and give rise to many of the same issues as those of the Amharas, it is the sentencing process that we have chosen to address. Discrimination against women is built into the structure of Somali culture and Somali criminal sentencing. The Somalis are, on the whole, Muslims, and themselves attribute certain of the discriminatory aspects of their legal system to their Islamic religion. The Somali people live in the Eastern outlying regions of Ethiopia. They are, by tradition, mainly pastoralists. Their traditional legal system is very highly developed. The degree of penetration of modern Ethiopian written state legal norms into Somali legal culture is minimal. Although the central Ethiopian government purports to apply its laws, including the Penal Code of 1957, to the Somali Region, and has provided the Somali region with a regional government, regional courts, and regional police, the courts are few and far between, the police stations exist only in regional centers, inaccessible to all but the wealthy few, and both the courts and the police are woefully understaffed. Further, a significant percentage of the civil servants who staffed these institutions in the past were not of ethnic Somali origin. The traditional Somali customary law system, in contrast to the formal legal system of the modern Ethiopian state, is fully staffed, by Somalis, and easily accessible to all. In short, the Somali people see no reason to replace their own sophisticated customary law system with the, to them, dysfunctional legal system of the modern Ethiopian state. The stark contrast between the efficiency, accessibility, and staffing of the two systems and the relative satisfaction of the Somali people with their own customary law has in no small part contributed to the current delegitimation of the national and regional state legal systems.

The sophistication of Somali customary law is seen in its two-tiered system and its clearly articulated subject-matter divisions. The elaborate customary law of the Somalis, known as xeer, is categorized as Xeer Donimo and Xeer Dulnimo. Xeer Donimo regulates the rights and responsibilities of particularized subsets, such as

\footnotetext{
${ }^{4}$ This case was taken from an exam prepared by Ato Gebreamlak G/Girogis in 2005 for students Legal Ethics at the Faculty of Law, Ethiopian Civil Service College (on file with the authors)
} 
clans of the Somali people, governs relationships within the clan, and regulates quasicontractual relationships between neighboring clans on such matters as allocation of shared natural resources. Xeer Donimo binds only that group of persons which has created it. Xeer Donimo is said to be dynamic and changing from time to time. Xeer Dulnimo, on the other hand, consists of the rules that apply to the whole Somali people. Thus, the rules applicable to homicide (dil), moral injury (dalliil) and bodily injury (qoon) are to be found in Xeer Dulnimo. And the corresponding compensations or blood money payments, respectively, are mag (or the Arabic loan-word "diya"), qoomaal and haal. The compensation scheme, which is the sentencing for the crime, is not a compensation paid to the victim per se but to the whole of the group on the side of the victim, which includes a kinship network far greater than the nuclear family. In the final analysis the victim's nuclear family gets only a third of the blood money (mug) that is paid. This is because the Somalis, being a highly communal society, view crime, even homicide, as their communal responsibility.

As previously stated, the Somali people are, on the whole, Muslim. Whether rightly or wrongly, most believe that their sentencing practices derive from Islam in general and the Shari'a in particular, modified by the Somali customary law, known as xeer (pronounced heer). Some of these sentencing practices are predicated on the premise that the value of a woman's life is less than that of a man. Whether due to religious indoctrination or to the socio-economic conditions of nomadic pastoralism, the devaluation of the lives of women is endemic in Somali culture.

For example, the unwritten rule establishing the relative values of male and female lives is that the murder of a man is compensated by one hundred camels; the murder of a woman by fifty camels. The lower value and status of women is seen in compensation practices that view women as a form of property. For example, in cases where a confessed or convicted killer does not have enough livestock to pay the compensation ordered, one of his sisters or daughters may be taken from his family and given as wife to a victim's family. In many cases the rate of payment is governed by contracts between clans. Thus, the rate of payment stated above does not apply across the board. According to I. M. Lewis, in the case of homicide between a male member of the Gadabuursi (a clan that lives in Northern Somalia and Ethiopia) and a member of the Iisse (a clan that also lives in North ex-Somalia, Ethiopia and 
Djibouti), the compensation to be paid, agreed upon by xeer between them, is 10 female camels, 100 sheep and goats and one nubile girl fitted out for marriage with all her household equipment. This practice has the dual benefit of transferring an item of value (the woman) and uniting the warring families by marriage, thereby hopefully minimizing the likelihood of a recurrence of conflict.

The question is whether replacement of the Somali customary law processes by the state legal system, with its statutorily non-discriminatory Ethiopian Penal Code, Criminal Procedure Code, and Constitution, is even possible. It is not likely that the Ethiopian state legal system will replace the Somali customary law system in the near or even not-so- near future. This is not for lack of effort on the part of the Ethiopian state. The Regional Government of the (Ethiopian) Somali Region is at present doing its best to create and extend the regional legal system in a form identical to that of the federal legal system. The fact that the few and far- between courts in the Regional Somali State apply the national laws of Ethiopia without concession to the Somali customary law speaks loudly to this effect. Nor has the Regional Government's recent ratification of a regional constitution which, on the fundamental points, is a replica of the Ethiopian Federal Constitution of 1994 done anything to solve the underlying policy problems in the area.

To the contrary, these efforts by the Ethiopian state to enforce legal uniformity under the authority of the central government may actually have widened the schism between the two legal systems. With respect to resistance to State legal authority, functionaries in both the state and traditional customary legal systems in the Somali Region have reported that the vast majority of crimes, including homicide, are dealt with by the customary law systems. Most of these cases never reach the formal court system. One observer has even reported that after arrest by the state of a suspected killer, the Somali traditional authorities proceed to settlement of the homicide by traditional customary law processes, order payment of compensation as determined by traditional processes, then contact the local state courts and suggest the dismissal of charges against the arrested suspected killer on the grounds that the case has been settled. It has been further reported that in at least some such cases that had been settled at customary law, the formal state charges were dropped by the Ethiopian courts. Likewise, reports have been received that even after a Somali man has been 
tried, convicted and sentenced to prison, his family and that of the victim do not view the matter as settled. Their expectation is that the customary law authorities must investigate the case and order the payment of blood money (mag), otherwise the cycle of revenge killings will commence and spiral into clan warfare.

Human rights and the customary laws: The question is whether a nation-state may tolerate customary law systems that condone such practices without running afoul of international law. As we have seen, the Amhara customary law system has traditionally turned a blind eye to the taking of life by private persons for the purpose of revenge - a purpose that a modern criminal justice system would deem illegitimate. The Gumuz customary law system turns a blind eye to sorcery killings and also occasionally even to killings done to achieve status or manhood. The Somali customary law system endorses sentencing practices based on the institutional devaluation of the lives of women and the personhood of female children.

In the case of revenge killings, the relevant Amhara customary law system does not seek to halt revenge killings, but rather responds, on request, to petitions for intervention from the affected families.

The purposes and goals of the response are different from those of a modern criminal justice system. The customary law purpose is to achieve settlement by payment of compensation between feuding families or clans. The customary law goal is restoration of peace to the community by effectuation of a reconciliation between the warring families or, where only one death has occurred, between the family of the victim and that of the offender. In the case of sorcery and adventure killings, the Gumuz customary law system does not respond at all, for such killings are viewed as justified. In the case of sentencing practices that de-value the lives and human dignity of women and children, the Somali customary law system incorporates and affirmatively endorses the offending practices. The failure of the Amhara and Gumuz customary law systems to prosecute, respectively, revenge killings and sorcery and adventure killings places at risk the right to life of Ethiopian citizens. The use of compensation rather than incarceration also arguably places at risk the right to life of Ethiopian citizens. The sentencing practices endorsed by the Somali customary law systems violate the right of Ethiopian women to equal treatment under the law, and 
the right of Ethiopian female children not to be forced into marriage. All of these rights are protected by the Ethiopian Constitution and international human rights law.

The Ethiopian Constitution of 1994 guarantees protection for virtually all human rights recognized under international law. In many cases the constitutional language is almost identical to the international human rights instruments to which Ethiopia is a signatory. The question then is three-fold: 1) why the excellent Ethiopian law on the books is not followed by the local authorities who administer customary law systems; 2) whether the modern Ethiopian state has the duty to correct the faulty human rights practices of the customary law systems within its borders; and 3) if so, how. As to the first question, the answers are multiple. First, many community elders are illiterate and hence unaware of the contents of the Constitution. Even were such local authorities to know of the existence of an Ethiopian Constitution requiring them to protect the notions of human rights contained therein, they would feel no obligation to obey it. Their primary loyalty is to their own people--the Somalis.

Third, many of these community and clan elders are suffering from divided loyalties. On the one hand, they are loyal to the modern Ethiopian state, but on the other they are loyal to the traditions of their people. In practice these divided loyalties often mean implementation of their own systems of familiar and local customary law rather than the abstract legal principles of the distant Ethiopian state. Fourth and finally, the customary law authorities, were the matter to be fully explained to them, might well take the position that the concept of human rights is a Western invention that has no place in and is destructive of the culture of which they are a part.

Cultural universalism and Particularism: The tension between universalist conceptions of human rights and the particularistic doctrine of cultural relativism complicates the melding of modern and traditional legal systems the world over. Cultural relativism is the doctrine that holds that moral rules and social institutions evidence a high degree of cultural and historical variability and that "(at least some) such variations are exempt from legitimate criticism by outsiders. The extreme statement of the culturally relativist position is that culture is the sole source of the validity of a moral right or rule. The radically universalistic position is that culture is irrelevant to the validity of moral rights and rules, which are universally valid. Legal scholars of international 
human rights law tend to fall into the universalistic camp; cultural anthropologists into the relativist camp. Government officials of modernizing nations such as Ethiopia typically eschew the luxury of either sort of extremism, opting instead for pragmatism. Charged with implementing the legal system of their country in a way that at once commands the respect of the international community and the allegiance of the traditionalist elements of their populations, they must strike a balance between the two extremes.

In the past few decades, increasing awareness of significant cultural variations in notions of rights has emerged among scholars in both the legal and anthropological fields. Efforts have been made to find functional analogues to western notions of rights in the incontrovertible fact that all cultures, including those without an indigenous concept of rights, have conceptions of morality, justice and human dignity that in practice work to achieve much the same social goals as does the concept of rights in the west. Further efforts have been undertaken to fuse such culturally diverse notions of human dignity with those of rights to establish a new grounding for claims of universalism. A related group of scholars has focused on the role of the state in those societies in which indigenous, customary-law- based notions of rights are absent. This latter group warns of the danger of self-serving state reliance on the absence of rights in a traditional culture both to justify state repression of the citizens of the culture in issue and also to legitimate the arbitrary exercise of state power.

Generalizations regarding traditional Ethiopian notions of rights are risky in view of the extreme ethnic, religious and linguistic diversity of the country. Reasoning by analogy from other African cultures is even more fraught with peril due to Ethiopia's unique stature as the oldest continuing nation in sub-Saharan Africa and the only nation never successfully colonized. Nonetheless, it is probably safe to conclude that the following broad generalizations by African scholars apply to the traditional Amhara, Gumuz and Somali social and legal systems described above. The first of these generalizations is that traditional African values include universalistic concepts such as humanity, respect and dignity. The second is that concrete expression of these values is usually found in and circumscribed by the extended family and tribal or clan affiliations. A third is that equal rights for all have not existed; rather rights and obligations were defined in interpersonal terms contingent on one's position within the 
kinship and tribal system. "The person was not a rational atomized individual in pursuit of his self-interest as in the West, but one enmeshed in multiple cross-linking, interpersonal relationships over laden by the spirit of his ancestors. These traditional African values, though different in emphasis, have much in common with the values articulated in modern African constitutions, including that of Ethiopia.

On the theoretical level, linking traditional notions of human dignity with the modern Ethiopian constitutional provisions relating to the right to life does not pose a problem. The problems arise when deeply-entrenched customs based on the older communitarian concept of the individual having no meaningful existence apart from his or her community are rejected or by-passed by the state in favor of modern practices based on the western notion of the atomized individual. This conflict is seen in the current relationship between the customary law's manner of dealing with homicide through familial compensation and reconciliation and the modern state's insistence on individual culpability, responsibility and punishment. The two legal systems are ships passing in the night. The customary law norms of familial reconciliation and compensation are deeply entrenched in the hearts and souls of a large percentage of Ethiopia's people. The modern state's attempt to substitute an ethic of individual culpability and individualized punishment for the more group-oriented procedures of traditional Ethiopian culture cannot succeed unless these older norms are accommodated.

Problems also arise when the attempt is made to reconcile traditional values relating to women and female children with the provisions of the modern Ethiopian constitution. In Ethiopia, as in many different parts of the world, there is continuing resistance to international human rights provisions relating to the rights of women. Today, more than half a century after the adoption of the Universal Declaration of Human Rights, the entire Declaration has still not achieved the status of binding international customary law, and the primary reason is resistance to the provisions relating to women. The provisions relating to the personal and family lives of individuals have failed to achieve universal acceptance because these matters have traditionally been covered by religious law and still are in many countries, including, as we have seen, in the Somali Region of Ethiopia. 
Acceptance. Fundamental, non-derogable rights such as the right to life, the right against torture, and the right not to be enslaved have achieved almost universal acceptance. The rights of women and children have not. It is against this contentious backdrop that the following question must be asked: does the Ethiopian state have the duty of correcting the faulty human rights practices of the customary law systems within its borders? The answer to this second question is far more difficult to come at than was the answer to the first. A threshold question is whether the language and theory of human rights is properly applied to the question of whether the state has a duty to act to prevent situations such as revenge killings among the Amharas or sorcery and status killings among the Gumuz.

Classic nineteenth-century western liberal democratic theory, of the sort still prevalent in the United States and the United Kingdom, would have it that the human rights theory has no place in such scenarios, for it is not the state that is arbitrarily taking the lives of its citizens. From this point of view, human rights are "negative," in the sense that rights can be realized only as claims against state action that infringes them. If it is not the state that is engaging in revenge killings or exploiting children, then no human rights have been violated.

A more modern perspective would have it that human rights are positive in the sense that a state bears the burden of creating conditions that enable its citizens to realize their human rights. The drafters of the International Covenant on Civil and Political Rights have taken the more modern position. ". . .[E]ach State Party to the present Covenant undertakes to take the necessary steps, in accordance with its constitutional processes and with the provisions of the present Covenant to adopt such measures as may be necessary to give effect to the rights recognized in the present Covenant." Further, "[e]ach State Party to the present Covenant undertakes to respect and to ensure to all individuals within its territory and subject to its jurisdiction the rights recognized in the present Covenant, without distinction of any kind, such as race, color, sex, language, religion, political or other opinion, national or social origin, property, birth or other status."

The plain language of the ICCPR is reinforced by the commentaries on the drafts of the relevant articles. According to these commentaries, the right to life, as guaranteed 
in article, 6(1), should not be understood as a claim to forbearance by the state, but rather as a provision requiring States Parties to protect life on the horizontal level (between citizens) as well as on the vertical (between citizen and state). For example, if a country were to grant impunity from prosecution for the crimes of murder and manslaughter, this would be a manifest violation of the state duty of protection pursuant to Art. 6(1).

Acknowledgment of the right of minority groups to cultural self-determination is necessary at this point. Although there is no need to deal with the complicated question of whether the Amharas, or the Gumuz, or the Somalis of Ethiopia constitute a "people" under international law, each of them surely have a right to preservation of their culture. All peoples have the right to self-determination. By virtue of that right they freely determine their political status and freely pursue their economic, cultural and social development. However, in this the 21st Century, cultural preservation and development is not, anywhere in the world, understood to justify the arbitrary taking of human life.

Unfortunately, the same cannot be said of forced marriage of children or systematic de-valuation of the lives of women, although these latter practices are also increasingly falling into ill-repute among the community of nations. Whether the reasons for this increasing governmental acceptance of international human rights norms be a desire to better the human condition or a desire to obtain foreign aid, the outcome is the same--the concepts of human rights contained in the standard international human rights covenants and treaties are everywhere increasingly accepted or given lip service. The state duty to protect the right to life of its citizens is not just a matter of legal interpretation of international human rights covenants. It is also a matter of realpolitik. To maintain its standing in the international community of nations, a modern state is not well-advised to tolerate the existence within its borders of customary law norms endorsing the arbitrary taking of life. The same is true, to a lesser extent, of tolerance of customary law norms endorsing the forced marriage of children and systematic de-valuation of the lives of women. These propositions have particular force where the state in question has, like Ethiopia, signed international protocols outlawing the arbitrary taking of life, discrimination on the basis of sex and the exploitation of children. 
The question addressed immediately above--whether the state has the duty to correct the faulty human rights practices of the customary law systems within its borders--is not the legalistic one of whether the state can be held legally responsible for genderbased discrimination carried out by customary law systems within its borders. Nor is it the question of whether the state can be held legally responsible for arbitrary deprivations of life resulting from its tolerance of customary law systems within its borders. Rather the question is normative in nature: should a state attempt to correct the faulty human rights practices of the customary law systems within its borders. Where the state in question has publicly and formally subscribed to or guaranteed the protection of the human rights in question, the answer must be yes. This is so even when a state is, like Ethiopia, officially committed to protection of its customary law systems and to legal pluralism, thus adjusting the values expressed by these rights.

Customary Laws under a Federal System: Ethiopia's adoption of a system of ethnic federalism requires resolution of two related matters. The first is whether the duty of the federal and state governments to establish and maintain the rule of law, including but not limited to the human rights guarantees contained within the federal constitution, mandates the elimination of all customary law systems existing within the state's boundaries. The second is whether adjusting the state's formal legal structure so as to accommodate the well-established and influential customary law systems found throughout Ethiopia will be detrimental to the establishment and consolidation of state power. With respect to the first matter, the answer is no--the rule of law does not necessarily mean the elimination of customary law systems. In Ethiopia the customary law systems currently share with the state legal system the duty to protect the lives and property of Ethiopian citizens. So long as the customary systems conform to minimum standards of human rights protection, there is no reason in law, domestic or international, to complain of the sharing of law enforcement responsibility and jurisdiction between the state and the customary law system. The present sharing of responsibility evolved historically and currently is done in an ad hoc manner. If the State does reach a considered decision formally to share jurisdiction with the customary law systems "within its borders and subject to its jurisdiction" then it must likewise develop considered techniques for monitoring the performance of the customary law systems to ensure that they are providing adequate 
protection for the human rights of Ethiopian citizens. The minimal standard for adequate protection of the human rights of Ethiopian citizens would be protection for those rights contained in the international human rights covenants to which Ethiopia is signatory. If it comes to the State's attention that one or more of the customary law systems with which shares jurisdiction is performing in such a way as to violate one or more provisions of those covenants, then the State must take steps to cure the $\operatorname{defect}(\mathrm{s})$.

The treatment of homicide in the Amhara, Gumuz and Somali customary law systems is no secret. Nor is it a secret that these systems are not, with respect to certain types of homicides, providing adequate protection for the human rights of Ethiopian citizens. The men and women who comprise the Ethiopian state are well aware of these facts. The Ethiopian state is therefore responsible for upgrading these systems to provide the necessary human rights protection. However, the limited resources of the Ethiopian state are such that an aggressive and well-financed nationwide campaign to eliminate all human rights abuses from the customary law systems is not possible. Selective strategies for gradual alteration of abusive practices are required, as is an ordering of priorities. In this regard, lessons may be learned from the experience of other nations.

In Latin America, a strategy of ranking human rights, designed to mediate the tension between international human rights norms and customary law proceedings, has been developed. This view takes issue with the position that all internationally recognized human rights must be upheld without reservation. Instead, the claim is that the need for protection of cultural minorities and local self-rule renders such across-the-board enforcement impossible. The better view, say the advocates of this position, is to focus enforcement efforts on the most fundamental rights, such as the right to life, the right against torture and the right not to be enslaved, and relegate enforcement of other rights to the back burner. Such an approach is arguably consistent with the ranking of human rights implied by the concept of derogation contained in the International Covenant of Political and Civil Rights.

Applied to Ethiopia, the ranking of rights would have more to do with operational strategy than procedural reform. The Ethiopian government has declared a state policy 
of establishing the rule of law, including the protection of human rights, in all corners of its country. The problem for the government is two-fold: lack of resources, human and financial, necessary to implement that state policy and the quandary posed by the need to maintain and extend state power while affording maximum autonomy, in the interests of political stability, to marginally assimilated ethnic groups. The ranking of rights would permit the Ethiopian government to develop a coherent plan of enforcement, directing its scarce prosecutorial and judicial resources where they are most needed. Although reasonable persons may disagree as to the proper ordering of priorities, it seems likely that the Ethiopian government would conclude that governmental initiatives designed to protect the right to life of Ethiopian citizens in the Amhara, Gumuz and Somali regions should receive a higher priority than initiatives designed to eradicate discrimination against women. Under this scenario, state prosecutions of revenge, sorcery and adventure killers would receive a higher priority than prosecution of persons involved in ordering and implementing inclusion of young girls in settlement packages (a form of kidnap or false imprisonment violating international and Ethiopian constitutional prohibitions against involuntary servitude). The Somali practice of valuing a woman's life as less than that of a man in homicide sentencing would be the last to receive state attention.

This practice of valuing women's lives as less than that of men is perhaps best reached by a state educational campaign rather than through the criminal justice system. Without further field work, it is difficult to know how deeply these sentencing practices that discriminate against women are embedded in Somali culture and consequently how amenable Somali elders may be to change at the behest of the modern state. On the one hand, a change in sentencing practices to eliminate discrimination against women would seem to be a minor procedural adjustment, easily accomplished. On the other hand, matters relating to the status of women relative to men are at the heart of the social structure of any society and thus not usually easily altered. Further, in the Somali case, local beliefs as to the dictates of Islam are no doubt at least partially responsible for the lower status of women. As has been seen in other Islamic societies such as Iran and Afghanistan, Islam can be twisted into a potent force for the oppression of women. The influence of Islam in general and the Sharia in particular on the customary law traditions of the Muslim peoples of Ethiopia is a field ripe for investigation. 
The second issue is whether the establishment and consolidation of state power would be impeded by adjusting the state's formal legal structure to accommodate the wellestablished and influential customary law systems found throughout Ethiopia. The question is not academic. Ethiopia is still in the early stages of re-constituting itself as a federation of states. One of its regions, Eritrea, has already seceded. The traditional European political and legal view is that state power and coercion may be exercised only through a unitary formal legal system. The underlying premise is that permitting to any other system the use of authoritative coercion flies in the face of the concept of the nation-state and is destructive of state power. According to this view, it would be an act of folly for a state such as Ethiopia, still struggling to establish its authority over its outlying regions, to permit its citizens to recognize any source of authority other than that of the centralized government. The thesis of this article is to the contrary. This article advocates a vigorous federal system with significant autonomy and power, both executive, legislative and judicial, at the local level.

Authority at the local level would be exercised both by the representatives of the state (regional) governments and by the representatives of the customary law systems present in the region. The underlying premise is that, in a multi-ethnic and multicultural society, provision of significant autonomy at the local level is not only necessary to prevent dissatisfaction with the central government but actually strengthens the government in the eyes of its citizens. The 1994 Constitution of the Federal Democratic Republic of Ethiopia provides the framework for such a system; what is missing is the necessary enabling legislation.

In favor of formal state recognition of customary law systems is the argument that statutory recognition of legal pluralism, if done correctly, can strengthen rather than weaken state power. The Ethiopian customary law systems are real and their power over the behavior of Ethiopian citizens is a fact of life in Ethiopia. To ignore these facts is the equivalent of the ostrich's putting its head in the sand. Statutory legal pluralism in Ethiopia could actually advance the establishment and consolidation of state power because recognition and incorporation of the ancient and widely-accepted sources of authority that are the customary law systems legitimates the new federal state and its formal legal system. The state can eliminate challenges to its authority by 
entering into statutory arrangements making operation of the customary law systems conditional on its permission and approval.

\section{Review Questions}

\section{Part I. Multiple-choice questions}

1. One of the following statement (s) is sound about the obligation of the Ethiopian state in respect of customary laws.

A) The state is constitutionally obliged to eliminate certain customary laws that offend human rights, democratic rights and human dignity.

B) He state is constitutionally obliged to support some customary laws consistent with human rights, democratic rights and human dignity.

C) The state does not have any constitutional obligation towards customary laws at all.

D) The state satisfies its obligations in relation to customary laws if it simply tolerates some of them, without any assistance.

E) $\mathrm{A} \& \mathrm{~B}$.

F) None of the above.

2. Recognition of some customary laws is important for the following reasons.

A) It enables the state to obtain legitimacy.

B) Recognition of useful customary laws is consistent with the saying: "If not broken do not mend it!".

C) Recognition of useful customary laws has a value in itself, as customary laws are aspects of the cultures of a community.

D) Recognition of customary laws can reduce the costs of the administration of justice by the state.

E) Recognition of certain customary practices can maintain community harmony and compromise.

F) All of the above.

\section{Part II. Answer the following questions.}

1. Is the Ethiopian government committed to customary laws systems and human rights at the same time? 
2. What are the possible reasons why the Ethiopian government is committed to human rights and the rule of law?

3. What are the possible reasons why the Ethiopian government is committed to customary laws systems?

4. Do you think that there is any theoretical tension between the commitment of the Ethiopian government to human rights and customary law systems at the same time?

5. Do the authors argue for the entire elimination of these practices immediately, i.e., revenge killing, status killing, witch killing and devaluation of women's lives?

6. Discuss the ranking of human rights and its relevance to the recognition of customary law systems.

\section{3: More on the Customary Dispute Resolution Mechanisms in Ethiopia}

The present section is set out to describe customary dispute settlement mechanisms in Ethiopia. It also aims at evaluating these dispute resolution methods; and it identifies and explains the key share denominators of customary dispute settlement mechanisms prevalent in Ethiopia. The materials in this section are taken from "Grass-roots Justice in Ethiopia: The Contributions of Customary Dispute Resolution, “ a book edited with excellent introductory and conclusion and recommendations chapters, by Alula Pankhurst and Getachew Assefa.

At the end of this section, you should be able to:

- Describe customary dispute resolution methods of some ethnic groups in Ethiopia

- Assess the merits and demerits of traditional dispute settlement mechanisms

- Identify share common elements of customary dispute settlements methods in Ethiopia.

Oromia Region and Southern Nations and Nationalities Peoples' Region ${ }^{5}$

\subsubsection{Oromia}

In a dispute one must either settle it or make haste to get safely away

\footnotetext{
${ }^{5}$ Alula Pankhurst and Getachew Assefa, Id., 24-38
} 
As long as fire stays in one's breast it does not cool down

Oromo sayings (Sumner 1995:200)

The State of Oromia is the largest of all the states of the Ethiopian Federation with an area of $353,690 \mathrm{~km}$. According to the 1994 Census, the population of the State amounted to about 20 million, and by $2.7 \%$ estimated annual growth rate, the estimate for 2008 stands at about $27,500,000$.

Oromo society is very rich and diverse in culture, history and legal traditions. Many types of CDR abound in the society. There are considerable regional variations within the Oromo society regarding types of dispute settlement. However, the various systems have some basic similarities in terms of who settles the disputes, the jurisdiction of the dispute settlers and the attitude of the society towards these systems. The most important reason for the relationship among the various CDR systems in Oromo society is their common origin which is the Gadaa cultural framework. The CDR systems now in operation within the diverse geo-cultural clusters of the Oromo society are offshoots of the former, developed under the influence of time since the Oromo migrations from the $16^{\text {th }}$ century, their relations with neighbouring groups, and changes in their way of life, economy, political, religious and cultural and social relations.

\section{CDR institutions}

The three major CDR Systems in Oromo society are: 1) the judicial (dispute settlement) aspect of Gadaa, 2) the Jaarsa Biyyaa (also known as Jaarsaa Araaraa or Jaarsumaa), 3) the Qallu spiritual leaders and their transformations into spirit-medium mediators. In additional regional institutions have developed such as the Allo Arssi Council and in contexts of interethnic relations funerary associations known as Qire in Wellega have taken on some dispute resolution roles.

Gadaa age-graded assemblies 
The gadaa has been portrayed as a egalitarian system of governance in which in every eight years one generation set (Luuba), consisting of a segment of one-fifth of the men of the same generation, becomes responsible for maintaining the Peace of the Boran through prayer and sacrifice. The Gadaa consists of a series of elaborate rules and rituals, and a number of Gadaa officials are appointed every eight years to act as arbitrators, law makers and ritual leaders. It has become a key word' and 'social ideology' of Oromo society. There has been some controversy as to the extent to which Gadaa has been a political institution rather than primarily a cultural and spiritual one and whether this has changed over time (Baxter and Almagor 1978). However, there is agreement that it plays a key role in integrating clans, promoting peace, and mediating between human and divine worlds (Baxter 2005:633-5, Bassi 1996). Moreover, the gumi gaayo 'meeting of the multitude', held every eight years provides the context for promulgating, adapting or repealing the seera law and aadaa customs. Furthermore the ritual calendar allows for meetings and provides an organisational capacity which provides a context for dispute settlement (Nicolas 2006).

\section{Judicial Process}

Clansmen are expected to settle their disputes amicably at clan meetings. Household heads can take part and air their views. However, age, experience and the ability to speak in public are respected. Decisions are taken by consensus, and reference is constantly made to the body of customary law called Aadaa Borana. Decisions and fines are made by councils or assemblies. If a consensus decision is impossible, or one of the parties does not accept the decision, then the case can be passed to a clan assembly, Kora Gossa. If the matter is not settled here, it goes to the highest level. The ultimate assembly of appeal is the assembly of all Boran (Gumi Gaayo) held every eight years at Gayu. However, most matters very rarely reach this level and are generally resolved by councils based on locality (kora olaa, kora deeda) or kinship (kora gossa). Inter-clan matters are resolved by the gadaa and qallu councils (yaa'a gadaa, yaa'a qallu). The councils rely largely on persuasion and the rhetorical threat of sanctions including fines and corporal punishments which, however, are not usually implemented. The ultimate sanction is exclusion from the Nagaa Boran, 'the peace of the Boran', such that the person will not be greeted or blessed and will not receive 
social and ritual support and may be cursed (abarsa). However, admission of guilt and the public humiliation of asking forgiveness involving using ritual formulas and or/riducule can lead to the sentence being reduced or even waved (Baxter 1978, Hogg 1993, Bassi 1994, 1996).

Dinsa (1975) documented that criminal and civil wrongs are punishable pursuant to the provisions of the Sera caffee (the law passed by the general assembly that serves as a legislative body). Depending on the gravity of the offences, the punishments include death penalty; payment of blood price with or without a reconciliation ceremony; exile; exclusion from association and participation in the communal socio-economic activities; corporal punishment; condemnation of the wrongdoer; and asking for apologies. However, with the exception of death penalty and corporal punishment, the emphasis in the Oromo administration of justice is on restitution and not retribution. Apart from the death penalty, because of its gravity and the nature of its commission, all wrongs are dealt with a system which resembles mediation or arbitration rather than punishment. According to Dinsa, in the Gadaa legal system, the death penalty is the highest form of punishment and would be imposed only in case of homicide of parents by their children; homicide committed by a wrongdoer after a peacesettlement ceremony was concluded; intentional homicide of a pregnant woman; murder after a kinsman who refuses to participate in the payment of the blood-price and recommends death penalty on the wrongdoer; and homicide where peacesettlement negotiation fails.

Dinsa's study shows that all dispute settlement proceedings are open to public participation by those who are assembled. Case proceedings are initiated either by the victims or by elders of the concerned clan or village. The parties present their case after taking an oath. Prior to the declaration of the decision by the Judges (Jilba), all who participated in the litigation alledgedly 'vote' in favour or against in a manner that resembles a trial by jury. As there are no written decisions, it is mandatory that the executive officers be present at the Jilba's proceedings, to be able to enforce decisions. The Jilba is independent of pressure or influence by the executive. It is the Messensa that selects or removes the Jilba members. Dinsa states that almost all cases are settled by compensation. For instance, one who kills a man intentionally would be required to pay about a hundred heads of cattle. Accidental killings involve mitigated 
payments or no payments at all. A man who rapes an unmarried woman was expected to pay about fifteen heads of cattle in compensation in addition to being forced to retain the raped woman as his wife subject to the fulfilment of marriage formalities. A man who rapes a married woman provides one head of cattle as compensation. For defaming the Aba Biya ('Chief Executive') a person is required to pay 4 to 16 heads of cattle. For defaming an ordinary person, the compensation was four heads of cattle.

The study by Wako (1997) stresses the democratic nature of the Gadaa system and its overall structures and organization for administration, law making and dispute settlement. The studies by Hinnant (1977) and Yacob Arsano (2001) suggest that the Borena and Guji Oromo have successfully maintained their Gadaa institution. They still retain the essential aspect of their customary polity with its capacity for conflict management and peace promotion. These two studies suggest that communities rely on the Gadaa-related CDR mechanisms for most of the cases since the solution needs to be lasting and aims at an overall peace and reconciliation. The dispute settlement procedures, the penalties to be imposed and the kinds of disputes to be settled by the Gadaa are similar to those among the rest of the Oromo. The study by Yacob however emphasizes that the death penalty seems no longer to be imposed by the Gadaa justice system because of an apparent relinquishment of this capacity to the formal system.

Jarsa Biyya (elders' assemblies)

Jaarsaa Biyyaa ('elders of the soil' i.e. 'of the country') is a customary institution for resolving conflicts. It is constituted by elderly and respected men who have the experience of resolving conflicts.

The Studies by Awel (2005), Ayalew (2001), Dejene and Abdurahman (2005), Demissie (2005), Dejene (2002) and Girma (1980) show that all types of cases from simple civil matter to complex criminal cases are subject to the jurisdiction of the Jaarsaa Biyyaa or Jarsa Araaraa (literally 'elders of reconciliation'). These include homicide, loans, cattle raiding, land, property or inheritance, personal injury, defamation, theft, accidental or wilful destruction of property, adultery and killing of animal. The Jaarsaa Biyyaa is the most widely used of the CDR systems in Oromo 
society with some minor regional variations brought about by the interplay of culture and way of life.

Judicial procedure

Mamo's (2006) study conducted on the resolution of land disputes asserts that the Jaarsaa Biyyaa successfully settle land related disputes. Cases can be taken to the disputants or an elder or elders may take initiatives to solve the disputes. Once cases are referred to them, the elders first listen to what both parties have to say. Then they contact other elders in the neighbourhood of the disputants to verify necessary facts. Then in the next meeting or so, the disputants are called separately and advised to compromise. The wrongdoing party would be advised to admit the offence and the truth (dhugaa) to the other party, and the wronged party also would be asked to give in some way to the offender in return for the truth, for the sake of the clan or the lineage and the elders, so that persistent hostilities are mitigated. The study describes cases of successful dispute settlement relating to land disputes.

Awel Ebrahim's (2005) research on the Jaarsaa Araaraa system of dispute settlement conducted in the Dinsho area shows that the Jaarsaa Araaraa is made up of elders constituted on an ad hoc basis whenever disputes arise, but that the same elders can participate in the settlement of many cases if so selected. According to Awel, the selection is made by the disputants depending on their own previous knowledge of the elders or any sort of relationship which gives rise to the trust.

As noted in many studies hearings often begin by one of the elders making prayers asking waqa (God) and the spirits to bless their deliberations after which the wronged person would be given the chance to present his part of the case. This will happen in the presence of the defendant. The disputants are strictly prohibited from interrupting one another when they make their statements. The hearing is open to allow the disputants to 'cross-examine' each other to find out the truth. Once the parties have spoken the public session is adjourned and the Jaarsaa Araaraa, will approach them separately in turn; when one party is approached, the other remains at some distance. This gives the elders the opportunity to concentrate on points of disagreement between the parties and assist in the fact finding and reconciliation or Araaraa. 
Depending on the outcome of the private deliberations with the parties, they continue the process. If the wrong-doing party makes admissions, without going to other procedures, the elders direct the discussion on how to reconcile the parties. If the defendant denies the claim, the case will proceed to the next step which is the evidence hearing process where the claimant will be asked to produce witnesses and/or other evidences.

If the evidence by the claimant could not establish the truth about the defendant's commission of the said wrong, the defendant will be required to take an oath (kakuu) which is considered to be very dangerous if he/she has committed the crime. The main purpose of taking an oath is to justify whether an individual is free from the act or not. An oath can be taken using material cultural objects prepared for such purposes such as a stick or knife. The assumption is that if the defendant accepts to take a kakuu, it means that he was not the wrongdoer. But if the real wrongdoer is found out by this process, the elders will proceed to redressing the claimant and consolidate the reconciliation process. Depending on the nature of the dispute, the wrongdoer would be made to pay compensation or do other things as found commensurate to the wrong done. Nicolas (2005) argues that the very procedure, including the setting and formalisation gives elders respect, provides efficacy and creates their ability to achieve rather than impose reconciliation over time.

Qallu (spirit-medium-based mediation)

The Qallu among the Western Oromo came to take on more than just a spiritual role, and are involved in dispute settlement institution based on spirit-possession-mediumship. The Qallu is a person who serves as a medium for the Ayyaanaa (the spirit) and is believed to have a capacity to communicate with Waaqa (God). He is considered as the spiritual leader of the community. In most cases the Qallu inherits the position and capacity from his forefathers. As Knutsson's study (1068) shows the Qallu adjudicates alongside the jarsa arraara, the elders of reconcilation. Cases may be taken to the Qallu if the elders are unable to solve the case or if it relates to ritual cases such as ritual appeasement or lifting of curses or serious matters, which may also be referred to him by the state legal system. Knutsson argues that the Qallu has sufficient authority to render his decisions effective and definitive. The institution has the 
jurisdiction to pass judgement upon any kind of matter from simple theft to homicide (Giday 2000; Ibsa 2003; H. Lewis 1988).

Tesema Tolera's (1997) study on the Ofa-Sarba is instructive of the Qallu institution's role in dispute settlement. Ofa-Sarba is the name of the male ayyaana (spirit) found in the District of Ginda Beret. The Qallu is considered to be the highest human judge who communicates with the ayyaana. The qaalluu is selected by the ayyaana based on the hereditary system and charisma of a given individual. A lower level traditional elders' court, known as Shanee-Seeraa, whose judges are appointed by the qaalluu on the basis of the purity, maturity and knowledge about the religious and cultural norms of the society, wisdom, ability to deal with conflict resolution, is organized and functions in the area. The appointment of the judges (Shanee-Seeraa) is approved by the ayyaana. According to Tesema, disputes on loans, land disputes, theft, inheritance disputes, marital disputes, defamation and injury which may arise between individuals, families, groups, clans, and tribes are subject to the jurisdiction of the qaalluu.

Judicial procedure

Though cases can be taken by the disputants directly to the Qallu, he also usually serves as the highest appellate body over the decisions of all other customary institutions of the Oromo in the locality. Parties dissatisfied with the decisions for example of Jaarsaa Biyyaa may take their cases to the Qallu. The verdicts of the Qallu have a better chance of being obeyed by the losers since the Qallu is believed to have the spiritual power to cause misfortunes to the party disobeying his decisions. A defiant opponent in a dispute is also most likely to be brought before this institution than to non-spiritual CDR systems.

According to Tesema (1997) a case is first taken to the Shanee-Seeraa by the victim and the elders send a messenger to the offender. The Shanee-Seeraa may also order the litigants to produce guarantors or sureties to make sure that the parties accept the judgment rendered by the elders, without affecting their right to appeal. Each session is opened with blessings and prayers so that the ayyaana helps the elders render justice impartially and conduct reconciliation peacefully. During the proceedings, the 
Shanee-Seeraa may hear each litigant separately and may require production of witnesses if needed. Finally, after discussing the case thoroughly, the presiding elder will ask the opinion of the other elders and the decision of the majority will be accepted. If the litigants are not satisfied with the decision, they can appeal to the qaalluu.

Allo Arsi

A study on the Allo Arsi council of elders among the Arsi by Abdurahman Kabato (1991) states that it is the unwritten local codes and customary norms which are implemented by the council of elders in the dispute settlement process. Under the Allo Arssi, the council of elders consist of notables, elders and clan chiefs. All these men are elected from the clan to take part in conflict resolution. In the Allo Arssi women have no role to play in the leadership. Abdurahman's account shows that Allo Arssi was originally part of the Gadaa system, but has undergone a considerable change under the influence of the Arssi Oromo culture and social composition. The disputes that are handled and resolved by the Allo Arssi include any type of individual disputes, inter-clan, and inter-ethnic conflicts. Like any other CDR system, it has a reconciliatory effect that is directed towards future cooperation that overrides the dispute resolution mechanisms in the formal state settings. Procedurally, cases could be taken to the Allo Arsi either by the disputants or the leaders of their clans. The elders' council members, the victim, and the criminal along with family members and clan elders normally participate in the proceedings and decisions can be based on pure confession (Dugaa) of the wrongdoer or on fact-finding process through evidences (ragaa).

Inter-ethnic dispute resolution

There are many kinds of institutions that promote inter-ethnic dispute resolution including Oromo traditions of group or individual adoption and fostering mogassa or gudifacha, patronage, harma hodha, , and bond-friendships, michu, which remains an important element of establishing and maintaining peaceful interethnic relations 
(Bartels 1983:167, Baxter 2005:901, Blackhurst 1996:240, Mohammed 1990:21, Tsega 2002).

In parts of Shewa where Oromo and Amhara lived intermingled in close proximity they developed a shared institution of dispute resolution (Nicolas 2005:62-68). This complex was able to develop due to a common tradition of reliance on elders in dispute settlement. Differences in traditional institutions, languages, and mediation procedures were overcome due to state influence, cultural exchange and assimilation, and some acceptance of elements of each others' traditions. Means of accommodation including 'supplementation' from each others traditions, 'doubling' by using both traditions, curtailing or replacement of traditions which did not have resonance from the other group (Nicolas 2005:66-7)

Various associations such as iddir funeral associations, mehaber, associations in the name of a Saint, and iqqub rotating credit associations play a dispute resolution role between members. Herbert Lewis (1989) suggests that this is part of a Cushitic emphasis on voluntary and achieved status. However, these institutions may also have developed in contexts of culture contact, exchange and urbanisation, and in reaction to the pervasive state and hierarchical religious system (Pankhurst 2003).

In North-eastern Wellega where Oromo live in close proximity with Amhara migrants the funeral association known as Qire is a social support institution which takes on some conflict resolution roles. It is managed by the elders of the community and is involved in the settlement of interpersonal and other types of disputes arising in the community (Assefa 1995). Cases are normally brought to the Qire by one of the parties in a conflict. The leader of the institution tells the disputants to select elders on each side, who would consider the case. The elders chosen to decide the case at hand and the conflicting parties participate in the process. After discussing among themselves the elders pass their decision, which is usually a compromise. The elders advise and convince the parties in a dispute to accept the decision passed. Offenders in the dispute are made to pay compensation, which might involve serving the participants with food and drink. 
To conclude, the CDR traditions among the Oromo are rich and diverse, involving assemblies in the context of the gadaa framework deriving from the Borana, councils of elders involved in reconcilation which is the most widespread form, and spiritmedium based adjudication by the qallu in western Oromia. Dispute resolution mechanisms in interethnic contexts have also been developed resulting in cultural borrowings and merged systems.

\section{B. Southern Nations and Nationalities Peoples' Region}

Let us forget our fighting, let our stomach become one

Aike Berinas (Baldambe) quoted in Lydall and Strecker (1979:33)

The SNNPR is the most diverse and complex region within Ethiopia. The SNNP Regional State is the third largest region in Ethiopia covering an area of over 100000 $\mathrm{km}^{2}$ bisected by the Rift Valley and the Omo-Gibe River Basin. The region is inhabited by some fifty groups with distinct language and traditions. The population was over 10 million in the 1994 Census with a projection of over 15 million in 2008. There were only three groups with over a million people in 1994, the Sidama whose CDR is considered in the chapter in this book, the Gurage and the Wolayta, and a large number of small groups, particularly in the Omo valley. The SNNPRS is administratively divided into thirteen Zones, 104 Weredas and eight Special Weredas.

Trying to discuss CDR throughout the SNNPR is a difficult task; this is partly because of the large number of different groups, many of whom have been researched by social anthropologists in general studies with only passing reference to CDR, and since the traditional socio-political structures are varied ranging from hierarchical kingdoms and chiefdoms with courts to small egalitarian agro-pastoral groups relying on consensual and deliberative dispute resolution. There is also a discrepancy in the literature with a few groups having been studied fairly intensively and many groups with no specific CDR studies; most of the studies relating to the more hierarchical and centralised societies. This review is limited largely to publications and theses that have a specific intention to consider dispute resolution. There is not the scope within this introduction to review the vast anthropological literature on ethnic groups in the 
southern region, as well as historical studies, notably history MAs and senior essays that discuss local institutions, some of which are involved in CDR.

Most of the CDR studies focus on three groups: the Gurage, the Kambata and the Sidama. CDR studies on Gurage include on the Sebat bet Gurage two articles by Shack (1966, 1967), an MA thesis in literature and folklore (Yewondwossen 2006) an MA in social anthropology on local institutions (Mengistu 2000), an MA in local and regional development studies on indigenous institutions (Getinet 1999), a senior essay in Law (Bereda 1999) focusing on marriage, a chapter by Bahru (2002) on the Yejoka qicha and some references in the book by Gebreyesus (1991). Among the Kistane there is a MA thesis in social anthropology (Walelign 2006), and the chapter by Bahru (2002) on the Gordena sera. CDR studies on Kambata include two articles by Singer $(1975,1980)$ a senior essay in political science (Seifu 1970) and a chapter by Yacob (2002). Sources on CDR among the Sidama include two articles by Hamer (1972, 1980) one by Stanley (1970), and a senior essay in political science (Melese 2002). Studies of CDR among other groups are much less common. These include three MA theses, one in social anthropology on traditional institutions among the Gedeo (Paulos 2005) and two MAs in literature and folkore, one on the Wolayta (Yilma 2006) and the other on Gamo (Temesgen 2006), and a chapter on inter-ethnic peace-making in South Omo among the Arbore and their neighbours (Pankhurst 2005).

\section{CDR institutions}

\section{A Gurage}

Among the Gurage the case of Chaha of the Sebat-bet Gurage was discussed by Shack in terms of the role of kinship sanctions, religious notions of morality and ethics and the ridicule of public opinion in dispute resolution. CDR institutions among the Gurage are based on notions of kinship and of territory. There are two levels and institutions involved in CDR: at a lower level 'moots' operate at village level involving elders from neighbourhoods (sabugnet) or clans (gosa or bet) called wofencha, (literally relatives) or senecha in Kistane. At a higher level the yejoka general assembly used to settle inter-clan and inter-tribe disputes among the Sebat Bet (Giday 2000, Yewondwossen 2006) and the Gordena Sera among the Kistane (Walelign 2005, Bahru 2002). The Yejoka is located in a specific place in Chaha 
where elders used to gather under a Podocarpus tree whose branches yaj were burred in the ground, yoka, only to sprout again (Gabreyesus 1991, Bahru 2002:21). The yejoka was said to be composed of seven 'judges' from each of the seven 'houses' of the Sebat-bet Gurage (Shack 1967). Among the Kistane in territorial terms there are village councils (sabugnet), and at a higher level district councils (Ye-Ager Shengo), as well as kinship-based councils of the patrilineal group (ye-Abotold Shengo) dealing with cases within family and clan groups. There is also an appeal court (Gefeche), a higher court (Wemano/Gutache Sera), and finally the general assembly of all male Kistane elders (Ye-Gordena Sera). Failure to respect the decision of the Yejoka can lead to ostracism from iddir funeral associations, refusal to act as the person's guarantor, to share food and drink, and potential exclusion of the person's supporters (Getinet 1999). This ostracism among the Muhur is termed eka, and participants at the meeting go to the person's house and curse him (Mengistu 2000); likewise in Kistane the person would be subjected to punitive visitations of progressively increasing numbers of 'guests' expecting hospitality (yekka); noncompliance could result in more serious measures ranging from confiscation of property to ostracism (Bahru 2002).

Judicial procedure

In terms of judicial procedure each disputant has to produce a guarantee. The plaintiff presents his case and litigants have a right to respond. Witnesses may be called, or disputants maybe asked to take oaths (Bereda 1999). If disputes cannot be solved in the neighbourhood by the village headman and elders they can select their own elders as judges, whose verdict is often limited to an apology in minor cases with reconciliation ceremonies involving consumption of food and drink; there may also be fines in cash, though the emphasis is on compensation of the victim, and restoring peaceful relations. Disputants who are not satisfied can take their cases to the yejoka whose verdict is final.

Cases related to marriage, adultery and desertion of wives were dealt with first by a special judge with a hereditary title known as Ye-Anq'it Dane (Bereda 1999). Land disputes were dealt with by another judge known as Ye-Zhre Dane, who distributed land, controlled boundaries and solved problems (Gabreyesus 1991). Among the 
Sebat-Bet there were legal experts known as Eqicha dana who would advise individuals. The assemblies termed shengo had standard procedures and a formal seating arrangement. Sessions dealt with all kinds of disputes notably marriage and divorce, homicide, arson and land use. Premeditated murder was differentiated terminologically from unpremeditated murder and inadvertent homicide (Bahru 2002). Decision were arrived at by consensus after exhaustive discussion, though occasionally cases would be referred to a smaller groups known as amseya among the Sebat Bet who would discuss the matter in detail and present their recommendations to the assembly (Bahru 2002). Sessions were opened and closed with blessings. Homicide cases involve guda a reconciliation ritual after the payment of the blood money (guma) (Walelign 2005). Shack suggests that the yejoka emerged in about the 1840s with the attempt by the Chaha to dominate the other groups, through their control of the main Gurage cults.

Until 1942 the CDR institutions were independent, after which the authority of the clan chiefs was brought under the central government which established courts in Gurageland over which the district Governor presided. However the yejoka continued to function and still has an important role. Gurage customary law is one of the very few to have been written and codified with the advice of legal experts resulting in the book translated as Kitcha: The Guraghe Customary Law (GPSDO 1999). Some changes and additions were effected in the codification process notably addressing gender concerns, especially in the section on marriage providing for mutual consent, divorce rights for women and penalties for adultery and abduction. Other articles included injunctions against lavish feasts, concern about enset being replaced by cash crops, wilful infection with HIV/AIDS being equated with homicide, and measures against smoking, alcoholism and chat-chewing. Among the Kistane the basic principles were laid down in 1994, and the more elaborate code approved in 2000, with similar attempts to oppose harmful customs notably abduction, excessive wedding and funeral customs and ostentation (Bahru 2002).

\section{B Kambata}

Among the Kambata the CDR system operates within the customary code of conduct termed seera, (also known at maretta meaning 'commitment to truth') which is 
widespread in southern Ethiopia (Yacob 2002). Local territorial institutions include the heera at the lowest level, followed by the cotcho at an intermediate level and the kokota as the largest territorial unit. Breech of the decision of the kokota was said to attract the 'black' eye and result in a curse. Kambata CDR was operative at two distinct levels (Singer 1980). There was a legal structure tied to the political system and a second one that was part of the overall kinship structure. However the two systems overlapped at both the lower village level and at the highest level of the king (woma) who was the ruler from the Oyeta dominant clan. Judges at the village level were referred to as woshebi dana (elders). Cases that could not be resolved by them were taken to district judges (gacho dana) who were appointed by the woma. The Ilemi dana or Boki Dana who was the chief judge, deals with all inheritance matters. Disputants dissatisfied with the verdict of village judges could take their case to the Ilemi dana and finally to the woma. The Kambata also had assemblies ya'a at which thieves could be found out and ostracised with no one visiting them or going to their funeral (Seifu 1970).

\section{Sidama}

Among the Sidama there are four to five levels of CDR: the hamlet or neighbourhood (olla or allauw), dealing with simple matters, lineage, village, sub-clan (bosello) and clan, and among the Aleta inter-clan (Hamer 1972, Melese 2002). At neighbourhood Olla level disputes are considered at Songo councils to which disputants present their cases in front of the elders presided by a respected elder. The oldest elder starts the proceedings with the phrase 'do you hear?'. The plaintiff presents his case, followed by the defendant. The elders then withdraw to consider the case and reach a consensual decision. The wrongdoer is asked to confess, pay a fine and render compensation when necessary. If guilt is not evident elders may take the suspect aside and attempt to persuade him to tell the truth. If the suspect refuses elders declare that only the sky god Magino can judge what is right, which is tantamount to a curse. The legal sanction of the songo was termed sera and fines could be imposed; so long as the person did not pay he would remain a ritual outcast. Litigants might be required to take an oath to testify that the information they give is based on truth. Witnesses might be called and also be asked to take an oath. At a higher level the ritual leader 
Godan was involved in stopping fighting and considered cases, along with Songo councils (Stanley 1970). Wrongdoers ask forgiveness, or pay fines or blood price in homicide cases. Those who dis not comply could face cursing and ostracism. Among the Sidama voluntary associations mahabar also play a role in settling disputes; the committee of this recent institution which arose with the monetisation of the economy took on the customary term songo, and sought to mediate between individual and collective interests (Hamar 1980).

\section{Gedeo}

Among the Gedeo according to Paulos (2005) the gadaa institution plays a key role in dispute resolution. The general assembly called ya'a takes overall decisions, and cases are considered at different levels depending on their severity. The fear of cursing and ostracism is a powerful force for compliance. Sanctions may include fines and cleansing rituals in the case of unintentional murder. Dissatisfied litigants can take their cases to higher gadaa officials, but the decision of the Aba Gadaa is considered binding, as it is the highest rank after the ya'a assembly.

\section{E Wolayta}

Among the Wolayta according to Yilma (2006) at a local level disputes are resolved between neighbours and/or relatives by chimata elders. Disputes involving homicide are dealt with by the chucha-checha institution. When an oath is required the mechanism is referred to as chako. The Protestant church is involved in dispute resolution through its elders, referred to as wassa keta chima. Where disputes involve inter-clan conflicts notably over land, grazing and livestock theft, 12 elders are selected from each side. An elder from the side that is considered guilty will cover his face in soot, and a cow and sheep are slaughtered in a reconciliation ceremony when the litigants eat and drink together. In homicide cases a day is set for a public reconciliation at which the offender appears with his face covered in soot and begs for forgiveness, and a cow and sheep are slaughtered. The offender and the father of the deceased will drink from the same cup to mark the end of the conflict.

\section{H Gamo}


Among the Gamo according to Temesgen (2006) in Doko there are a range of individuals and institutions involved in dispute resolution. The korefinie is the senior man in a given clan responsible for administering the clan and settling internal disputes. The shalle are the elders of the area by this name who are considered to be particularly knowledgeable about dispute resolution. In homicide cases they go to the house of the deceased carrying a stone and plead for forgiveness and organise a reconciliation ritual. If the relatives refuse they leave the stone at the gate and curse them. At the reconciliation the offender shaves his hair and covers his body with soot. The ceremony involves slaughtering a cow and the offender falls at the feet of the deceased's brother, kissing his knees asking for forgiveness and the brother is expected to embrace him. They then both eat the liver of a cow starting from opposite directions and drink together. The Bollanne Donna is involved in homicide cases and is a hereditary role. The Giqqa Eeqa are hereditary positions involved in boundary and land disputes, with one person for each of the three areas within Doko. The Gesho maaka is a clan involved in reconciling people who commit incest with the rest of the society, which requires a purification ritual by a river and the shaving of the heads of the offenders by the despised degala tanners to avoid ostracism. The maro are ritual experts that can suggest the causes of conflicts and may suggest solutions. The Kare is a person responsible to protect people from other areas and resolve disputes with them. The Wogaa Era so are people knowledgeable about the traditional institutions of other areas of Gamo and are consulted when decisions made in Doko generate disagreements. The study by Freeman (2002:134-8) shows the importance of assembly places Dubusha in Doko where sacrifices are carried out to maintain or reassert the peace and fertility of the community dere, preceded by blessings. Often a wise and neutral third party, ganna, is involved in helping resolve conflicts. The assemblies allow all persons to speak, and continue till a consensus is reached, whereupon the wrongdoer gets down on his knees and asks for forgiveness; first the wronged person forgives him and then the rest of the assembly.

\section{G The south-west}

In the southwest notably among agro-pastoralist groups authority has often been based on oratory, and decision making and dispute settlement depends on lengthy discussion 
to reach a consensus, after which the position is summed up by leaders (Turton 1975, Strecker 1988). Inter-group conflict and warfare has been common in the southwest and particularly South Omo area. Starting with the book Warfare among East African herders edited by Fukui and Turton published in 1979, there has been considerable debate about the reasons for these conflicts and the relative importance of ecology, economic factors, the spread of automatic firearms, resource competition, cultural values, age-organisation, ritual, and human agency (Strecker 1994, Abbink 1994, 1999, 2000, Tadesse Berisso 1994, Turton 1999, Taddesse Wolde 1999).

There has been much less writing on traditions of dispute resolution although there are cross cutting institutions notably bond-friendships and trading networks (Taddesse 2005). Lydall and Strecker (1979:33) noted how Baldame game an outline of peacemaking between the Hamar and Nyangatom over half a century ago. Abbink (1994) suggests that peace-making is constrained by insecurities, resource competition, relations between highland and lowland groups, among pastoralist groups, and with the state. He concludes that only if new resources become available with shared development projects can a trans-local 'community' emerge. A peace ceremony with the participation of several groups in the region was carried out in 1993 with the involvement of anthropologists, an NGO and government representatives. The ceremony involved cursing war by blunting, breaking and burying spears and blessing peace through the sacrifice of animals, the wearing of fatty strips and the exchange of staffs and agricultural tools symbolic of the different groups, as well as much debating about the causes of the conflict and ways to resolve it. At the event the discourse that sought to create convergence used of mutual metaphors, allusions to shared kinship, reference to commensality, recalling economic links necessary for social and political reproduction, reference to similar and interrelated forms of leadership and institutions, and shared conceptions of spiritual agency along with blessing and cursing as archetypal cultural forms (Pankhurst 2006). There have also been a number of more recent government and/or NGO organised 'peace conferences', that have sought to promote inter-ethnic harmony, which it is beyond the scope of this chapter to review.

To conclude CDR institutions in the SNNPR are extremely diverse and complex, involving a wide range of systems including hierarchical institutions with courts, and 
a layered structure, sometimes with judicial experts, the involvement of religious and clan leaders, in some societies highly regulated assemblies, some involving agegrading, and often elders' councils.

\section{Conclusion and Recommendations}

If those concerned with criminal justice reform in Africa wish to have any real impact on improving access to justice for the majority, then the vital role played by traditional and informal mechanisms in providing justice for the majority of people living outside town centres needs to be acknowledged. They will also need to seek to broaden understanding of how and where these forums operate and to pursue policies that take full account of their existence. Training on, resources for, and regulation of traditional and informal justice forums is also required. There should be co-operation between informal justice and the relevant state institutions... as well as cross referrals between state courts and informal forums. For far too long traditional and informal forums have been ignored, in part owing to entrenched positions on the undesirability of 'traditional justice'. In the absence of studies aimed specifically at finding practical solutions, such arguments have been used to justify continued inaction. The policy of turning a blind eye to traditional and informal justice systems is long overdue for replacement. (Penal Reform International 2001:5; emphasis added)

The studies in this book have been able to establish conclusively that customary dispute resolution systems are widely distributed and prevalent throughout Ethiopia. Despite their wide coverage, CDR institutions are quintessentially local serving particular groups. Most such institutions are built on cultural rules linked to local belief systems, and are based on localised trust among people who know each other in face-to-face communities. Nonetheless in certain societies CDR institutions with several levels have developed and there are a number of more inclusive CDR institutions that have formed across-ethnic boundaries, in border areas and in towns.

This book has shown that CDR institutions co-exist with the formal justice system and are very relevant in the day-to-day lives of the members of communities within all Ethiopian societies. Moreover, despite lack of formal recognition in practice CDR 
institutions at a local level have strong de facto linkages with the formal justice system.

In this conclusion we start by reviewing ten major characteristics of CDR. This is followed by a discussion of ten advantages and five limitations of CDR. We then consider the state of relationships between the formal and customary systems which we characterise as "coexistence and collaboration without mutual recognition". In the recommendations we note the lack of constitutional recognition of CDR institutions despite the extensive cooperation in practice. We recognise the potential risks of greater integration between the formal and customary systems, as evidenced from accounts of international experience, and in relations to rights of women, children and minorities. However, we argue for greater partnership to appreciate the value and enhance the role of CDR and reduce the burden on the formal system. We present ten practical suggestions of ways in which greater collaboration may be achieved. We conclude by suggesting that Ethiopia is at a crossroads with the current greater decentralisation to the wereda level offering opportunities for enhancing local level justice through greater recognition and involvement of customary institutions while simultaneously guaranteeing and protecting human rights, notably those of women, children and minorities in compliance with national and international norms.

Major Characteristics of Customary Dispute Resolution.

The studies discussed in the book have identified the following ten somewhat overlapping characteristics of CDR systems: 1) Voluntary and consensual proceedings, 2) Litigants' involvement in selection of local mediators, 3) Locally circumscribed constituency, 4) Public participation, 5) Accepted and flexible norms, rules and values, 6) Group-based responsibility, 7) Negotiation and compromise, 8) Forgiveness and compensation, 9) Restoration and maintenance of peaceful coexistence, and 10) Dynamism and responsiveness to change. 
1. Voluntary and consensual proceedings

CDR generally requires the voluntary participation of both parties in a dispute and an agreement to abide by the outcome. CDR institutions usually do not have the kind of coercive mechanisms at the disposal of formal systems and rely on social pressure and the invocation of potential ostracism or exclusion from the community to deal with non-compliance.

2. Litigants' involvement in selection of local mediators

CDR institutions usually deliver justice through the vehicle of participant-selected or community-selected mediators and decision-makers. Arbitrators are from within the community and known to the litigants. Those who are selected usually have experience, knowledge or skills in dispute resolution, and they often have a respected and higher status than the litigants. However, in some cases there are hereditary or self-appointed positions.

3. Locally circumscribed constituency

CDR institutions generally operate locally, that is, they resolve disputes within particular ethnic groups and often within specifically circumscribed geographic locations, often within a community of people who know each other and live within close proximity. However, in a few cases CDR institutions exist that cut across boundaries and have the capacity to resolve inter-ethnic disputes.

4. Public participation

CDR institutions are usually held in public and often allow for participation by those attending. Rather than being imposed, the outcome is negotiated and discussion may continue till the decision is agreed upon by all those present. The outcome needs to be consensual and requires public approval to enable decisions to be backed by community sanctions of exclusion if required. 
5. Accepted and flexible norms, rules and values

CDR institutions generally deliver justice in accordance with norms, rules and values that are generally known and accepted by participants. However, the rules and evidence are often flexible and can be adapted to particular cases and circumstances.

6. Group-based responsibility

CDR institutions often consider that the responsibility for the harm rests, not with the individual but with the broader social grouping, often the family or clan. The kin are involved in ensuring that the offender among their midst complies with the verdict and where compensation is required may be expected to contribute.

7. Negotiation and compromise

CDR systems generally involve negotiation between the disputing parties to try and resolve the case amicably. This usually involves compromise with both parties accepting some measure of responsibility for the dispute and agreeing to the verdict. Rather than one party being viewed as the winner and the other as loosing both parties stand to benefit from reconciliation.

8. Forgiveness and compensation

CDR institutions often require the loser or wrongdoer to ask for forgiveness and/or pay compensation, rather than imposing a physical punishment or imprisonment. However, sometimes both parties are considered guilty and expected to make amends. Compensation is often paid by one individual, family or clan to another as a form of restorative penalty that enable to parties to be reconciled.

9. Restoration and maintenance of peaceful coexistence

CDR institutions aim to restore peace and harmony between the disputing family members, neighbours, clan or local group so that former litigants can continue to live together in frequent interaction. Often the litigants are expected to eat and drink 
together in 'rituals or reintegration' involving animal sacrifices to seal their reconciliation and ensure that social harmony is maintained.

10. Dynamism and responsiveness to change

CDR institutions are not static but have evolved over generations to their current status, and can respond to changes in views and values. Many have evolved in recent times and changed over the past few decades to become more formalized in response to interactions with the formal systems and regional, national or international pressures. There has been increasing use of writing notably for the final contractual agreements. Some CDR institutions have also been written down or codified as in the Gurage case, and have been self-critical and reforming notably regarding gender power relations and discrimination against women and customs considered harmful such substance abuse and ostentatious feasting.

Advantages of Customary Dispute Resolution

The studies in this book have documented very significant advantages of the CDR systems, particularly for the sections of the Ethiopian society far or removed from the formal justice system both in terms of the physical location and financial ability. The following ten are among the noteworthy advantages of the CDR systems identified: 1) Accessibility, 2) Timeliness, 3) Limited cost, 4) Legitimacy and appropriateness, 5) Restorative capacity, 6) Participatory procedures, 7) Predictable processes and outcomes, 8) Enforceable community-based sanctions, 9) Avoidance of coercive measures and 10) Building community cohesion.

1. Accessibility

Many CDR systems work at a very local level through community mediators and decision makers. Generally CDR institutions are within walking distance avoiding the need for litigants to pay for transport. They are conducted in the local language and involve almost exclusively oral proceedings obviating the need for litigants or participants to be literate, or know national or regional languages. However, written recordings in 
some CDR institutions have been evolving and have become commonplace, particularly where decisions involve commitments on the part of litigants which could need verifying and where there is a possibility that formal institutions could later be involved.

\section{Timeliness}

Most CDR systems are able to respond immediately or very quickly to disputes that arise before they become serious thereby usually avoiding escalation into conflict. The procedures are generally simple and most disputes can be resolved fairly easily. However, the CDR experts sometimes use delaying tactics, adjournment or postponement of sessions to allow for litigants to 'cool off', reconsider or be reconciled on their own or through kin pressure.

3. Limited cost

The cost of resolving disputes in CDR systems is generally very low. Litigants tend not to need to pay for transport or to hire lawyers or legal experts. Litigants may be expected to provide food and drink for a reconciliation occasion and/or to provide the elders with a small payment, usually in kind and often consumed directly at reconciliation ceremonies. Compensation payments, depending on the severity of the case, may be nominal but are generally more limited than in the formal system, are usually in kind in the form of livestock, and may be subject to negotiation and/or reduction. CDR systems can thus be considered to be cost-effective.

\section{Legitimacy and appropriateness}

CDR systems are culturally relevant and often viewed as the most legitimate source of justice to the participants. The systems reflect widely held beliefs, norms and values of the community. They are generally appropriate to local contexts, particularly in close-knit rural communities where people need to cooperate on a daily basis. 
5. Restorative capacity

Most CDR systems focus upon restoring harmony within the community when a dispute has arisen. They operate to reconcile the parties so that they can live in peace and cooperation and recognize the harm done to the community. Often, this is achieved by requiring that the guilty party asks for forgiveness and/or that the aggrieved receive compensation. In the absence of CDR, systems of feuding or revenge may prevail.

6. Participatory procedures

Many CDR systems conduct proceedings in public places within the community, often at established fora. The victim, offender and the members of the community participate in most aspects of the proceedings. The decisions taken are therefore publicly known and communicated orally, forming part of the local legal norms, and the whole community, particularly the younger generation, are educated in the rules, procedures and means of solving disputes and preventing conflict through the public proceedings.

7. Predictable processes and outcomes

Most CDR systems operate on the basis of a known set of rules often based upon local case precedence, with established procedures which are well known by all community members. These rules and precedents are communicated orally among those who are responsible for delivering justice and are easily understood by the community members.

8. Enforceable community-based sanctions

The decisions of most CDR systems are, in their local context, easily enforced. Customary systems tend to be able to ensure compliance through blessings and the threat of curses. Failure to comply can result in social ostracism and being left alone in good and bad times, in effect forcing the litigants to seek to regain community approval by complying with the decision, or alternatively leave the area. 
9. Avoidance of coercive measures

Generally CDR systems do not have custodial sentences at their disposal and avoid harsh sentences and physical punishments. Problems are often solved before they become very serious resulting in loss of property or life. By paying compensation to victims, offenders provide support and avoid the economic problems and social dislocation for families resulting from imprisonment.

10. Building community cohesion

CDR systems keep community values alive and help build common ground between members providing a sense of togetherness and a collective spirit which enhances solidarity and self governance which can also be harnessed for community-led development endeavours.

To conclude one can go so far as to make the argument that many CDR institutions are more democratic, humane and appropriate to local contexts than formal justice systems in the following five respects.

1. They often provide fora for a wide range of members of the society to participate in the judicial process;

2. They tend to rely on consensus allowing litigants to argue without interruption until one side is more persuasive;

3. They seldom impose severe punishments and seek to obtain pardon, reconciliation and compensation payments. They tend to avoid imprisonment, and physical punishments and in extreme cases opt for banishment;

4. They are better at restoring peace and enabling litigants to continue to live in close proximity and harmony.

5. They can fairly easily be modified to take account of cultural changes and reforms such as those relating to gender issues and harmful customary practices.

We do not wish to suggest that all aspects of every customary CDR institution are acceptable or can be seen as conforming with national and international and universal norms and human rights. Major problems with CDR institutions in this respect are discussed in the next section. However, there are principles and procedures common 
to many CDR institutions that are rational, reasonable and judicious which modern systems could emulate and with which they are beginning to experiment, notably in Western countries that have lost such traditions, such as community service as an alternative to imprisonment (ICRC 2004).

\section{Limitations of Customary Dispute Resolution}

The studies in this book have shown that CDR systems have some serious limitations especially when seen from the point of view of the core beliefs of modern formal laws and institutions such as the Ethiopian Constitution and the institutional conventions, instruments and machineries in place under it, and international legal norms and conventions. The following five are the major the limitations identified: 1) inequitability, 2) non-compliance with human rights standards, 3) undermining of individual rights, 4) inability to guarantee procedural fairness, and 5) lack of uniformity.

\section{Inequitability}

Firstly in gender terms, generally women are excluded from participation in CDR justice systems. They are usually not decision makers, and customary mediators and arbitrators are almost always exclusively male. However, as Penal Reform International (2001:2-3) argues women are also grossly under-represented on formal court benches in Africa, and the same is true in Ethiopia, and customary systems like formal ones have evolved to become more gender conscious. Nonetheless, women often do not have the standing to appear before mediators and decision makers in the customary systems on their own and may require a male relative to represent them. CDR institutions may also pass judgments that are against the interests of women, notably regarding matrimonial litigation, divorce settlement, and violence against women, particularly rape, female-genital mutilation, domestic violence (Meaza 2007).

Secondly, CDR institutions may not reflect the specific needs, rights and interests of children and young persons, who are often treated the same as adults. For instance in some traditional cases of homicides girls may be provided in compensation against their will, and girls may not inherit equally from their parents.

Thirdly, CDR institutions sometimes exclude the participation of minority groups, such as occupational craftworkers or clans that are considered inferior. There has been 
very widespread discrimination of such minorities in political, economic, social and cultural terms, and CDR institutions tend to reproduce existing hierarchies and domination (Pankhurst 1999, 2003).

Finally, the compromising spirit that is a major feature of most customary systems may reflect the existing power structure and reinforce all whole range of inequalities based on gender, age or other status.

2. Non compliance with the human rights standards

CDR systems operate on the basis of their own laws and procedures. These may differ significantly from those written and passed by the legislative bodies. Thus individuals may find themselves convicted of a crime that is unknown to law or subject to a consequence that is not supported by the formal legal system.

3. Undermining of individual rights

Because CDR systems are often based upon collective responsibility for wrongs that are defined as those things which harm the community as a whole rather than individuals, they generally do not reflect and fully respect the individual human rights provisions of the Constitution or those enshrined in international instruments. This is most notable in the case of women's reproductive rights, property inheritance and division during divorce, and violence against women. Children's rights may also be undermined. Moreover, individuals may be drawn into disputes for which they were not responsible. 
4. Inability to guarantee procedural fairness

An often expressed concern about CDR systems is that they can be perceived as corrupt and biased. Traditional leaders or arbitrators may favor their kin or be open to bribery. In some CDR systems persons are held responsible for behavior, not on the basis of objectively assessed and reliable evidence, but rather on the basis of their willingness to give the requisite oath, or upon the word of spiritual powers as expressed by spirit mediums.

\section{Lack of uniformity}

There are a large number of ethnic groups in Ethiopia and most of them have their own specific CDR institutions. There are significant differences between these systems. Thus the justice received may be dependent upon ethnicity and locality and not solely upon the issues or matters in dispute. This can give rise to different verdicts about the same offence or the same verdicts for different offences resulting in lack of consistency and potentially unfair judgments. Furthermore, as pointed out by several studies in this book, CDR systems may not be able to cope with 'modern' contexts and types of disputes in which they are not usually involved.

Coexistence and collaboration without mutual recognition

It has been noted that, currently, the formal justice system and CDR systems operate at the simultaneously and in the same place with limited overt support or recognition of each other. The formal system officially ignores the existence of the CDR systems or views them as irrelevant to the legal system and gives them no credence or legitimacy in areas other than those recognized by the Constitution. Conversely the CDR systems operate without regard to the claims of the formal system to jurisdiction or legitimacy. Each system has its own sphere of influence and sometimes client group and operates relatively successfully within it. However, in a number of cases there is significant collaboration between customary and state systems and even some acknowledgement of the former by the latter as noted in the Somali case study in this book. 
In practice the state has tended to rely on the formal justice system with limited attempts to involve customary institutions. In the early EPRDF period there were cases of yeselam komité, 'peace committees' that sought to involve local elders and customary leaders for instance in finding culprits responsible for cutting trees from community forest. (Pankhurst 2001). However, there is the possibility that such collaboration can tarnish the reputation of customary leaders.

The State has at times organised 'peace and democracy' conferences under the former Regional Affairs Bureau at the Prime Minister's office, to address conflicts between groups such as between the Borana and Garri, between the Afar and Somali, and between different Gambella factions, and sometimes sought to co-opt local elders to participate in such processes (Asknake 2006:942). There have also been a number of initiatives by NGOs to advocate peace meetings and promote reconciliation, some trying to involve women in peace conferences, to counter gender biases for instance in Gambella (Sommer 2005, 2007). However, overall Asnake concludes that: "the participation of civil society and the use of traditional institutions in conflict management processes are abysmally low" (2006:942).

In practice there are significant informal linkages between the two systems at the local level, particularly in remoter contexts. The formal system often relies on customary institutions to deal with more simple and localised cases often relating to family matters, to review cases and forward those that are complex, serious and involving matters that are considered the jurisdiction of the state system such as land disputes and murder, and to ensure that decisions taken in the courts are executed and that the parties comply with the verdicts (Pankhurst 2006).

The coexistence of the two systems has also given disputants a choice of alternative ways of resolving their disputes, such that if a verdict is considered unfair in one system litigants may resort to the alternative. The availability of both systems also provides most people with ready access to at least some dispute resolution institutions. The maintenance of CDR systems may strengthen and legitimize local customs and practice and keep people more involved in community affairs. They may support the development of cultural awareness and pride thereby enriching the 
cultural heritage and contributing to the development of Ethiopia as a great pluralist nation.

However, the fact that there is no official link between the formal and the CDR systems has given rise to several problems. One of such problem is the promotion of 'forum shopping' and a multiplicity of proceedings with disputants dissatisfied with the formal or CDR process turning to the other to again try to come out as more advantaged or as the winner. Though this creates choices and options it may also result in abuses, particularly if there is no coordination between the two systems. This can also undermine the legitimacy and credibility of both systems. It further adds unnecessary time, expense and complexity to proceedings thereby making the justice system incapable of being principled. Importantly also, due to the absence of any formal link, the assumption of jurisdiction by both systems on a given dispute might lead to insecurity, instability and increase risk of conflict within a community.

\section{Recommendations}

The reality is that CDR systems do exist throughout Ethiopia and are delivering justice to a broad sector of the Ethiopian society side by side with the formal justice system. As noted in the introductory chapter of this book the 1995 Constitution of Ethiopia has formally recognized the operation of customary laws in family and personal matters with respect to consenting disputants. However, as noted, the Constitution did not recognize any formal space for the customary laws and courts regarding other civil and the whole of criminal matters. This question deserves reviewing.

It should be stressed that attempts to simply or mechanically incorporate traditional and informal justice forms into the formal state system in other African countries in post-colonial contexts have often failed (Penal Reform International 1991:129). This resulted in loss of positive attributes of customary systems, by undermining their legitimacy, reducing their flexibility and ability to adapt to changing circumstances, making them unnecessarily bureaucratic, fixing them through written codification, subjecting them to interference and relegating them to an inferior status. 
There are also serious risks for individual human rights, notably of women, children and minorities that need to be taken into consideration and protected through federal as well as state legislation and legal provisions. The advocacy work of the Ethiopian Women's Lawyers Association achieved considerable progress in this respect in obtaining the revision of the Family Code in 2000 and the Penal Code which was renamed the Criminal Code in 2004. This removed the discrimination between men and women apparent in the 1960 Civil Code which had differential marriage ages for men and women, designated the husband as the head with the right to chose common residence and manage common property, disallowed divorce until fault was proved, and did not recognize common law marriages. Likewise the Penal Code of 1957 criminalised abortion, did not recognise or criminalise domestic violence, or female genital mutilation, and provided an inadequate penalty for rape. However, three Regions have still to adopt their enacted family laws (Meaza 2007:100-2)

Maintaining the state and customary systems separate which seems to have become an emerging consensus among academic writers, should not mean that they should not borrow from each other or that there is no scope for the systems to work together (Penal Reform International 1991:136). A number of different options pursued by various African countries, their advantages and risks have been discussed by Kohlhagen in his background chapter in this book.

The following ten ways of enhancing partnership and collaboration are worthy of consideration: 1) rethinking constitutional choices regarding customary laws and courts, 2) developing institutional linkages between the two systems, 3) providing appropriate support to acceptable CDR institutions, 4) developing relationships between actors in the two systems, 5) supervising and monitoring the performance of CDR systems in key areas, 6) encouraging reform of CDR institutions notably regarding gender, minorities and harmful customs, 7) promoting the writing down and codification of CDR institutions, 8) carrying out further research on CDR institutions and their relationships with the formal justice system, and 9) establishing pilot collaborative projects for potential replication and upscaling, and 10) sharing experiences with other countries on reconciliation of state law and CDR. 
1. Re-thinking Constitutional and legal choices regarding customary laws and courts.

In view the pervasive existence of CDR systems particularly throughout the rural society of the country, the constitutional limitation of their jurisdiction to only family and personal matters may not serve the cultural needs of the society. Therefore, ways of expanding the jurisdiction of the CDR systems to an acceptable level should be considered, while making sure that individual human rights and those of women, children and minorities are recognized and respected. If this recommendation is acceptable, the approaches to be taken in relation to civil matters and criminal matters should be carefully looked into. Such a decision may be best taken in consultation with the relevant sections and stakeholders within the society at federal, regional and local levels. In a similar argument, based on his law thesis in 2004, Alemayehu Fentaw argues that the Federal Government should: "Extend full recognition to the ethnically based customary law systems; particularly redraw the boundaries of formal legal pluralism to accommodate at least the well-established and dominant customary dispute (criminal) settlement mechanisms; stated differently, leave elbowroom for the non-state actors".

2. Building institutional linkages between the formal and CDR systems.

Linkages betweeen state and customary systems can be seen as facilitating cooperation between the two systems and might be best visualized as using each system to complement the other. There is a continuum along which linkages can be built from sharing information, through sharing jurisdiction, to sharing responsibility for individual matters. Recommendations can be provided along that continuum. By so doing, the legal system can take advantage of the benefits of the CDR systems that were articulated in the studies, while ensuring that they respect the concern of international and national human rights and those of women, children and minorities. 
3. Strengthening and supporting acceptable CDR Justice Systems.

This would mean supporting the development of both the formal and the CDR systems simultaneously with a view to eventually having a fully functioning pluralist legal system that has two or more aspects to it. The support to be given to the CDR systems should be done while attempting to reform the unfair and discriminatory aspects of the former as documented by the studies. The following ten examples are potential ways of supporting the CDR systems and promoting a more fruitful partnership and collaboration with the formal justice system:

3.1. Providing financial support to cover basic costs associated with customary procedures and more globally, to provide budget support to selected CDR institutions identified locally that fulfill acceptable criteria (at regional level);

3.2. Recognizing and supporting local meeting places and fora; and where appropriate improving shelter options.

3.3. Recording decisions taken in CDR processes. These records can be used to learn how the CDR system operates and to assist in providing relevant background in cases taken thereafter to the formal courts.

3.4. Providing fora for the exchange of information about customary practices and profiling successful and difficult matters brought to them for resolution.

3.5. Encouraging dissemination of information and publication of the CDR and formal court decisions taken so that they can be known throughout the country, and encouraging them to undertake self-critical reforms.

3.6. Providing training and workshops to those involved in CDR institutions on the legal provisions in the country, and the rights of particular sections of the population, notably women, children and minority groups. 
3.7. Organising workshops for a wide range of stakeholders including government, civil society, business, etc to debate the issues and potentials and options for greater collaboration between the formal and CDR justice systems.

3.8. Promoting state and private media discussion of the issues relating to legal pluralism in newspapers, radio, and television.

3.9. Assessing public opinion of this issue of justice system reforms in towns and rural areas in the different regions through surveys and polls.

3.10. Conducting awareness campaigns about the issues among the younger generation through schools and clubs.

4. Developing relationships between actors in the formal justice and CDR systems

The success of any program to link the two systems will depend to a great deal on the nature of the relationships that exist on the ground. Should a decision be taken to attempt to build linkages then prosecutors, police and judges in the formal system must work to establish a climate of confidence and mutual trust in which discussions, exchange of information and division of labour with CDR actors can occur.

5. Supervising and monitoring the performance of CDR systems in key areas.

This could be an interim measure if and until jurisdiction in certain areas such as homicide, are clearly given to the formal system and this is accepted by the actors in the customary system. It has been shown that the customary rules in certain areas do not live up to the minimum standards of human rights. The question of rights of women, children and minorities are a major concern. Moreover, implicit in some CDR systems is an acceptance or at least toleration of self-help in engaging in killings in certain cases such as sorcery and revenge, and more generally that the customary systems are sometimes not reliably effective in dealing with homicide cases (Donovan and Getachew 2003). The Ethiopian Government has to therefore monitor the activities of the CDR systems in such fundamental areas of concern. Efforts to address these shortfalls should embrace carefully designed legal and educational methods. 
6. Encouraging reform of CDR institutions notably regarding gender, minorities and harmful customs

Some reform of CDR institutions regarding gender discrimination and harmful customs is already happening spontaneously as the Gurage example shows. This could be enhanced through dialogue with associations such as the Ethiopian Women's Lawyers Association, and other women, child and minority rights groups. Given the flexibility of CDR instutions changes can be instituted once agreed and advocacy work to influence elders and CDR institutions that have customary legitimacy and popular recognition could be an important avenue for promoting locally accepted, instituted and implemented change, notably regarding gender discrimination, and child and minority rights.

7. Promoting the writing down and codification of CDR institutions

The writing down of Afar customary law and the codification of the Gurage Kitcha Customary law are good examples of how customary law can be both codified and revised, updated and improved. Similarly support for codification of other customary law could be an important step in cultural self determination, recognition and use of CDR institutions and what is valuable about them, while at the same time providing a forum for discussion, revision, updating and transforming customary law to comply with national and international norms.

8. Assessing CDR institutions in the country through further research

Though this book provides cases studies from each of the Regions of Ethiopia it was based on a small project involving a very limited field period and does not cover the wide range of CDR institutions in the country. There is a great need for further research particularly in the southwest to understand the prevalence, status, workings of CDR institutions and their relationships with the formal justice systems throughout the country. As the proceedings of the workshop on Ethiopia's justice system reform (2002:11) noted: "Research must be carried out on how to use alternative dispute resolution mechanisms (ADR) for the purposes of settling disputes. There should also 
be continuous observation to check whether there might be problems in using the mechanisms. The mechanisms that are found to be working should be developed and strengthened." Likewise, Alemayehu Fentaw based on this law thesis in 2004 argues that the Federal government should: "Launch a state-led statewide field research by legal anthropologists with an eye to studying and analysing all of the customary law systems within its boundaries and conforming them to the minimal standards for adequate protection of human rights of its citizens" There should also be actionoriented research with regards to rights of women, children and minorities and ways of encouraging customary to be self-critical and institute reforms, as have already been taking place in some CDR systems.

9. Establishing pilot collaboration projects for potential replication and upscaling.

Prior to implementing any constitutional change or amendment of legal jurisdiction and institutional structure it would be judicious to experiment with small-scale pilot projects of greater partnership and collaboration between the formal and informal justice systems and monitor, assess and evaluate the outcome within a specified timeframe. This could be done in selected conducive localities starting with greater recognition of each other by actors in the two systems, the development of mutual trust and a discussion of the cases with which they are dealing.

This could involve the following three steps. First, it may be possible to formalise a clearer division of labour, in which the customary systems deal with more simple cases to relieve the burden on the formal system to concentrate on more serious cases. Second, the customary systems may be able to play a greater role in the implementation and follow up of formal court decisions thereby also reducing the tasks of the formal system. Third, to avoid court congestion and prison crowding the customary institutions could be involved in organising and managing reconciliation and community service rehabilitation alternatives to custody to restore peace among litigants, as has been experimented successfully in a number of other countries (ICRC 2004).

10. Sharing experiences with other countries on reconciling state law and CDR

As Kohlhagen points out in his background chapter in this book there are a range of ways of reconciling state law and local realities. The different experiments in the post- 
colonial African contexts present specific advantages and risks relating to codification, integration, incorporation, tolerated self-regulation, cooperation, and innovation.

There can be much to be learnt from sharing experiences with other countries, particularly in Africa, with regard to the potentials and limitations of justice reform designed to give a greater voice to CDR and enhance legal efficacy and pluralism. This could be achieved through workshops, exchange visits, comparative research projects, publications, media debates and civil society discussions. Comparative experiences in protecting and enhancing the rights of women, children and minorities should be part of this endeavour.

The challenge of Decentralisation: Ethiopia at a justice cross-roads

Since most CDR processes take place at the local level, the current trend of greater decentralisation from the Federal level beyond the second level of the regional states to the third wereda level provides a unique opportunity with regard to enhancing justice at the local level. On the one hand the state judicial system could enter a genuine dialogue with customary institutions and create a partnership that could enhance local democratic governance and the efficiency of justice delivery. On the other hand the greater state involvement to a lower level could be a means to strengthen the formal justice system and implement more uniform legal norms, procedures and guarantees particularly where the state machineries have been weak, and especially with regard to protecting and enhancing individual human rights, notably those of women, children and minorities.

It can be hoped that this opportunity for constructive change will be seized and exploited judiciously to allow for more recognition and involvement of customary institutions by promoting tolerant, flexible and cooperative relations between the wereda and community levels, as well as guaranteeing individual and minority rights and ensuring understanding of and compliance with national and universal international norms. 


\section{Unit four: Legal Pluralism}

Introduction

This unit is designed to introduce you to the subject of legal pluralism. You will explore a good number of issues associated with these concepts. Legal pluralism is an expression of tolerating the existence and operation of multiple legal orders in a given legal system at the same time. Legal pluralism allows several groups to handle some of their legal problems differently. Legal centralism, however, works in the opposite way. Legal centralism either silences multiple legal orders or denies their existence. Legal centralism rests on the assumption that law comes only from the central government. Laws coming from other sources should not have a place at all. Legal pluralism is concerned with what a legal system does with its several communities having their own method of solving legal problems. Should the legal system simply abolish them? Should the legal system recognize all the diverse legal institutions? Should the legal system reject some of the customary rules and maintain the others? There is a need to give sound reasons for a legal system faced with diverse legal institutions in its jurisdiction either abolishing all or some of them?

In handling these issues, the unit is divided into two sections. The first section deals with the essential attributes of legal pluralism emphasizing on its definitions, merits and demerits. The second section is about the various forms of legal pluralism; that section examines the Ethiopian position as well as the experiences of some other selected African countries in this regard.

In this unit, you should be able to:

\footnotetext{
- $\quad$ Analyze such concepts as legal pluralism and legal centralism.

- $\quad$ Appreciate the various approaches to legal pluralism.

- $\quad$ Evaluate legal pluralism.

- $\quad$ Recognize the type of legal pluralism adopted in the FDRE Constitution.
} 


\section{1: Attributes of Legal Pluralism}

This section defines legal pluralism, examines the merits and demerits of legal pluralism and defines legal centralism. The section also discusses the purposes and de-merits of legal centralism.

In this section, you should be able to:
$\bullet$
Define legal pluralism.
Examine the merits and demerits of legal pluralism.
Define legal centralism.
Discuss the purposes and de-merits of legal centralism.

Legal Pluralism: The basic issue in legal pluralism is: how does one conceptualize law in such a way that it expresses common norms in which people can live together while also tolerating their differences? At one end there is the danger of a totalizing approach that silences any alternative ideas; at the other is the danger of endless fragmentation.

The term "legal pluralism is difficult to define in a precise manner. The concept of legal pluralism implies the inclusion of different orders, which co-exist with the state law, although maintaining a level of autonomy. The existence of multiple "legal" orders in any one particular community is a manifestation of legal pluralism. Legal pluralism also is concerned with the relation between state law and indigenous law. State or government law is only one of the types of law that apply. In practice, there is co-existence and interaction between multiple legal orders such as international, state, customary, religious and local laws.

? How does John Griffiths define legal pluralism? What is the objective of legal pluralism for John Griffiths? John Griffiths defines legal pluralism as the state of affairs, for any social field in which behavior pursuant to more than one legal order occurs. A central objective of legal pluralism is to attack the idea that what law is a single, unified and exclusive hierarchical normative ordering descending from the 
power of the state, and to destroy the illusion that the legal world actually looks the way such a conception requires it.

In the strong sense, legal pluralism refers to a situation, which is morally excluded by the ideology of legal centralism a situation in which not all law is state law nor administered by a single set of state legal institutions, and in which law is therefore neither systematic nor uniform. Legal pluralism in its weaker sense can refer within the ideology of legal centralism, to a particular sub-type of the sort of phenomenon.

Different senses of legal pluralism: According to Alice Tay, there are four senses of legal pluralism. Most broadly, the phrase simply reminds us that there are many and different legal systems, legal arrangements, legal customs, and legal 'cultures' in the world, and that they may and do conflict with each other.

In the second sense, for Alice Tay, legal pluralism can be understood nationally, internally, as something that exists in each society. The plurality of legal cultures and legal systems in the world is paralleled by the plurality of legal attitudes, traditions, expectations, and 'cultures' within any one society. This view has, in some places, been somewhat obscured for the lawyer in the past by the tendency to see only statebacked and state-sanctioned 'official' law as truly law. That is especially so since the concept of the rule of law was developed as part of a struggle against feudal particularism, fragmentation, inequality, and decentralization; the pluralism of estates or classes, and their legal centrality in medieval Europe, were taken to militate against the equality of human beings before the law and the doctrine that human rights applied to all, irrespective of status. In established, secure democracies, there is increasing demand that the 'official' legal system takes more and more account of such legal pluralism, of the differing informal traditions and expectations of various sections of the population. Thus, the second sense of the term 'legal pluralism' stresses internal social complexity and not merely the existence throughout the world of many different national or political communities or comities.

For Alice Tay, the third sense of legal pluralism is the systematic and intellectual reconciliation, by a lawyer of such pluralistic demands and concerns within a general legal system that sees itself as creating rules binding on all citizens and which gives a 
principled foundation for making distinctions between one class of citizens or activities and another and which coherently works out how such distinctions shall be made. 'Legal pluralism,' as the doctrine that there are competing legal systems, traditions, and expectations in the world and in any one society, is simply the statement of a fairly obvious fact that forms part of the background of the lawyer's work. It cannot do away with the need for the lawyer to consider whether, in given circumstances or even generally, some legal principles, arrangements, or presumptions are better than others and what kind of morality, view of society, and view of life particular legal systems incorporate and promote. It might be argued that there is an inherent and indeed central theoretical bias in the modern Western conception of law in favor of universality, freedom, and equality which has revolutionized and continues to revolutionize Western societies and which was a primary stimulus in revolutionizing the legal and political conceptions of the nonWestern world. Legal relativism simply closes its eyes to the central legal and political issues of the modern world. The same, of course, applies to the past -- the Code Napoleon did sweep Europe and was welcomed even where Napoleon's troops were not.

For Alice Tay, the fourth sense of the term `legal pluralism` is the recognition by and in a system of law of differing or special customs and traditions within a society or the recognition and legal protection of such customs in situations where the legal system is exported to a community different from that, which gave it birth.

Any sort of pluralism necessarily implies that more than one of the sorts of thing concerned is present within the field described. In the case of legal pluralism, more than one "law" must be present. This cannot be conceived of as a situation in which more than one rule is applicable to the "same" situation. Legal pluralism identifies a situation in which law is non-uniform not one of legal pluralism. Legal pluralism deals with the fact that within any field, law of various communities may be operative. It is when in a social field more than one source of 'law', more than one 'legal order' is observable, that the social order of that field can be said to exhibit legal pluralism. 
Legal pluralism assumes that a situation in human society-is one in which law and legal institutions are not all lumped within one 'system' but have their sources in the self-regulatory activities of all the multifarious social fields present.

Legal pluralism suggests the presence on a social field of more than one legal order, as that state of affairs, for any social field, in which behavior pursuant to more than one legal order occurs.

Legal pluralism bases itself on cultural relativism. Cultural relativism has many meanings. One of such meanings holds that culture may be an important source of the validity of a moral right or rule; there is a weak presumption of universality, but the relativity of human nature, communities, and rights senses as a check on potential excesses of universalism.

Legal centralism: Legal centralism may also be called legal singularism. Law is and should be the law of the state, uniform for all persons, exclusive of all other law, and administered by a single set of state institutions. To the extent that other, lesser normative orderings, such as the church, the family, the voluntary association and the economic organization exist, they ought to be and in fact are hierarchically subordinate to the law and institutions of the state. Law is an exclusive, systematic and unified hierarchical ordering of normative propositions, which can either be looked at either from the top down wards as descending from a sovereign command or from the bottom upward.

A criticism directed against legal centralism is that it fails to see the other side of the legal world. Legal centralism disregards the factual situations on the ground. The failure to see the factual world leads legal centralism not to accept that law in modern society is plural rather than monolithic, that law is private as well as public in character and that the national (official) legal system is often a secondary rather than a primary base of regulation.

Legal centralism bases itself on a number of fallacies. You can mention the following wrong assumptions: that law is neutral and "above" society, that law and justice are related, that decision-making is rational, that legal norms are universal, that law is 
centralized in the state, etc. Legal centralism with these assumptions appears to be a singular viewpoint (bourgeois, masculinist and imperialist) that has repeatedly repudiated, repressed, and silenced the socially marginalized.

Importance of Legal Pluralism: Legal pluralism appears to advocate for popular justice. Popular justice means justice that is popular in form, in that its language is open and accessible; popular in its functioning in that its proceeding, are based essentially on active community participation; and popular in its substance, in that judges drawn directly from the people are to give judgment in interests of the people.

We need to talk about legal pluralism because, in a multi-national states such as Ethiopia, there is a need to seek ways of organizing the peaceful coexistence of different communities, while at the same time strengthening and nurturing a common plane of shared values and institutions on the level of society as a whole.

In terms of property rights, individuals may choose from multiple legal frameworks as the basis for their claims on a resource, in a process referred to as "forum shopping." Each type of law, and the claims derived from it, is only as strong as the enforcement institutions that stand behind it. Legal pluralism introduces a sense of dynamism in property rights, as the different legal frameworks do not exist in isolation, but influence each other, and can change over time. Unless the complexity of overlapping types of law are recognized, changes in state law may not have their intended effects. For example, new government laws intended to increase tenure security may instead increase uncertainty, especially for groups with less education and contacts.

The definition of law, some write, should change from an institution that finds the right answer to disputes to one that negotiates patterns of consensus and difference. Nation-states increasingly face political contestation arising out of cultural diversity. Cultural diversity, if not given a place, can pose a challenge for existing legal orders. A failure by those orders to respond to this diversification could lead to the fall of that whole politico-legal system (and the start of civil war, for example).

Distinctions: Formal and Informal Legal Pluralism: Professor Andre Hoekema makes distinctions between a formal and informal legal pluralism. Hoekema also calls formal 
legal pluralism as the official or sate legal pluralism. He calls the informal legal pluralism as the unofficial or empirical legal pluralism. You will study the nature of formal and informal legal pluralism in the following pages. The following pages will also help you learn some examples of formal legal pluralism in the Ethiopian codes especially in the Ethiopian Civil Code.

Formal Legal Pluralism: Hoekema states that a formal legal pluralism is a concept referring to the inclusion within the national legal order of a principle of recognizing other law. Here the state picks certain customary rules and practices and gives them the status of the law. The state does this in the process of incorporation. The state uses its lawmaking institution to say that certain practices of a given community shall been taken as the law made by the state itself.

A legal system is pluralistic when the sovereign commands different bodies of law for different groups in the population. When the state turns the "customs" of various subgroups of the population into "law" that in specified circumstances is allowed to replace the uniform general law, it finds it necessary to formulate rules which determine which sub-group's law applies to a given transaction or conflict.

Formal legal pluralism is primarily associated with colonial and post-colonial societies. Formal legal pluralism is written under the sign of unification: unification is inevitable, necessary, normal, modern and good. Formal legal pluralism in the weaker sense is the designation of a possible legal policy within the internal discourse of state law.

Informal Legal Pluralism: Informal legal pluralism suggests that there are a number of institutions, practices and customary rules governing the society. But the state does not give recognition to these institutions, practices and customary rules. These institutions, practices and customary rules are outside the formal legal system. Yet, in many occasions, those non-recognized customary practices control the behavior of members of a given community. You can say that legal pluralism in an informal sense covers any situation in which within the jurisdiction of a state a variety of differently organized systems of norms and patterns of enforcement effectively and legitimately control the behavior of specific parts of the population. This concept of informal 
legal pluralism concerns factual social practice. Informal legal pluralism does not address the legal question whether or not this plurality has any official legal recognition within the legal order of society at large. Particularly interesting is the case in which local norms manifest the specific culture of a distinct community, such as a people. Informal legal pluralism is an empirical state of affairs, namely the coexistence within a social group of legal orders, which do not belong to a single "system". Ethiopia has an informal legal pluralism. Among the variety of legal orders are Islamic laws, a great many systems of customary law.

It appears that through the present constitution of Ethiopia and its implementation parts of this informal legal pluralism will be elevated to the status of being part of a system of formal legal pluralism. The current constitution permits the regional states to produce their own legal order. The regional states are legally empowered to incorporate local custom into state formal law or produce mixtures of customary and western style legal rules.

Approaches to Formal Legal Pluralism: There are several possible approaches to formal legal pluralism. You can mention these: unitary, the dual, the integration and legal pluralism approaches. Next, I will briefly explain each of these approaches.

The strong need for national identity/unity and modernization pushed certain countries in Africa including Ethiopia in 1960`s to adopt the unitary approach. The unitary approach to pluralism exists the case where government-made laws abolish all existing customary practices and traditional institutions and replace them a single system. Ethiopia in 1960`s did adopt this approach. So did other African countries such as Kenya. You will study the case of Kenya in the next section of this unit.

The second approach is the dualist approach. A dual system attempts to undertake a compilation of customary rules subject to repugnancy test. The dual system also recognizes the operation of customary courts side by side with state-established courts. So, the dual system permits traditional institutions and customary rules to survive on certain matters parallel to the state created institutions. The dual system shows greater tolerance to customary institutions than the unitary system. Botswana has adopted this approach. 
The integration approach, like the dual approach, tries to make compromise between pluralism and legal uniformity. The integration approach, as the name indicates, tries to synthesize uniformity and diversity. The integration approach seeks to conduct the inventory of customary rules and examines if there are any common ground with the state-made laws. In the process conflicts among customary practices are removed and again conflicts between customary rules and the state-made laws are again attempted. Then, finally, the two systems are blended in a single system.

The final approach is legal pluralism. This is theoretically leaving the diverse practices as they are. No repeal is made. No integration is attempted. The parallel systems are there to operate within their own jurisdiction. Some say that there should not be such approach as there should be a limit to official recognition of the other legal order. The basis of the limitation should be the identity of the distinct community whose customary practice is to be recognized or human rights values.

Issues in Recognizing Legal Pluralism: A legal system may encounter problems while giving a space to customary rules. It is not simple and easy to integrate customary laws to the official (state-made law). You can have the following issues. Any genuine attempt to recognize customary law should answer at least these questions.

- Which group's law applies to a given transaction or conflict?

- How do you apply this rule to a person (e.g., by voluntarily or marriage)?

- In which areas (e.g., family or succession) customary law should prevail?

- How do you ascertain the customary rules?

- Who should be the institution settling the issue, should it be subject to review by a regular courts?

- To what extent non-uniformity is to be tolerated (criminal law)?

- How should customary rules adapt themselves to the changing situations?

In addition to the above issues, a country, for example, Ethiopia, in order to recognize customary rules needs to address the following questions. 
- How many customary practices are there in the country?

- Is the Ethiopian state duty bound to prevent human rights violation by other groups?

- Does rule of law mean an elimination of customary practices?

- Is giving a space to customary system harmful to state power?

- Is it useful to recognize customary system for its own sake? Or is there a disadvantage to do so?

- Does the country need to study and list customary practices?

- Does the country need to rank customary practices?

- Does the country need to see if it can maintain some of the customary practices and eliminate others?

- Does the country need to give reasons why it should eliminate some customary practices?

Criteria for integration: Customary law is, by its nature, in a greater state of flux than written law. The right to customary law is implicit in the right to culture and of minority. According to Article 27 of the International Covenant on Civil and Political Rights, governments are expected not only to tolerate the existence of customary law but also to foster it and thus take a positive action. A seminar under UNESCO in 1965 on multinational society urged "recognition of the importance of maintaining permissible legal traditions in fields such as laws of succession, marriage, dietary law. In discussing limitations which should be placed on traditional group customs, the participants unanimously state "that nothing should be prohibited unless it threatened the freedom of others or was contrary to public order, morality or health-in the sense of constituting an offense to the law or conflicts with the technological, social or economic advancement of the nation as a whole.

Radical cultural relativism holds that culture is the sole source of the validity of a moral right or rule. Radical universalism holds that culture is irrelevant to the validity of moral rights and rules, which are universally valid. Strong cultural relativism holds that culture is the principal source of the validity of a moral right or rule. The presumption is that rights (and other social practices, values, and moral rules) are 
culturally determined, but the universality of human nature and rights serves as a check on the potential excesses of relativism.

Recognition of other legal orders within one political society cannot and should not be without limits. There are legal rules, procedures and institutions that help us solve this conflict problem. For example, the FDRE Constitution lists certain powers that need to be uniformly regulated by the federal government. These are conflict avoiding constitutional rules. The FDRE provides for the House of Federation to make sure that legal rules and practices inconsistent with the constitution will not have effect. These conflict rules enable the peaceful coexistence of the legal systems of various regional states (nations, nationalities and peoples) within one socio-political whole. These conflict rules define the nature and content of distinct autonomous legal orders, provide for special law to govern cases of multinational transactions, determine material and personal competences of the various legal orders, and finally indicate procedures with which to solve problems of competence between these orders as well as with the federal order.

The typical case here is one in which representatives of a regional state accuse, for example in a constitutional court, the higher government of, for instance, unilaterally issuing a permit for forest exploitation on territory supposed to be legally under the control of that regional state. Once, national defense interests were weighed against the collective right of an indigenous people to have its religion and culture respected in Columbia. In this case, the Colombian government had erected a radar post to counter drug trafficking by air. It planned and built the post on a sacred spot revered by a local indigenous people. The Colombian Constitutional Court had to decide about the limits of the collective right to have religious and cultural expressions respected. It eventually weighed the defense interests higher than the collective rights involved. Both types of interests are of a collective nature, national interests versus the sub-state-nation's interest.

The test for some is: is this practice "identity related" or is it central to that local community's basic features around which people build their identity? Some identified the right to life, the right not to be tortured, and the right not to be enslaved, the right to fair procedure and judgment, which means roughly the right not to be exposed to 
procedures or punishments that go beyond what a reasonable member of that community could expect. Respect for difference of cultures and related social practices requires acceptance of the idea that individual human rights do not automatically prevail over the collective right invoked in such a conflict.

Formal Legal Pluralism in the Ethiopian Legal System: There is a need to be aware of the provisions of the Ethiopian present constitution and the Ethiopian Civil Code that recognize the role of customary practices to a certain extent. Such type of recognition may give a sense of legitimacy to the official legal system. Such recognition may also contribute to the effectiveness of the formal legal system. To some degree, such recognition also pay attention to the reality, that is, a number of human behaviors in Ethiopia are being regulated, not by the laws the central government makes, but by customary practices in the localities.

The FDRE Constitution: Article 9 (1) of the FDRE Constitution states that "...Any law... customary practices that are inconsistent with this Constitution shall be invalid." The message of this constitutional provision is very important. This provision assumes that there are several customary practices in the country. It also assumes that some of those customary practices may not be in harmony with the provisions of the constitution. Further, the constitution assumes that some of the customary practices prevalent in the country may be consistent with the constitution. The key message of this provision is that those customary practices that do not offend the constitution would be given space and application. The drafters of the constitution did not think it desirable for Ethiopia to give a wider recognition of customary practices.

The key issue this constitutional provision raises is: what is the test to adopt in saying that a certain customary practice should be rejected? The simple answer to this question appears to be the values such as human rights the Constitution has incorporated. For example, if a certain community in Ethiopia has a practice that offends the right to life and the right to enter into marriage by the free consent of the intending spouses only, that practice will be invalidated, that is will not have legal effect. Article 9 of the FDRE Constitution does accommodate some customary practices while it rejects others. 
Article 9 (1) is the key provision in the FDRE Constitution that allows the operation of customary practices. However, there are other provisions that also permit custom. I will reproduce those articles below. Go through these provisions with care and try to find out their messages.

Article 34 (4) provides that:

In accordance with provisions to be specified by law, a law giving recognition to marriage concluded under systems of religious or customary laws may be enacted.

Article 34 (5) states that:

This Constitution shall not preclude the adjudication of disputes relating to personal and family laws in accordance with religious or customary laws, with the consent of the parties to the dispute.

Article 35 (4) stipulates that:

The State shall enforce the right of women to eliminate the influences of harmful customs. Customs and practices that oppress or cause bodily or mental harm to women are prohibited.

Article 78 (5) provides that:

...State Councils can establish or give official recognition to religious and customary courts. Religious and customary courts that had state recognition and functioned prior to the adoption of the Constitution shall be organized on the basis of recognition accorded to them by this Constitution.

It is based on these constitutional provisions that the Sharia courts are operating in the various parts of Ethiopia. There is a proclamation establishing the Sharia courts at the federal level. Jurisdiction to the Sharia courts is based on the consent of the parties to a dispute. The Sharia courts have the power to handle family and succession cases if 
the parties to such dispute submit to the power of the Sharia court handling such sorts of cases.

Based on the above constitutional provisions, it is possible for other religions to establish their respective religious courts too.

This question deals with a very important question: what should be the proper criteria to reject a given customary practice: the human right approach and the identity approach. A legal system should adopt a customary practice if such practice is associated with the identity of the community practicing it. Or a customary practice should be abolished if it clashes with a basic human right. The two tests may be incompatible, that is, they may not go together. The FDRE Constitution seems to adopt the human right approach; customary practices in Ethiopia will not be given a place if they do not go with the human rights the constitution recognizes.

The present Ethiopian constitution provides that any law or customary practice that contravenes the Constitution is invalid. Article 34 (2) of this Constitution states that marriage shall be entered into only with the free and full consent of the prospective spouses. In view of this clause it should not be difficult to dissolve marriages, say, in Gedeo society in South Ethiopia, which were concluded on the basis of the consent of the parents only. Those marriages would not be valid.

\section{Part I. Answer the following questions.}

1. In which areas of law do you think customary laws should be given a place in Ethiopia?

2. What is the problem with not giving a space to customary law in a country where there are diverse customary laws?

3. Do you agree with the idea that customary practices should be recognized if they are related to the identity of the community practicing them or if those practices are not in conflict with basic human rights?

4. Do you think that practices such as female circumcision, corporal punishment, arranged marriages, expelling people, not tolerating religious freedom, unequal gender relations, etc., are tolerable under the FDRE Constitution? 
5. Do you think marriages concluded based on the consent of the parents only constitutionally valid?

6. Define the following terms.

a) Legal pluralism

b) Legal centralism

c) Formal legal pluralism

d) Informal legal pluralism

7.Assume that the Ministry of Justice has submitted a Draft Revised Penal Code to the House of People's Representatives (HPR) for discussion. Assume also that the HPR has referred the draft penal code to a committee for a scrutiny. On the issue of the power of state councils on penal matters, the committee has unanimously proposed that it is within the discretion of the HPR to make every conceivable penal offense a federal offense since the FDRE Constitution does not give legislative power to states on penal matters. This proposal of the committee is based on Article 55 (5) of the FDRE Constitution, which provides that: 'It (the HPR) shall enact a penal code. The states may, however, enact penal laws on matters that are not specifically covered by the federal penal legislation.'

State the way the committee has interpreted this sub-article. You are also expected to indicate another way of interpreting this constitutional provision.

Part II. Multiple-choice questions

Choose the best answer from the give choices.

1. __ holds that "law is the law of the state, uniform for all persons, exclusive of all other law, and administered by a single set of state institutions.
A) Legal centralism
B) Legal pluralism
C) Descriptive legal pluralism
D) Recognized legal pluralism
E) Capitulation
F) Legal theory 
2. implies "the presence in a social field of more than one legal order, ... for any social field, in which behavior more than one legal order occurs.
A) Legal centralism
B) Legal theory
C) Legal pluralism
D) Capitulation
E) The validity theory
F) None of the above

3. Tell the test Andre Hoekema adopts in giving a space for customary practices.
A) The Repugnancy test
B) The Identity Test
C) He does not adopt any test in this regard.
D) The Harm Test
E) He seeks to see every customary law in Ethiopia recognized.
F) The clarity Test

4. Identify the correct statement about Article 9(1) of the FDRE Constitution, which provides, in part, that "...Any ...customary practice... which contravenes this Constitution shall be of no effect."
A) Any customary law in Ethiopia will be given a place if consistent with the values in the constitution.
B) Any customary practice consistent with the values in the constitution will be given a place.
C) The term "customary practice" is broader in scope than the term customary law.
D) Any customary laws that do not go with the values in the constitution will be given no effect.
E) The constitutional provision in question seems to refer only to customary laws, not to customary practices.
F) All of the above, except "E," are the correct answer. 
5. Identify the sound statement about the actual effect of Article 9(1) of the FDRE Constitution, which states, in part, that "...Any ...customary practice...which contravenes this Constitution shall be of no effect."

A) It is probable that there will be a big gap between legal penetration and legal extension in the foreseeable future.

B) It is probable that the gap between legal penetration and legal extension will dramatically narrow down in the foreseeable future.

C) It is impossible to predict the existence of a gap between legal penetration and legal extension in the foreseeable future.

D) It is probable that there will be no gap between legal penetration and legal extension in the near future.

E) It is probable that the deep rooted customary practices among the different communities in Ethiopia will very soon give way to the ideals in the Constitution.

F) None of the Above.

6. In relation to approaches to the co-existence of state-made laws and customary laws, identify the approach that does not go with the others.
A) The Rejection Approach
B) The Unitary Approach
C) The Dual Approach
D) The Integration Approach
E) The Legal Pluralism Approach
F) None of the above

7. Which one of the following interpretations of Article 55 (5) of the FDRE Constitution do you think is best in the light of the general spirit of the Constitution? The subarticle provides that: " ...the House of Peoples` Representatives (HPR) shall...enact a penal code. The states may, however, enact penal laws on matters that are not specifically covered by Federal penal legislation. “

A) The states will make penal laws only if there is a gap in the federal penal laws.

B) The HPR can decide to give no penal law making power. 
C) The spirit of the Constitution demands that the HPR must leave certain space for state penal laws.

D) Article 55 (5) is planned to bring uniformity in all penal matters in Ethiopia.

E) Article 55 (5) is planned to give some room for local differences in penal matters.

F) $\mathrm{C} \& \mathrm{E}$.

8. Identify the test the FDRE Constitution uses in recognizing certain customary practices while discouraging some other customary practices.
A) The Human and Democratic Rights Test
B) The Barbaric Test
C) The Repugnancy Test
D) The Equity Test
E) The Identity Test
F) The Progress Test

\section{2: Approaches to Legal Pluralism}

As you discussed in the previous section of this unit, formal legal pluralism may have different approaches, which differ in one significant way: the extent of recognition of customary rules. One approach might give little place to customary rules and another approach a very broader space. You can list the following approaches: the incorporation approach, the dual approach and the integration approach. You will consolidate your knowledge about these approaches in the present section.

In the previous section, you have also learned about the definitions of legal pluralism and legal centralism. You realized the importance of legal pluralism and the place the current Ethiopian legal system has given to diverse legal institutions. You will address issues of formal legal pluralism mainly in countries under colonial rule. You will deal with the changes the African customary rules underwent during and after colonization. You will take the examples of some African countries. You will also 
touch on the position of Ethiopia. You get additional tips on the approaches to formal legal pluralism.

At the end of this section, you should be able to:

- Learn about the positions taken by some African countries on legal pluralism.

- Explain the reasons why several countries in Africa gave little attention to customary laws.

- Learn about the conflicting values in the recognition of customary laws.

- Identify issues associated with the recognition of some form of legal pluralism.

- Learn about the methods of recognition of customary laws.

Customary Laws, Unity and Modernization: When there appears to be a clash between recognition of customary law and the unity of a country, there is a view that gives preference to unification. The reason advanced by the promoters of unity at the expense of diversity is the difficulty of articulating customary law and the problem of greater co-existence and a national identity. Given these difficulties, a constitution written for a country of legal diversity should not give a room for customary law.

The London Conference on the Future of Law in Africa, held from Dec. 1959 to Jan 1960, concluded that: uniformity of law would undoubtedly make available contribution to the administration of the law, and is therefore desirable in principle. Between communities and areas there are many variations especially in native law and custom that could and should be eliminated, thereby creating a greater degree of uniformity than of present exists.

Throughout the developing world, the requirements of modernization or the necessity of fostering national unity are reasons for replacing a customary law with a single national system. In some African states, governments view customary law with hostility. Since the colonizers applied customary law on a racial basis, it is considered that its use is tainted by discrimination and opposed to the goals of African nationalism. Many nationalists see diversity as representative of the old unprogressive 
order, while both capitalist and socialist western law have been seen as representing the forces of modernity, especially in the Civil and economic areas.

More on Method of Recognition of Customary Rules: There are a lot of methods of recognizing customary law. First, as in Ethiopia, they have endeavored to change the entire legal system dramatically by virtually abolishing customary law.

Rene David, the drafter of the Ethiopian Civil Code of 1960, said: "it is not an evolution (i.e., making the legal system compatible with customary rules and legal traditions) that the country needs; it is a revolution (i.e., changing the traditional rules in a fundamental manner)." In his view, customary law was not stable, was not really jurisprudential, and differed greatly from place to place. He argued that it was responsible for Ethiopian underdevelopment. Thus, "Ethiopia cannot wait 300 or 500 years to construct in an empirical fashion a system of law which is unique to itself, as was done... by the Romans and the English. The development and modernization of Ethiopia necessitate the adoption of a "ready-made" system; development and modernization force the reception of a foreign system of law in such a manner as to assure as quickly as possible a minimal security in legal relations.

The only concession to Ethiopian customary law was that no rule contrary to Ethiopian values would be incorporated into the code. Even this minor acknowledgement of customary law in Ethiopia in the 1960`s was to be permitted only if the customary practice was widely, in harmony with the Ethiopian conceptual justices, in accordance with economic progress, and clear enough to be committed to civil law terminology.

The second approach to codification has been to create a code that closely follows customary. This systematic approach derives from the feeling that customary law best mirrors the social realities in which the people find themselves and comports with their value systems. An example of this approach to formal legal pluralism is Madagascar. The change in Madagascar was evolutionary while in Ethiopia it was revolutionary. But even in Madagascar, customary law was modified to harmonize conflicting rules, to remove aspects deemed unacceptable by the central government and in certain instances, to consolidate it with civil law. 
Advantages of Customary Rules: It is advantageous to give a room for customary practices for:

- Local custom may continue to be followed despite the pronouncements of the central government. It is unrealistic to think that people will suddenly abandon their traditions because of an edict from a remote central government.

- Attempts to remove customary law may have the opposite effect from that intended. Abolition of customary law ca undermine the power of the traditional authorities who up held it; namely those attempts may cause great resentment on the part of the populations whose law is challenged and instead of fostering national unity, invigorate separatist claims.

- African countries typically have a high illiteracy rate.

Customary law is communal. National law is more individualistic in nature. Customary law is abased on kinship; legal proceedings are about the community as much as the individual. The goal is to foster reconciliation and harmony with in the community.

In a case where a country has two laws, two courts, the problems that country may face are:

- Forum shopping,

- Conflict of rules between customary and national law rules,

- The problem of finding out a test to be applied to override customary law in a particular case,

- The method of ascertaining the customary rule,

- Finding out the subject of customary law and

- The criteria for identifying the subjects of customary law.

In the next few pages of this section, you will look at the position of Botswana and Kenya on customary rules in some detail. 
The Case of Botswana: In Botswana, customary law is the law of any "tribe or tribal community' which is not in conflict with the written law or contrary to morality, humanity or natural justice. A tribesman is defined as a member of a tribe or section of a tribe; or a member of a tribal community organized in a tribal manner, meaning outside a tribal territory; or a member of a tribe or tribal community of any other African country. In Botswana, earlier, the national courts treated customary law as a factual matter had to be proven. The court could not take judicial notice of it. Now judicial notice can be taken but if a court is uncertain about a particular element of customary law, it can consult reported cases, textbooks or experts.

England made a law applicable to its colonies, for example Kenya. Section 20 of the 1902 East Africa Native Courts Amendment Ordinance provided that: “'In all cases civil and criminal to which natives are parties, every Court (a) shall be guided by native law so far as it is applicable and is not repugnant to justice and morality or inconsistent with any law of the central government and (b) shall decide all such cases according to substantial justice without undue regard to technicalities of procedure and without due delay." This shows that England gave customary rules and legal institutions some room.

The recognition of African Customary Law was significant to the colonial rule. With limited resources and incongruent policy objectives, it was highly unlikely that the governance of the colony could be achieved without the help of the indigenous communities. Moreover, implementation of the principles of indirect rule necessitated the maintenance of traditional rules and regulation so as to eliminate active dissent to the British occupation. One scholar argued that African Customary Law provided a means of control because the nature of its application was imprecise, yet adaptable. No matter what the motive of the colonial administrators, African Customary Law enjoyed the support of the indigenous communities. As Lord Atkins remarked, "it is the assent of the native community that gives custom its validity, and, therefore, barbarous or mild, it must be shown to be recognized by the native community whose conduct it is supposed to regulate."

The conception of customary law, as a tool for colonial administration, led to the modification of its principles to suit the aims of imperialism. The transformation in 
the African way of life, occasioned by the introduction of religion, changed economic relations, and the exercise of stringent powers of the state, influenced the evolution of customary law.

At independence, the duality of courts was abolished, but the stature of customary law never improved. The strong desire for economic prosperity and the wholesale adoption of colonial laws diminished the relevance of African Customary Law. Instead, African Customary Rules remained applicable only within the narrow margins set by the colonial legal system. In fact, the belief amongst the ruling elitist that indigenous institutions may "help to keep the masses backward" hindered any positive political and legislative changes that may have enhanced the image of African Customary Law.

After independence, the majority of African governments tried to introduce codes of law that would integrate or unify the different areas of law existing within the country. Tanzania codified the African Customary Law into written law. Kenya, however, never made any attempt to reduce its vast and divergent body of customary law into written law. Perhaps it was the assumption that written English law would, in time, swallow the customary principles and thus help in the process of political unification. Nonetheless, because Kenya has over 42 different tribes and because African Customary Law enjoys local application, several aspects of it differ from tribe to tribe.

The primacy of customary law, which is a vital component of the legal system, was not explicitly recognized when Kenya adopted the independence constitution. Instead, the constitution, limited its application in favor of received law. In some cases, it eliminated customary principles and implanted general principles of law borrowed from the English constitutional tradition. For example, the constitution abolished customary law crimes. Under Section 77 of the constitution, no person can be convicted of a criminal offence, unless that offence is defined and the penalty is prescribed by law. Subsequent to the constitution, several pieces of subordinate legislation, having the same effect on African Customary Law, have been passed. For example, the Law of Succession Act, passed in 1981, currently repeals all forms of applicable Customary, Hindu or Islamic laws of succession. This integration was 
widely acclaimed as a positive step towards the protection of rights of spouses after the death of their loved ones. The attainment of universal standards in the face of the differing areas of laws has proved unachievable by mere enactment of statute. As far as the Kenyan legal system is concerned, the substance of African Customary Law remains principally in the fields of contract law, tort law, and family law and land law.

Within the Kenyan legal system, the African Customary Law is inferior to other laws. Some commentators have argued that this is understandable because it is unwritten and its principles have not been developed as much as the English common law or statutory law. Moreover, African Customary Law is not only inferior to written laws, but also to the English common law and doctrines of equity, both applicable by virtue of the reception clause. While the application of African Customary Law is subject to the Repugnancy Clause, the English common law and doctrines of equity are not at all limited. Similarly, the courts have been reluctant to recognize custom as a valid defense in criminal proceedings.

A characteristic feature of native law is flexibility in its contact with European civilization. Foreign concepts may creep into the native customary law and influence it without necessarily depriving it of its essential character of custom. A customary law that once prevailed may now exist in a modified form owing to modern political, social and economic developments. The modified custom may be deemed to have acquired the force of law if it is shown that the members of the community recognize it as an obligatory rule, which regulates the conduct of persons within that community.

The mere adjustment of law to conform to standards established under international law, or the denial of jurisdiction to customary claims, without offering a concurrent process of adjudicating customary disputes, may lead to a considerable criticism.

African Customary Law cannot be reformed by mere imposition of rules and enforcement of decrees; neither can it change its main principles based on rulings of superior courts completely removed from the daily lives and aspirations of the people. 
In the pre-colonial African societies, African Customary Law prescribed a system of "courts" and adjudication for all matters. The most frequent cases concerned divorce, which involved sexual rights and rights over offspring, land or other property such as cattle. The law also prescribed the procedure for trials. In many cases, evidence would be adduced by the principals, the witnesses, and sometimes by the "experts" specifically called by those in charge of the process. However, speed was not an important component of the process. Trials relied on accurate presentation of information and a thorough examination of all the issues involved. Since no records were kept, verbal recall of similar cases, particularly by elders, were admissible. The overall purpose of the trials was not only to arrive at a settlement, but also to reconcile the parties concerned in order that they can live in peace in the future. According to one writer, the traditional adjudication process aimed at repairing societal fractures by mediation and conciliation rather than by declaring clear winners and losers. In addition, recourse to some supernatural power was allowed in difficult cases, especially when there were doubts on witnesses' truthfulness or when the evidence was inconclusive. For example, in some communities, innocence in a trial would be sworn to a spirit, while in others, there would be consultation of a diviner or an oracle; meanwhile, others combined both. This would indeed be the final step in any trial process.

However, the African traditional modes of dispute settlement became irrelevant when the colonial governments introduced the modern court system. Adjudication of customary claims became a matter of great difficulty to the judicial enterprise in the colonial setting. The answer was provided by the establishment of a dual court system. A specialized court system, known as "Native Courts," was established to deal with cases of African Customary Law and were allowed to follow procedures familiar to the local people. The idea of specialized courts for African customary issues was not very favorable to political establishment at independence. Kenya was not successful in dismantling signs of colonialism and restoring dignity to the African. On the one hand, the reform effort sought to restore and glorify African culture; while on the other, it rapidly abolished all institutions of colonial administration that had fostered and preserved African custom and values, such as the Native courts and tribunals. With the enactment of the Magistrate's Courts Act in 1967, in Kenya, the native court system was completely abolished. A mainstream judicial system was 
established comprising of the Court of Appeal at the top, the High Court, and the Magistracy at the bottom.

The African Customary Law is ascertained by reference to traditional African practices; some of these practices do not reflect the true African way of life. This is because, when customary law is subjected to judicial scrutiny of modern courts, proof of the existence of a custom may require evidence of experts on the particular custom or by written exposition, which are rarely used. In either case, the ideas of change by which all customs are subject to, are the least considered. In effect, customary law has become subject to varying interpretations by individual courts. The courts are not the only forums in which customary law issues may be adjudicated. In rural areas, local elders settle disputes. Local elders handle complaints relating to cattle ownership, marriage, land, drunkenness, and in some cases succession.

The unification of the courts system in Kenya was undertaken with the hope that, in the near future, all laws, including customary law, would be formally promulgated as codes. The main actors of the Kenyan law believed that a unified court system would promote development and facilitate political unity. The Kenyan government never seriously supported the codification of African Customary Law. In effect, customary law was left un-tendered and its principles completely omitted in the formulation of government policies. With regard to the efficacy of courts, the jurisprudence revealed an enduring inconsistency in the application of custom in resolving disputes.

The problems of finding custom, such as dealing with its changes, adapting to conditions of life, and determining its position in the wake of emerging principles of international law and the imposed common law, have rendered mainstream courts poor arbiters in matters of customary law. Further, the legal system as a whole (i.e., the legal profession, legal education, rules of evidence, practice and even procedure) is based on the English legal tradition. This scheme of things perpetuates reliance on the English common law and diminishes the courts' ability to make meaningful enquiry on matters of African Customary Law and its applicability in resolving contemporary problems.

The experience of many countries shows the need for some form of specialized 
adjudicative structures for customary law. Papua New Guinea, which attained its independence in the 1970's, has retained its network of village courts. The Village Courts Act of 1973 and the Land Disputes Act of 1975 establish a system of local courts that adjudicate on disputes in the "traditional" way. According to a 1965 account, the customary courts in Nigeria adjudicate about $90 \%$ of all cases reaching the courts. The administration of these courts is a power of regional authorities and, thus, differs from state to state. For example, in Abia State, the village council of elders has wide powers of adjudication on matters of civil law. These councils operate in parallel with the Magistrates Courts. When Zimbabwe became independent, the customary courts established under the colonial administration were not abolished. Instead, the new government passed the Customary Law and Primary Courts Act to enhance their operation. The bill integrated the primary courts (the village and community courts) into the mainstream judicial structure. The courts were given the jurisdiction to "hear, try and determine any civil case in which customary law was applicable," provided that: the defendant was a resident within the court's jurisdiction; that the cause of action arose within the jurisdiction; and that the parties consented to the court's jurisdiction. Furthermore, in an effort to strengthen the operation of these courts and bring them into conformity with modern principles of law and administration of justice, the government enacted another law - the customary law and Local Courts Bill of 1990. The government in Zimbabwe has maintained that the restructuring of the local court system is in harmony with the overall objective of building a new Zimbabwean Nation. Similar courts exist in the United States and Canada.

Integration of Dual System: Some suggest that those countries such as Namibia having a dual system should adopt the integration approach. This means integrating the plurality of systems as much as possible. The systems of customary law followed by the various ethnic groups would be harmonized with one another and with the national law. During unification the imposition of a uniform law is more desirable in terms of efficiency. Integration is more viable for the foreseeable future because it brings together laws of diverse origins without obliterating them and will minimize social dislocation. Integration is a halfway between pluralism and uniformity. Integration allows varying laws to continue to exist but attempts to standardize and remove conflicts between them. 
Integration of state-made law and customary institutions should follow the study of customary rules and codification of those customary rules. The study should focus on not individual customary laws, but all of the existing customary rules in a given country. Since integration means the creation of a single system applicable to all, integration is to be carried on in two stapes. In the initial period, the basic dualism of the legal system would remain but the laws of different ethnic groups would be harmonized and standardized. After a period of time in which the process of nation building will create a favorable social climate, the diverse systems of customary and national law would be replaced with one system. Integration would involve in the systems of customary law followed by the various ethnic groups would be harmonized with one another and with the supreme national law.

\section{Summary}

Legal pluralism and legal centralism are two opposing tendencies in a legal system. Legal pluralism may be a difficult concept to define. But one aspect of it is clear; legal pluralism accommodates differences in legal institutions and different modes of solving legal issues in a given country at the same time. On the other hand legal centralism does not bother about accommodation of differences. It seeks to obtain uniformity at any cost. Legal centralism has it that in a given state only one legal system that which comes from the central authority, should prevail; all the other legal institutions should be silenced.

In Ethiopia, the present constitution appears to give a place to legal pluralism. The details of that recognition have not yet been worked out.

Just like human rights, African Customary Law comprises norms and rules. These norms and rules aim at protecting individuals against institutional or other abuses. They offer wide and general principles of morality and public policy. They are flexible and can be adaptable to changing conditions and standards. A few of these norms may be less adaptable, and thus, would become an impediment to the realization of common juridical standards and human rights principles. Notwithstanding, the traditional norms and rules, "may differ spatially, but the variance is perceptible only in details since all the principles are aimed at preserving 
the dignity of man as perceived by the relevant society. The manner in which African Customary Law evolves shows its capacity to accommodate change. However, the process of change must begin from within, rather than being imposed through legal centralism. Redefining the roles of institutions borne out of African traditions and values may be a good starting point.

Suppose a country does give no or little room to legal pluralism. What problems would this country face? A legal system with an exclusive centralist approach will suffer from a number of problems. People would disregard the official laws that do not have regard to their practice. So the rules would fail to achieve the planned effects. In the case of criminal law people refuse to give evidence. People would feel that the official legal system does not have legitimacy to govern them. The community would feel that the official law is not part of such community.

\section{Review Questions}

1. Explain the repugnancy test.

2. What happened to the African Customary Law after African countries got independence?

3. Do you think that customary law is an impediment to modernization and unity?

4. Explain the different approaches to formal legal pluralism.

5. Do you think that "Tikure Deme" (revenge killing) has attained the status of a customary rule? Why? Why not? For the purpose of argument, assume that "Tikure Deme" has attained the status of a customary rule. Based on this assumption, present arguments both for and against its recognition by the Ethiopian Federal Constitution.

6. Do you think that the Ethiopian Civil Code incorporated sufficiently representative Ethiopian indigenous legal institutions? In attempting this question, you are expected to present as many views as possible on the issue.

7. Do you think that Ethiopia in the 1960`s adopted a revolutionary approach to codification of laws? Why? Why not? 
8. One of the key distinctions between the 1987 PDRE Constitution and the 1995 FDRE Constitution is the concept of legal pluralism the latter incorporates. Do you agree with this idea? Why? Why not? Support your position with a legal provision.

The Ethiopian government is currently constitutionally committed to the recognition of certain customary law systems in its territory to:

- Obtain internal legitimacy; the groups would accept the state legal system if their perspectives are duly appreciated.

- Decrease the burden of the state with regard to the administration of justice.

- Appreciate the saying that 'if something is not broken, do not mend it." So those customary rules that helpful should be promoted and used.

- Accord recognition to an aspect of the identity of groups, as customary laws are elements of culture. It is a question of appreciating different points of view.

- Alternate dispute resolution is gaining currency these days.

At present, there are sufficient reasons why the Ethiopian government cannot recognize every customary law systems that exist in its territory. You can mention the following reasons for this argument:

- To obtain international acceptance; full recognition of customary laws would be contrary to accepted international principles.

- That would jeopardize Ethiopia's efforts to obtain resources form other countries and organizations in the forms of aid and loans.

- There are several customary laws and practices that offend human rights or gender insensitive.

- There legitimate grounds for the government to promote legal uniformity in some areas of laws.

7. The Ethiopian government has opted for the co-existence of human rights and customary law systems for: 
On the one hand, there is a need to side with customary laws systems to:

- Obtain internal legitimacy; the groups would accept the state legal system if their perspectives are duly appreciated. Doing so is considered by many to consolidate the project of nation building.

- Decrease the burden of the state with regard to the administration of justice.

- Appreciate the saying that if something is not broken, do not mend it." So those customary rules that helpful should be promoted and used.

- Accord recognition to an aspect of the identity of groups, as customary laws are elements of culture. It a question of appreciating different points of view.

- Alternate dispute resolution is gaining currency these days.

And on the other hand, the government ought to set aside the issue of human rights,

- To obtain international acceptance; full recognition of customary laws would be contrary to accepted international principles.

- That would jeopardize Ethiopia's efforts to obtain resources form other countries and organizations in the forms of aid and loans.

- There are several customary laws and practices that offend human rights or gender insensitive.

- There legitimate grounds for the government to promote legal uniformity in some areas of laws.

Further, the coexistence of the two systems, human rights and customary laws systems, is taken to be based on the common grounds-both stand for the dignity of the human person. Contrary to the assertion of many, it is argued that customary laws do not necessarily undermine this central value of humanity.

In countries such as Ethiopia featured by the existence of a dual legal system, the cooperation of the two systems is essential. The entire rejection of one system, for example the customary law systems, would be unrealistic; moreover, it would be inimical to the objectives of state-builders.

8. Article 9 (1) of the FDRE Constitution: 
- Assumes that there are several customary laws or customary practices in Ethiopia,

- That some of these customary laws or practices may conflict with the provisions of the Constitution,

- That those that contravene it will not have any legal effect,

- That those that go with it shall have recognition and

- That giving legal effect by any federal or state actors to those customary laws or practices that evolve in the future or existing ones shall be unconstitutional.

Article 91(1):

- Specifies the general test `this Constitution` under Article 9(1) against which a distinction between customary laws and practices to be recognized and those to be eliminated. These specific criteria are " ... equality, the growth and the enrichment of cultures and traditions that are compatible with fundamental rights, human dignity, democratic norms and ideals, and the provisions of the Constitution."

- States the obligation of the government to tolerate and support, in terms of resources, customary laws that are in line with the values of the Constitution. The state would not satisfy its obligations in relation to customary laws if it simply tolerates some of them, without any assistance.

- Provides for the obligation of the government to eliminate those customary laws and practices that are not inconformity with the values enshrined in the Constitution. Is the state obliged to prevent horizontal violation of human rights, for example, by groups in the exercise of their customary practices?

- Raises the issue of the level of government, federal or state or local or all, responsible for this duty.

- Raises the nature of the obligation.

- Is there any theoretical tension between the ideas of the two constitutional clauses? 
References

1. Aberra Jembere, “'Legal History of Ethiopia 1434-1974: Some Aspects of Substantive and Procedural Laws“ (1998.)

2. Alan Watson, “'Legal Transplants: An Approach to Comparative Law”, England:

London, the University of Georgia Press (1993.)

3. Alan Watson, “the Evolution of Law”, Maryland: Baltimore, The Jhons Hopkins University Press (1989.)

4. Vanderlinden, “An Introduction to the Sources of Ethiopian Law, Vol. III No. 1 June (1966).

5. Vinogradoff Eze, 'Justice for Sale: A Report on the Administration of Justice in the Magistrates and Customary Courts, Nigeria: Lagos, Civil Liberties Organization (1996.)

6. Charles R. Cutshall, “Justice for the People: Community Courts and Legal

Transformation, Zimbabwe: University Publications (1991.)

7. A.N. Allott (editor), "Judicial and Legal Systems in Africa“, London: Butterworths (1962.)

8. Emmet V. Mittlebeeler, “ African Custom and Western Law: the Development of the Rhodesian Criminal Law for Africans, London: African Publishing Company (1976.)

9. Maryman, John, H. Clark, David, “The Civil Law Traditions: Europe, Latin America \& East Asia”, Verginia: the Michie Co. (1997.)

10. Rene David \& John E. C. Brieley, "'Major Legal Systems in the World Today: An Introduction to Comparative Law”, $2^{\text {nd }}$ ed.(1978.)

11. Steven Lowenstein, “'The Penal System of Ethiopia”, EJL, Vol. II No.2 (Dec. 1965)

12. George Krzeczunowicz, “Code and Custom in Ethiopia”, EJL, Vol. II No. (2 Dec 1965)

13. John Griffths, “What Is Legal Pluralism?" 25 J Leg. Plu.1 (1986.)

14. Lynn Berat, 'The Future of Customary Law in Namibia: A Call for Integration Model`, 28 Hastings Int`1 \& Comp. L. Rev. (1991.)

15. Aklilu Wolde Amanuel, “'The Fallacies of Family Arbitration Under the 1960

Ethiopian Civil Code“", JEL, Vol. IX No. 1 (June 1973.)

16. George Krzeczunowicz, “Putting the Legal Clock Back? The Law \& Its Sources," JEL, Vol. III No. (2 December 1966.)

17. Jacques Vanderlinden, “'A Further Note on an Introduction to the Sources of Ethiopian Law”, JEL, Vol. III No. (2 December 1966) 
18. Rene David, "Sources of the Ethiopian Civil Code", JEL, Vol. IV No. (2 December 1967)

19. Alan Watson, An Approach to Customary Law, 1984 U. Ill. L. Rev. 561(1984)

20. Laurence Juma, “'Recognizing African Customary Law and Human Rights in Kenya:

Making A Case for Institutional Reformation and Revitalizations of Customary

Adjudication Processes, “ St. Thomas Law Review (Spring 2002)

21. Lynn Berat, 'Customary Law in A New South Africa: A Proposal,“ Fordham International Law Journal (1991).

22. Bojosi Otlhogile, “Criminal Justice and the Problems of a Dual Legal System in Botswana," the Rutgers University School of Law (1993).

23. A Draft Discussion Document, Towards A White Paper on Traditional Leadership Leadership and Institutions (26 April 2000)

24. Dr. Loukas A. Mistelis,Regulatory Aspects: Globalization, Harmonization, Legal Transplants, and Law Reform -- Some Fundamental Observations, 34 International Lawyer (2000.)

25. A. Watson, “'Legal Transplants and European Private Law," vol 4.4 ELECTRONIC Journal of Comparative Law, (December 2000), <http://www.ejcl.org/ejcl/44/44-2.html>

26. Jill Zimmerman, “'The Reconstitution of Customary Law in South African: Method and

Discourse, “ Harvard BlackLetter Law Journal (Spring, 2001)

27. David M. Bigge \& Amélie von Briesen, “Conflict in the Zimbabwean Courts:

Women's Rights and Indigenous Self-determination in Magaya v. Magaya, “ Harvard Human Rights Journal (Spring, 2000)

28. Daniel Haile, "Law and Social Change in Africa: Preliminary Look at the Ethiopian Experience', JEL

\section{World Bank Discussion Paper N0. 405 Work in Progress WDP405 for public discussion August 1999 Gender-Related Legal Reform and Access to Economic Resources in Eastern Africa.}

30. Alice Tay, “'Legal Culture and Legal Pluralism in Common Law, Customary Law, and Chinese Law, “ 26 Hong Kong L.J. 194 (1996)

Laws

The FDRE Constitution 
The Ethiopian Penal Code

The Ethiopian Civil Code

The Revised Family Code

The family laws of the Amhara National State and Tigray National State 